US Army Corps

of Engineers ${ }_{\circledast}$

Engineer Research and

Development Center

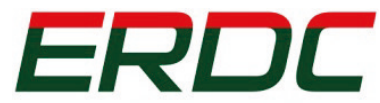

INNOVATIVE SOLUTIONS

for a safer, better world

Aquatic Plant Control Research Program

\title{
Use of Remote Sensing to Detect and Predict Aquatic Nuisance Vegetation Growth in Coastal Louisiana
}

Summary of Findings

Glenn M. Suir, Kevin J. Suir, and Sijan Sapkota

February 2018

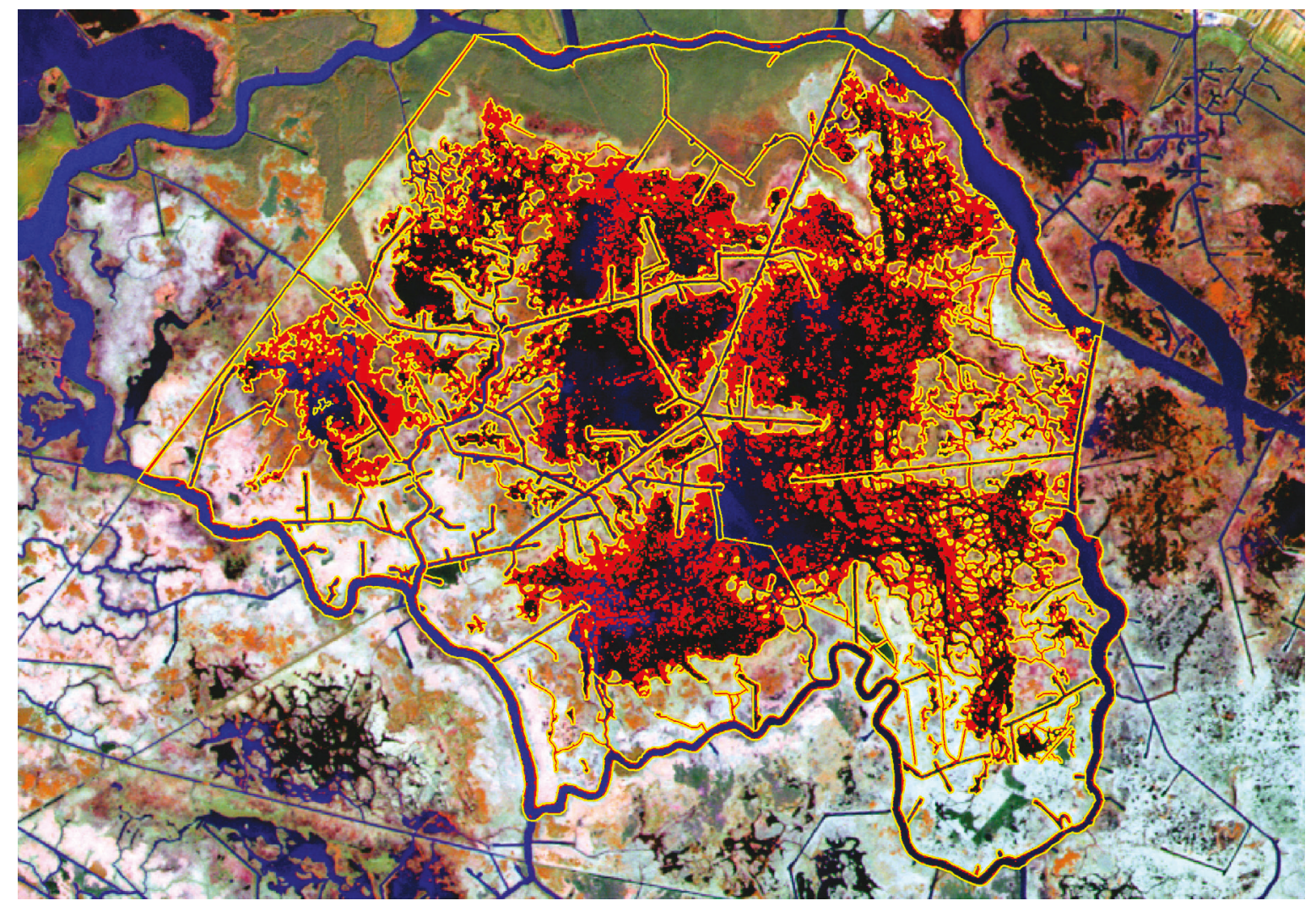


The U.S. Army Engineer Research and Development Center (ERDC) solves the nation's toughest engineering and environmental challenges. ERDC develops innovative solutions in civil and military engineering, geospatial sciences, water resources, and environmental sciences for the Army, the Department of Defense, civilian agencies, and our nation's public good. Find out more at www.erdc.usace.army.mil.

To search for other technical reports published by ERDC, visit the ERDC online library at http://acwc.sdp.sirsi.net/client/default. 


\title{
Use of Remote Sensing to Detect and Predict Aquatic Nuisance Vegetation Growth in Coastal Louisiana
}

\author{
Summary of Findings \\ Glenn M. Suir \\ Environmental Laboratory \\ U.S. Army Engineer Research and Development Center \\ 3909 Halls Ferry Road \\ Vicksburg, MS 39180-6199 \\ Kevin J. Suir \\ U.S. Geological Survey \\ Wetland and Aquatic Research Center \\ 700 Cajundome Boulevard \\ Lafayette, LA 70506 \\ Sijan Sapkota \\ U.S. Army Medical Department Center and School \\ Health Readiness Center of Excellence \\ 2377 Greeley Road \\ Fort Sam Houston, TX 78234
}

Final report

Approved for public release; distribution is unlimited.

\footnotetext{
Prepared for U.S. Army Corps of Engineers

Washington, DC 20314-1000

Under Project 450620, “Aquatic Plant Control Research Program”
} 


\section{Abstract}

On an annual basis, federal and state agencies are responsible for mapping and removing large expanses of aquatic nuisance vegetation from navigable waterways. This study set out to achieve four primary objectives: (1) utilize recent advancements in remote sensing techniques to classify the extent and distribution of aquatic vegetation in coastal ecosystems using satellite imagery, (2) assess primary aquatic vegetation growth and management efforts in coastal Louisiana, (3) statistically identify the ecological drivers that promote growth and infestation of aquatic nuisance vegetation, and (4) develop numerical models and a spatial tool to predict the probability of occurrence and growth of aquatic vegetation given ecological drivers. Moderate spatial resolution multispectral satellite imagery were used in conjunction with environmental variables from available data streams to generate regression models that predict aquatic vegetation occurrence in the eastern coastal region of south Louisiana. Geospatial tools were developed to execute the model logic using recent environmental conditions, thereby predicting aquatic vegetation occurrence and producing classified maps for end users. These products provide more efficient and enhanced capabilities for management of aquatic nuisance vegetation.

DISCLAIMER: The contents of this report are not to be used for advertising, publication, or promotional purposes. Citation of trade names does not constitute an official endorsement or approval of the use of such commercial products. All product names and trademarks cited are the property of their respective owners. The findings of this report are not to be construed as an official Department of the Army position unless so designated by other authorized documents. 


\section{Contents}

Abstract................................................................................................................................... ii

Figures and Tables.........................................................................................................

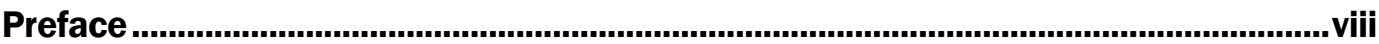

Acronyms and Abbreviations ............................................................................... ix

Unit Conversion Factors................................................................................................ xi

1 Introduction ................................................................................................................ 1

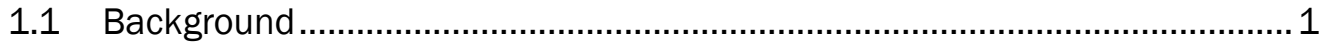

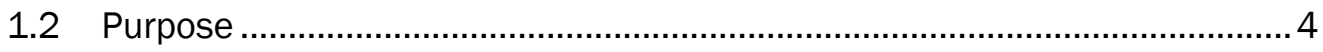

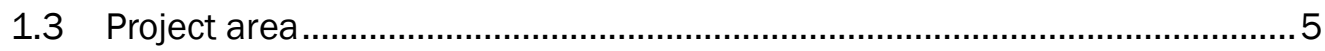

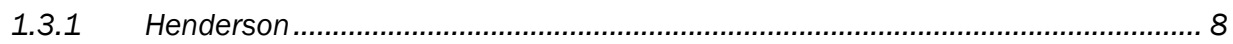

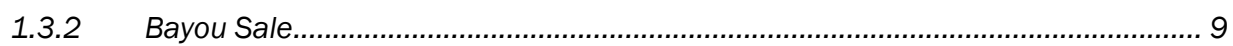

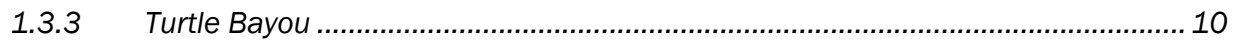

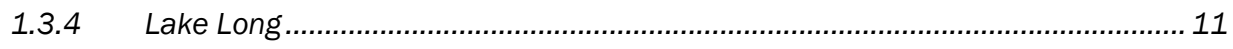

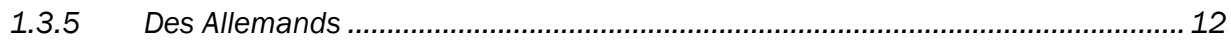

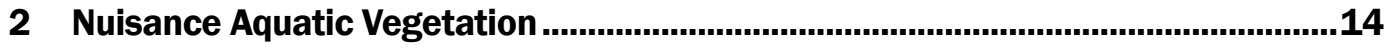

2.1 Background .................................................................................. 14

2.1.1 Henderson vegetation .............................................................................. 16

2.1.2 Bayou Sale vegetation ............................................................................... 18

2.1.3 Turtle Bayou vegetation.......................................................................................... 20

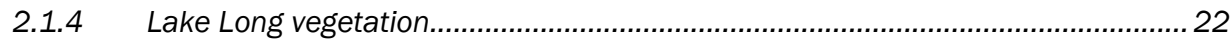

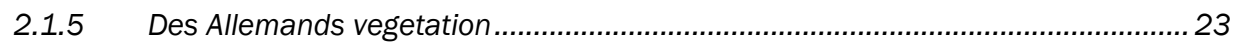

2.2 Vegetation mapping.......................................................................... 24

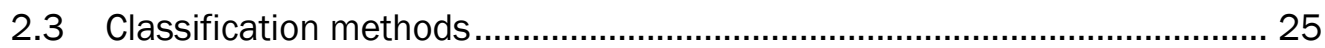

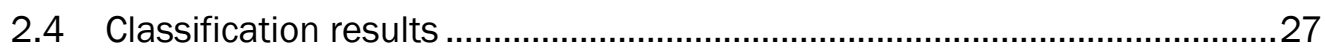

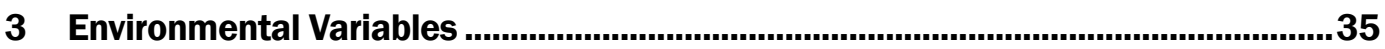

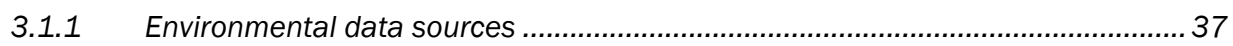

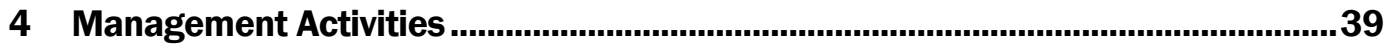

4.1 Chemical control ........................................................................... 39

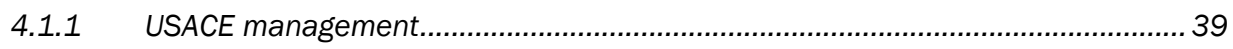

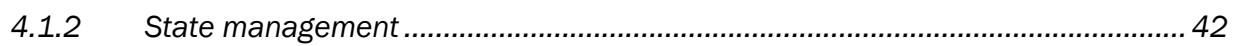

4.2 Physical control............................................................................... 44

4.3 Biological control ........................................................................ 45

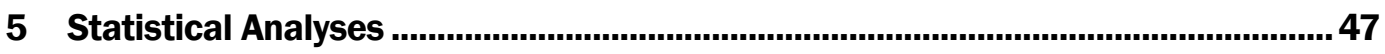

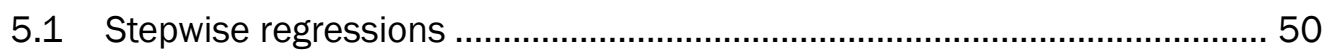

5.1.1 Henderson statistics ................................................................................ 51 


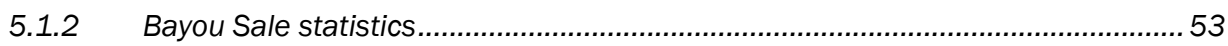

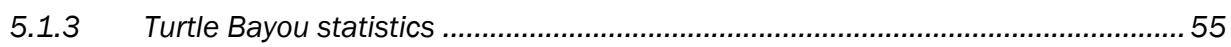

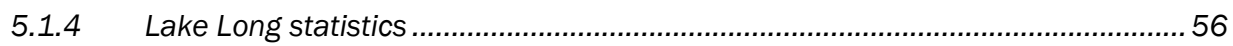

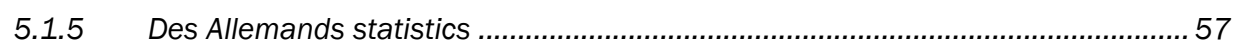

5.2 Other statistical assessments ............................................................ 59

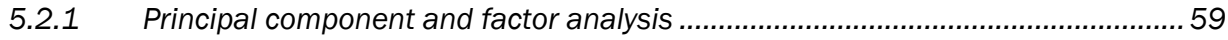

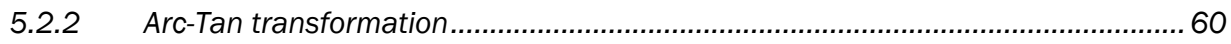

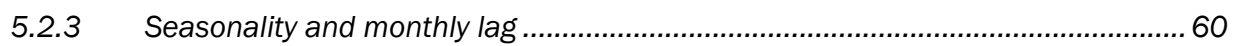

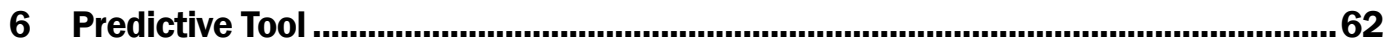

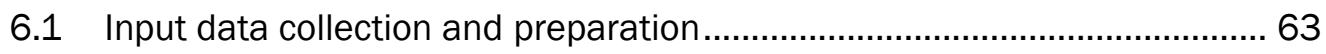

6.2 Data storage and model execution ............................................................. 66

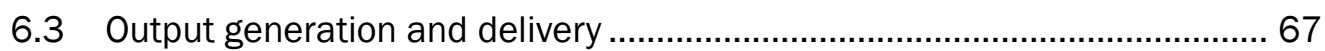

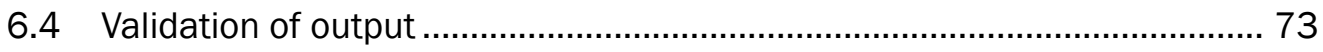

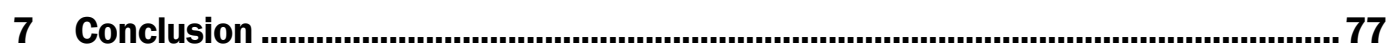

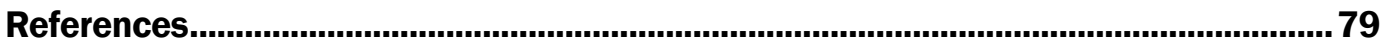

Report Documentation Page 


\section{Figures and Tables}

\section{Figures}

Figure 1. Map depicting USACE MVN and Louisiana Department of Wildlife and Fisheries (LDWF) areas for aquatic plant control responsibility in Louisiana. Orange regions represent areas where responsibilities were transferred from USACE to LDWF. 3

Figure 2. Generalized “hotspot' study area locations....................................................... 7

Figure 3. Henderson location map............................................................................... 8

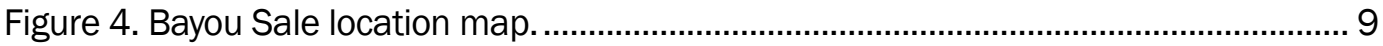

Figure 5. Turtle Bayou location map................................................................................. 10

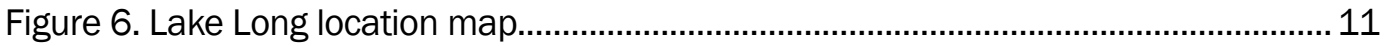

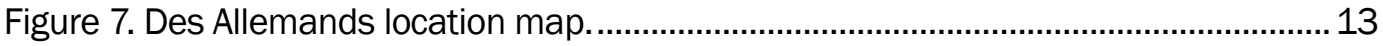

Figure 8. Vegetation surveys (from 1997, 2001, 2007, and 2013) showing locations of previously identified primary nuisance species of concern in relation to vegetation zones of coastal Louisiana. These specific vegetative surveys are not performed outside of Louisiana's coastal zone, and therefore they do not include the Henderson site.

Figure 9. Recent identification and mapping of nuisance aquatic vegetation in the Henderson study area. Henderson Lake hydrilla coverage as of June 2013 (LDWF 2013a).

Figure 10. Recent identification and mapping of nuisance aquatic vegetation in the Bayou Sale study area.

Figure 11. Recent identification and mapping of nuisance aquatic vegetation in the Turtle Bayou study area.

Figure 12. Recent identification and mapping of nuisance aquatic vegetation in the Lake Long study area.

Figure 13. Recent identification and mapping of nuisance aquatic vegetation in the Des Allemands study area.

Figure 14. Landsat derived vegetation area from 2003-2012.

Figure 15. Spatial distribution and frequency of aquatic vegetation within the Henderson study site (2003-2012).

Figure 16. Spatial distribution and frequency of aquatic vegetation within the Bayou Sale study site (2003-2012).

Figure 17. Spatial distribution and frequency of aquatic vegetation within the Turtle Bayou study site (2003-2012).

Figure 18. Spatial distribution and frequency of aquatic vegetation within the Lake Long study site (2003-2012).

Figure 19. Spatial distribution and frequency of aquatic vegetation within the Des Allemands study site (2003-2012).

Figure 20. Study site variable data station location. 
Figure 21. USACE chemical control acres treated with aquatic herbicides within each study site from 2003-2011. Total acres treated within the entire MVN Area of Responsibility for each period of control is provided in parentheses.

Figure 22. Goodness-of-fit plot - Model-predicted aquatic vegetation (AV) area in percent versus percentage of observed $\mathrm{AV}$ area from the satellite imageries for Henderson study site from 2003-2013.

Figure 23. Goodness-of-fit plot - Model-predicted aquatic vegetation (AV) area in percent versus percentage of observed $\mathrm{AV}$ area from the satellite imageries for Bayou Sale study site from 2003-2013.

Figure 24. Goodness-of-fit plot - Model-predicted aquatic vegetation (AV) area in percent versus percentage of observed $A V$ area from the satellite imageries for Lake Long study site from 2003-2013.

Figure 25. Goodness-of-fit plot-Model-predicted aquatic vegetation (AV) area in percent versus percentage of observed $\mathrm{AV}$ area from the satellite imageries for Lake Long study site from 2003-2013.

Figure 26. Goodness-of-fit plot - Model-predicted aquatic vegetation (AV) area in percent versus percentage of observed $\mathrm{AV}$ area from the satellite imageries for Des Allemands study site from 2003-2013.

Figure 27. Predictive tool automated workflow, including actions taken and technologies used for each step.

Figure 28. Classified map of study site models selected for use in each of 61

HUCs.

Figure 29. Diagram of relational database central to predictive tool.

Figure 30. Map images for January, April, and July 2015 detailing preliminary classified monthly AV growth potential in each HUC..

Figure 31. Updated map images for January, April, and July 2015 detailing classified monthly AV growth potential in current MVN AOR HUCs in relation to local historic growth patterns.

Figure 32. Actual versus predicted percentages of aquatic vegetation in the Henderson study area and HUC from 2010-2012.

Figure 33. Actual versus predicted percentages of aquatic vegetation in the Bayou Sale study area and HUC from 2010-2012.

Figure 34. Actual versus predicted percentages of aquatic vegetation in the Turtle Bayou study area and HUC from 2010-2012.

Figure 35. Actual versus predicted percentages of aquatic vegetation in the Lake Long study area and HUC from 2010-2012.

Figure 36. Actual versus predicted percentages of aquatic vegetation in the Des Allemands study area and HUC from 2010-2012.

\section{Tables}

Table 1. Factors limiting the potential abundance, distribution, growth, and spread of aquatic plants (modified from Madsen and Owens 2000).

Table 2. Acres of aquatic vegetation treated by LDWF spray crews in Henderson Lake - listed by vegetation type and applied herbicide, for the years 2008-2013 (modified from LDWF 2013a). 
Table 3. Vegetation sprayed and herbicides used in the Des Allemands study area in 2012 (modified from LDWF 2013b).

Table 4. Henderson Lake drawdown history (LDWF 2013a). 45

Table 5. Number of giant salvinia weevils (Cyrtobagous salviniae) released per water body (LDEQ water feature identification number provided in parentheses) in the Des Allemands through 2012 (LDWF 2013b).

Table 6. Sample size $(\mathrm{N})$ and average statistics (Mean) of the measurement variables from the five study sites during 2003-2013 study period.

Table 7. Henderson Stepwise Selection: Step 5 Variable AirTemp Entered: $r^{2}=$ 0.8434 and $C(p)=2.6697$.

Table 8. Bayou Sale Stepwise Selection: Step 8 Variable DewPt Entered: $r^{2}$ $=0.7252$ and $C(p)=9.0$.

Table 9. Turtle Bayou Stepwise Selection: Step 8 Variable Salinity Removed: $r^{2}=$ 0.7962 and $C(p)=8.0028$.

Table 10. Lake Long Stepwise Selection: Step 6 Variable Precip Entered: $\mathrm{r}^{2}=$ 0.7238 and $C(p)=6.0007$.

Table 11. Des Allemands Stepwise Selection: Step 7 Variable WindDir Removed: $r^{2}=0.8350$ and $C(p)=3.8596$.

Table 12. Online data sources and variables collected from each source by the automated predictive tool. 


\section{Preface}

This study was conducted for the Aquatic Plant Control Research Program (APCRP) under Project Number 450620. The program manager was Dr. Linda Nelson.

The work was performed by the Environmental Systems Branch (EEC), of the Ecosystem Evaluation and Engineering Division, U.S. Army Engineer Research and Development Center-Environmental Laboratory (ERDCEL). At the time of publication, Mr. Mark Graves was Chief, CEERD-EE-C, Mr. Mark Farr was Chief, CEERD-EE, and Dr. Alfred F. Cofrancesco was the Technical Director for the Civil Works Environmental Engineering and Sciences Office. The Deputy Director of ERDC-EL was Dr. Jack Davis and the Director was Dr. Beth Fleming.

The authors would like to thank Dr. Christopher Mudge and Ms. Christina Saltus for review of the technical report and Mrs. Sumani Chimmula, Mrs. Swathi Yandapally, and Dr. Donald Schoolmaster for technical assistance for this project.

COL Bryan S. Green was the Commander of ERDC, and Dr. David W. Pittman was the Director. 


\section{Acronyms and Abbreviations}

ac

AOR

APC

APCRP

API

ANOVA

ANSRP

AV

AWQMN

CRMS

CSV

CWPPRA

DN

DoD

EEC

EL

ERDC

EROS

ETM+

FA

GIS

GLM

HUC

IIS

IPM

LCWCRTF
Acres

Areas of Responsibility

Aquatic Plant Control

Aquatic Plant Control Research Program

Application Program Interface

Analysis Of Variance

Aquatic Nuisance Species Research Program

Aquatic Vegetation

Ambient Water Quality Monitoring Network

Coastwide Reference Monitoring System

Comma Separated Values

Coastal Wetlands Planning, Protection and Restoration

Authority

Digital Number

Department of Defense

Environmental Systems Branch

Environmental Laboratory

Engineer Research and Development Center

Earth Resources Observation Systems

Enhanced TM Plus

Factor Analysis

Geographic Information Systems

Generalized Linear Model

Hydrologic Unit Codes

Internet Information Services

Integrated Pest Management

Louisiana Coastal Wetlands Conservation and Restoration Task Force 


\begin{tabular}{ll} 
LDEQ & Louisiana Department of Environmental Quality \\
LDNR & Louisiana Department of Natural Resources \\
LDWF & Louisiana Department of Wildlife and Fisheries \\
LOSC & Louisiana Office of State Climatology \\
LSU & Louisiana State University \\
MSL & Mean Sea Level \\
MVN & USACE New Orleans District \\
NDVI & Normalized Difference Vegetative Index \\
NOAA & National Oceanic and Atmospheric Administration \\
NWI & National Wetlands Inventory \\
NWIS & USGS National Water Information System \\
NWS & National Weather Service \\
OMs & Operations Managers \\
O\&M & Operation and Maintenance \\
PCA & Principle Component Analysis \\
PDF & Portable Document Format \\
PPT & Parts Per Thousand \\
RAG & Removal of Aquatic Growth \\
RS & Remote Sensing \\
SAJ & USACE Jacksonville District \\
SAV & Submerged Aquatic Vegetation \\
SSURGO & Soil Survey Geographic \\
TM & Landsat Thematic Mapper \\
USACE & U.S. Army Corps of Engineers \\
USEPA & United States Environmental Protection Agency \\
USGS & United States Geological Survey \\
WARC & Wetland and Aquatic Research Center \\
WCDS & USACE Water Control Data System \\
WOTS & Water Operations Technical Support \\
\hline
\end{tabular}




\section{Unit Conversion Factors}

\begin{tabular}{|l|c|l|}
\hline Multiply & \multicolumn{1}{|l|}{ By } & To Obtain \\
\hline acres & $4,046.873$ & square meters \\
\hline cubic feet & 0.02831685 & cubic meters \\
\hline inches & 0.0254 & meters \\
\hline miles (U.S. statute) & $1,609.347$ & meters \\
\hline
\end{tabular}




\section{Introduction}

\subsection{Background}

Aquatic plants are important components for many ecosystems. This is especially true in the highly productive wetland ecosystems, where wetlands provide optimal conditions for aquatic plants and the goods and services that they render. Aquatic plants provide habitat and food to a wide range of wildlife and aquatic organisms. They also increase sedimentation and shoreline stability and regulate water quality through the assimilation of nutrients (Brix and Schierup 1989; Poirrier et al. 2010). However, not all aquatic plants are comparable. For example, indigenous plant species typically provide biological, chemical, and physical benefits to their ecosystems, while non-native plant species can cause severe ecological and economic damage (Office of Technology Assessment 1993; United States Environmental Protection Agency (USEPA) 2008; and Smart et al. 2009).

Non-native species (also described as alien, exotic, or non-indigenous species) that are intentionally or unintentionally released into new environments can become invasive species (USEPA 2008). The number of non-native species introduced into the United States is unknown, but estimates have ranged upwards of 50,000 (Pimentel et al. 2005). Impacts of non-native species can be devastating because they out-compete and threaten the existence of native species, and disrupt the natural and productive function of these environments (Mack et al. 2000; Novacek and Cleland 2001; Clavero and García-Berthou 2005; Smart et al. 2009). Valinoti et al. (2011) have noted that species invasions pose the second greatest threat to biodiversity in many ecosystems, surpassed only by habitat destruction.

Aquatic plants account for a large portion of the world's non-native or introduced species. Though only a small percentage of non-native aquatic plants become invasive, they cause significant ecological and economic damage (Office of Technology Assessment 1993). In some regions, prolific non-native species produce dense surface canopies or excessive biomass that cause economic damage by clogging drainage canals, damaging industrial water systems, limiting recreational access, and affecting navigation and navigation-related commerce (Alimi and Akinyemiju 1991, 
Schmitz et al. 1993; Evans 2008; Smart et al. 2009). Within the United States, impacts from non-native aquatic plants account for approximately $\$ 36.6$ billion in economic losses per year (Pimentel et al. 2000).

Protecting ecosystem structure and functions have long been priorities of the United States government. Multiple federal agencies (e.g., National Park Service, Bureau of Land Management, Forest Service, Fish and Wildlife Service, U.S. Army Corps of Engineers (USACE), and Bureau of Reclamation) are responsible for managing approximately 655 million acres (ac) of land and operating and maintaining approximately 12,000 miles of inland and intracoastal waterways and navigable channels in the United States (Walls et al. 2009; USACE 2009). Though these resources have historically been subjected to management plans that are designed to enhance wildlife, fisheries, and commercial and recreational navigation, impacts from invasive plants is an ever increasing consideration (Sanders and Decell 1977).

In an attempt to reduce environmental and economic impacts from invasive plants, the U.S. Congress made provisions through the 1899 River and Harbor Act to authorize the removal of vegetation that hinders navigation in federal waters. Additional authorizations were granted in 1958, 1990, and 1996 through the River and Harbor Act, creating the Aquatic Plant Control program, the Non-Indigenous Aquatic Nuisance Prevention and Control Act (16 U.S.C. $\S 4701$ et seq.), and the National Invasive Species Act, respectively (Lovell and Stone 2005). In 2009, USACE supplemented these authorizations by mandating an invasive species policy. The purpose of this policy was to implement measures to either prevent or reduce the establishment of invasive and non-native species as a component to all USACE projects (Mobley 2013).

Since implementing the invasive species policy, USACE has had an average annual cost of $\$ 135$ million for its invasive species programs, with the majority of those funds (60\%) being used for control measures (Mobley 2013). A small, yet vital, segment of those costs is related to the USACE Removal of Aquatic Growth (RAG) program. The RAG program provides USACE the authority to control any species (including native vegetation) that poses a threat to navigation. Currently, there are two USACE Districts, New Orleans (MVN) and Jacksonville (SAJ), that have active RAG programs. Due to the number of waterway miles and the sheer expanse of ecosystems that are hospitable to aquatic and invasive 
vegetation, RAG in these Districts is critical for effective prevention, control, and eradication of nuisance aquatic species. In 2016, Florida and Louisiana had more than twice the average number of introduced aquatic plants as other states-sixty four and forty, respectively (Tulane University 2010; United States Geological Survey (USGS) 2016).

Figure 1 shows the Areas of Responsibility (AOR) for aquatic growth control operations in Louisiana. The beige colored regions are the responsibility of the Louisiana Department of Wildlife and Fisheries (LDWF), while the red coastal zone regions are the responsibility of USACE. The orange regions represent areas that USACE once controlled, but those responsibilities were transferred to LDWF in 2010. The USACE RAG program has also shared growth control operations within the Atchafalaya Basin Floodway System with LDWF, primarily the Henderson Lake region (Figure 1, dark blue). However, these MVN operations were curtailed in 2010 with reductions in RAG program funding.

Figure 1. Map depicting USACE MVN and Louisiana Department of Wildlife and Fisheries (LDWF) areas for aquatic plant control responsibility in Louisiana. Orange regions represent areas where responsibilities were transferred from USACE to LDWF.

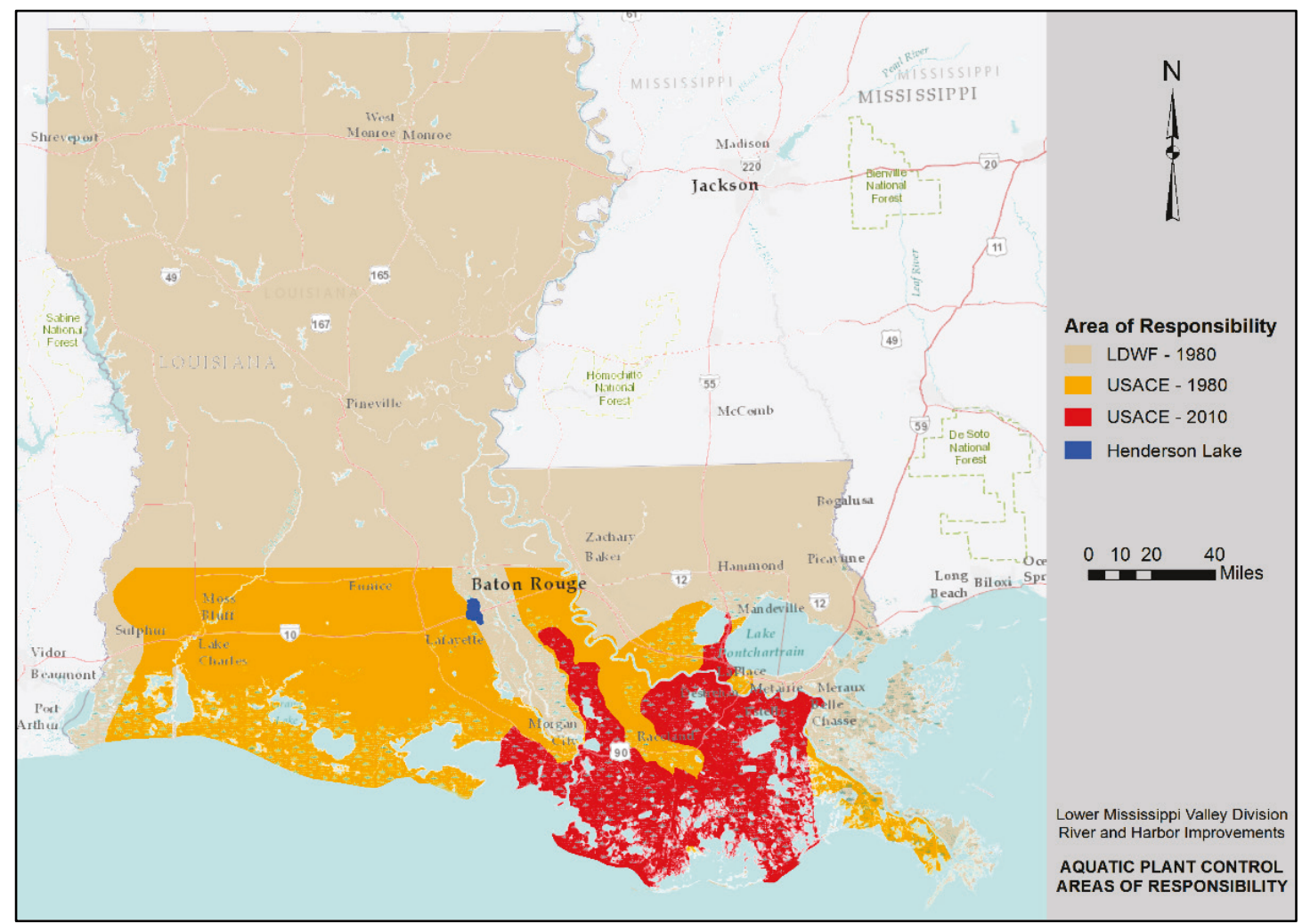


Historically, the MVN RAG program utilized field personnel on boats to regularly perform reconnaissance and map nuisance vegetation expansions in coastal Louisiana that: 1) posed a direct impediment to navigation in navigation channels, and 2) had potential to become an impediment to navigation in these channels due to growth in and drift from side waterways into these navigation channels. Once impediments were identified, MVN primarily utilized chemical control measures (through third-party contracts) to inhibit growth and restore navigability. However, since the recent budget reductions, infestations have not been monitored to the levels necessary to accurately identify areas requiring control operations. Without sufficient assessments and management of nuisance aquatic vegetation (AV), there is high potential for coastal navigation to become impeded and ecosystem resources to become degraded.

\subsection{Purpose}

While recent concerns about AV infestations have increased, MVN RAG funding has decreased, resulting in insufficient assessments and management (Allen and Suir 2014). As a result, field reconnaissance necessary for mapping and identifying areas in need of AV control has been limited, hindering normal MVN control operations (Allen and Suir 2014). Consequently, reductions in RAG activity has resulted in higher potential for impeded navigation on waterways in the MVN AOR.

Regardless of budget constraints, identifying methods to more rapidly and efficiently locate and/or predict high growth areas of AV is desired. This would allow for more effective use of resources, field reconnaissance, and passive and direct management activities. Additionally, these methods could provide opportunities for long-term assessment and monitoring of environmental and management impacts on the density and distribution of AV in Louisiana's lotic ecosystems. This study consists of two primary tasks: 1) using regional-scale data to characterize aquatic nuisance vegetation in coastal Louisiana navigation channels, and 2) assessing the potential for remote sensing and environmental conditions to detect and predict aquatic nuisance vegetation growth in coastal Louisiana.

Task 1 (results published in Allen and Suir 2014) was used to develop an innovative capability for regularly and rapidly-generating regional-scale mapping products that characterize the presence of floating aquatic nuisance vegetation in USACE district navigation channels. The new capability strategically enables district Operations Managers (OMs) to 
regularly and comprehensively inform navigation stakeholders on channel conditions, as well as to direct field operations for the authorized RAG. This technological improvement delivers a level of accuracy and detail not currently possible with traditional methods and resources. This task established and demonstrated new protocols through exploitation of satellite imagery that had not been utilized for RAG applications until recently. The resulting new capability enhanced how seasonal RAG OM requirements are accomplished, as a major improvement over traditional practices (i.e., field reconnaissance).

The purpose of Task 2, described in this report, was to extend these new capabilities to make scientifically-based predictions on seasonal plant growth potential using aquatic vegetation growth trends, watershed flows and circulation, influxes and distributions of nutrients, climatic and weather influences, and their interactions with management activities. The objectives of this study were four-fold: 1) utilize methods developed in Task 1 to classify the extent and distribution of AV in lotic ecosystem areas using satellite imagery, 2) evaluate primary AV growth and control trends in coastal Louisiana, 3) statistically identify the ecological drivers that promote growth and infestation of nuisance $\mathrm{AV}$, and 4) develop a numerical model and spatial tool to predict the probability of occurrence and growth of AV given ecological drivers. This capability will further enhance the management abilities of MVN OMs in directing their RAG Program.

\subsection{Project area}

The rich and productive natural ecosystems of Louisiana's southeastern coastal zone (Deltaic Plain), specifically the inland, wetlands, swamps, and estuaries where fresh and salt water mix and form ideal habitat for invasive aquatic plants (Tulane University 2010). Exacerbating the aquatic plant invasion is the network of natural and manmade waterways intersecting Louisiana, these serve as pathways for aquatic species to proliferate throughout entire drainage basins (Tulane University 2010). Likewise, with a constant river flow through these basins, aquatic plants are continuously moving with the current. However, plants eventually amass in channels, restricting navigability and ultimately degrading ecosystem conditions (LDWF 2013c).

Over the course of the RAG program, MVN has monitored and controlled AV throughout the USACE AOR (Figure 1). For this study, representative "hotspot" sites were selected based on personal communication with MVN 
RAG personnel, the frequency at which sites have previously required chemical control (based on RAG program work plans), and exclusivity of climate and environmental conditions and drivers. Five sites were selected for inclusion in this study. These include, from west to east: Henderson, Bayou Sale, Turtle Bayou, Lake Long, and Des Allemands (Figure 2). All five sites contain a large number of waterways and water features that are vital for local recreational and commercial fishing, as well as oil and natural gas activities.

For ease of description and illustration, each site is represented in two ways: 1) aquatic vegetation-specific boundaries and 2) generalized boundaries (Figures 3-7). The aquatic vegetation-specific boundaries encompass all water features within a study site that are capable of bearing aquatic vegetation. The generalized boundaries are the maximum extent of the aquatic vegetation-specific boundaries that have been aggregated, simplified, and smoothed.

Since the vegetative species of concern are aquatic, the approach of this study was to quantify the percentage of water features within each of the five hotspot study sites (Figures 3-7) that AV occupied. Establishing the AV specific study sites bounding areas consisted of utilizing the latest high-resolution National Wetlands Inventory (NWI) habitat and Soil Survey Geographic (SSURGO) data to identify all water features (consisting of open water and floating or submerged aquatics) and delineating the land and water interface within each site. To account for differing grain size (between NWI data and moderate resolution Landsat TM imagery) and the potential for positional shifting of the Landsat imagery, the land and water interface boundary was buffered 30 meters to increase the potential for water and aquatic vegetation feature inclusion. 


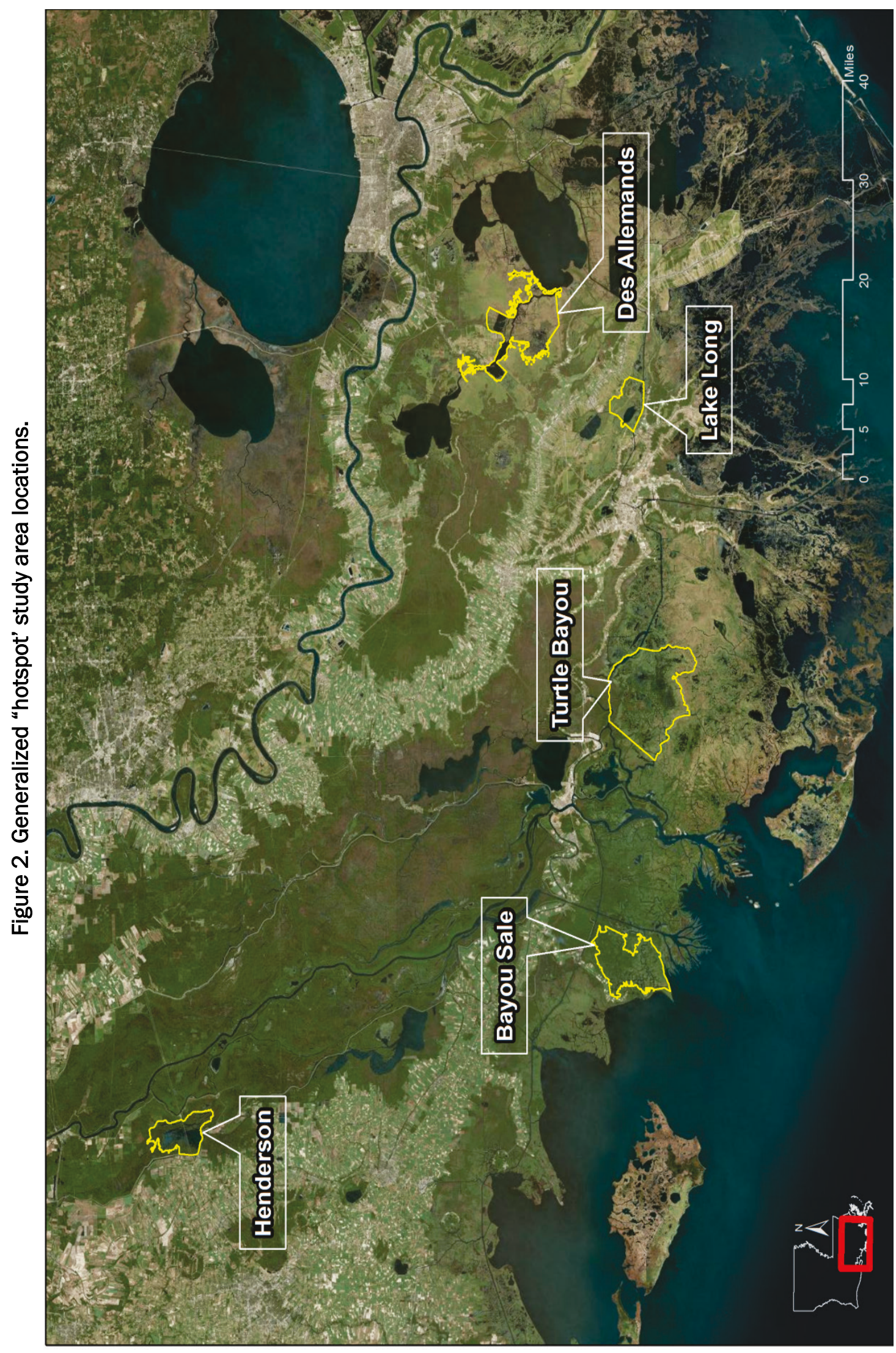




\subsubsection{Henderson}

The Henderson study site is located within St. Martin Parish in southcentral Louisiana (Figure 3). This site, consisting primarily of freshwater swamp and natural waterways at the northern terminus of the Teche Delta, extends east from the West Atchafalaya Basin Protection Levee to Bayou Haha and Gin Slough, and extends south from Little Fordoche Bayou to Bay Farine. Henderson receives backwater from the Atchafalaya River, and source water from Bayou Courtableau, during high and low water conditions, respectively (LDWF 2013a). Depending on inflow and control, water levels in Henderson Lake typically fluctuate four to five feet annually, increasing the acreage of the lake from 5,000 to 7,500 acres (LDWF 2013a). The generalized study site (Figure 3, black boundary) is approximately $12,400 \mathrm{ac}$, and the aquatic vegetation-specific study areas (hatched regions) account for approximately 7,500 ac.

Figure 3. Henderson location map.

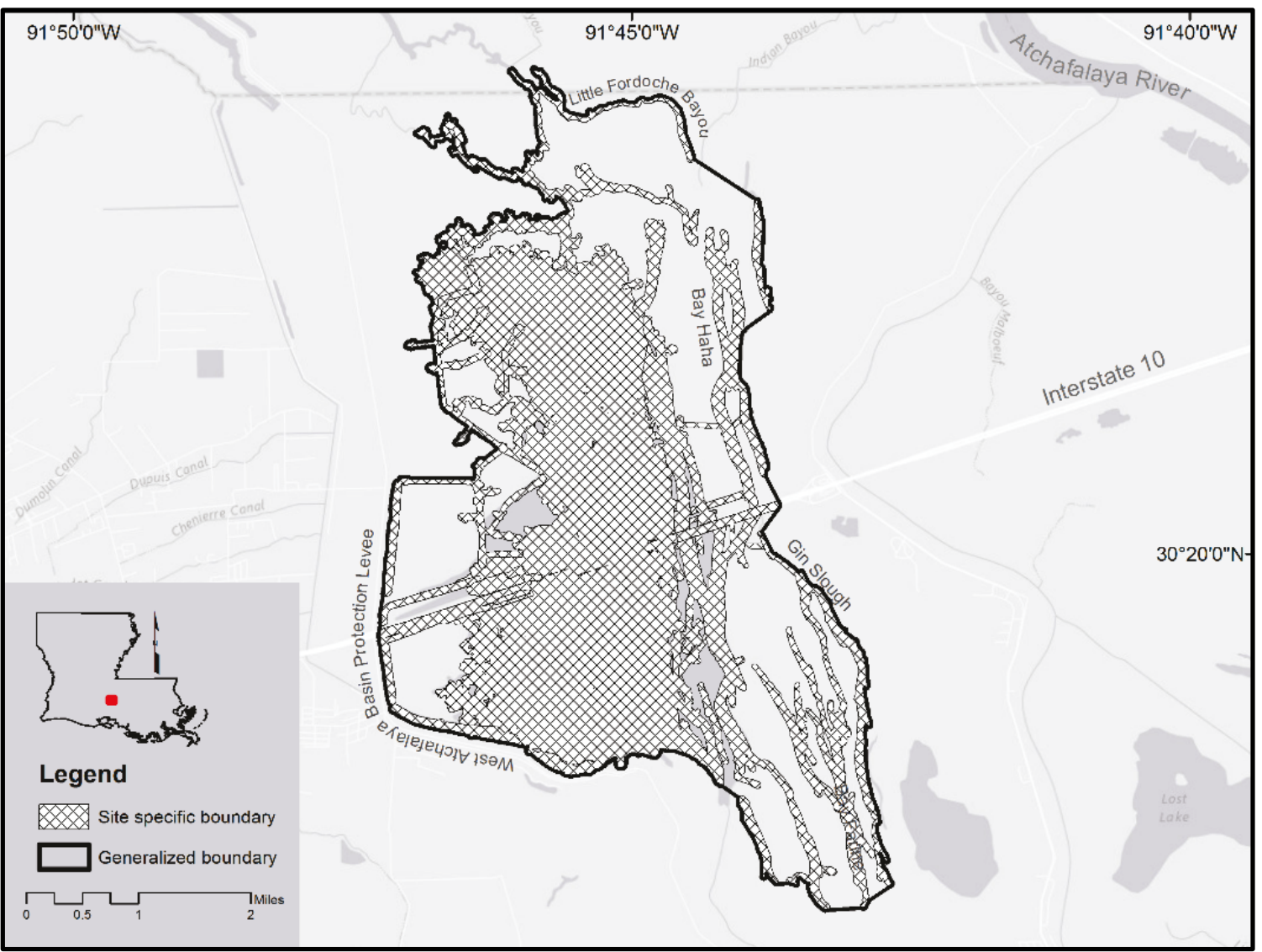




\subsubsection{Bayou Sale}

The Bayou Sale study site is located in St. Mary parish, within the southcentral coastal zone of Louisiana (Figure 4). The study site is bounded on the north by the Gulf Intracoastal Waterway, the west by Bayou Sale and Bayou Sale Bay, the south by the Atchafalaya Bay, and the east by Wax Lake and Wax Lake Pass. This area falls within the marshland of the Teche Delta Plain and consists of fresh marsh and swamp. Features of the area include numerous bayous and small open water areas, oil and gas pipeline and access canals (with associated spoil banks and retention areas), and a narrow strip of natural levee hardwoods (USACE 2012). Due to its close proximity to the Wax Lake Outlet freshwater diversion (total discharge ranging from $900-8,800 \mathrm{~m}^{3} / \mathrm{s}$ ), the area receives a steady inflow of freshwater from the diversion as well as from overflow during seasonal flooding (USACE 1998). The generalized study site (Figure 4, black boundary) is approximately $22,800 \mathrm{ac}$, and the aquatic vegetation-specific study areas (hatched regions) account for approximately 7,400 ac.

Figure 4. Bayou Sale location map.

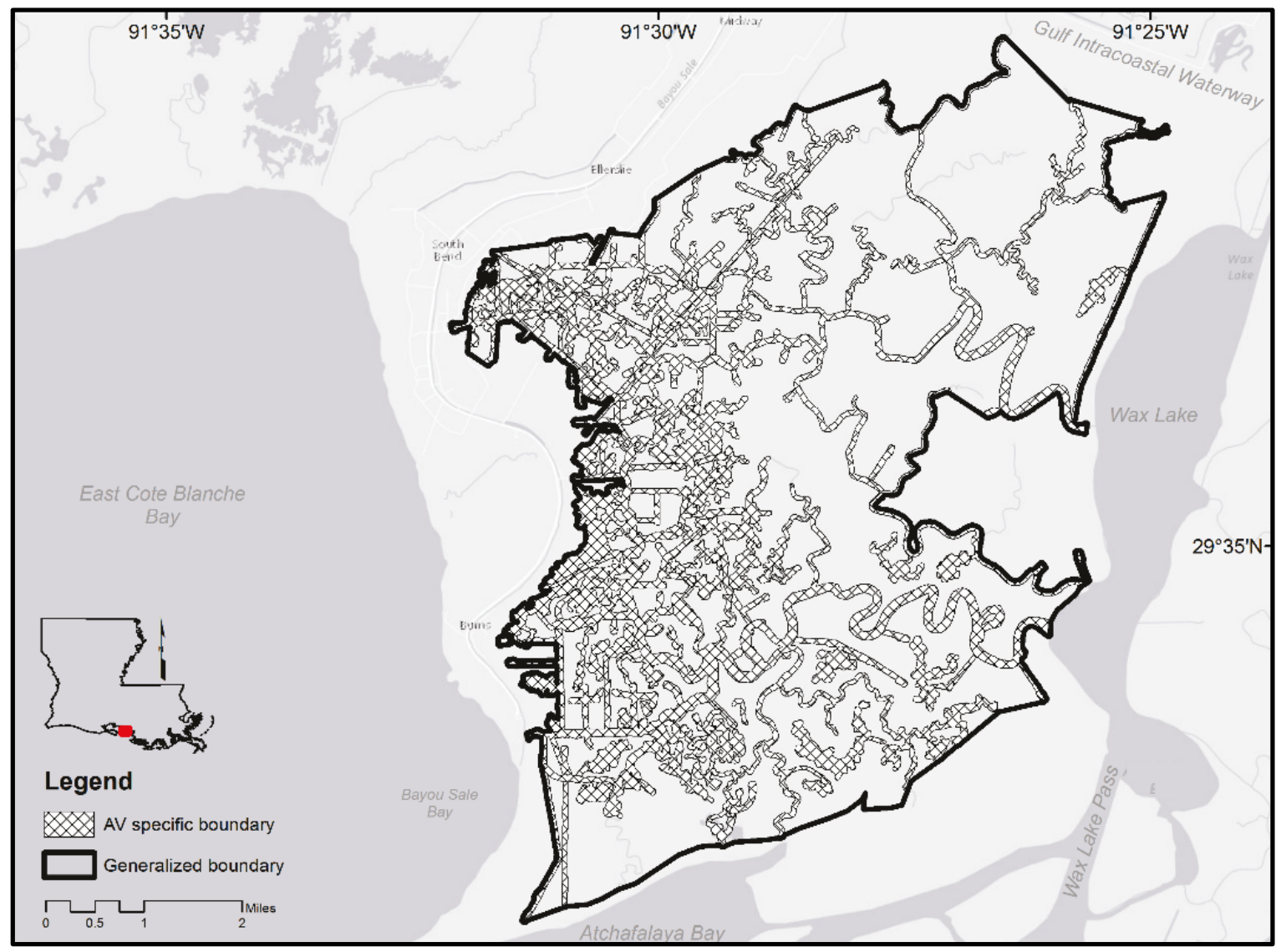




\subsubsection{Turtle Bayou}

The Turtle Bayou study site is located in the upper Bayou Penchant Basin, where the Lafourche overlays the Teche Delta, in northwestern Terrebonne parish (Figure 5). The Turtle Bayou site extends east from the North Kent Pipeline Canal to Bayou Copasaw, and south from the Intracoastal Waterway to Bayou Penchant. This site, consisting primarily of forested and fresh marsh, scrub/shrub, and aquatic vegetation habitat, is intermixed with natural bayous, a major channelized waterway, and numerous oil and gas access canals. The study site is in close proximity to the Atchafalaya River, and therefore receives large water inflows via natural and channelized distributaries (U.S. Department of Agriculture 2002). The generalized study site (Figure 5 , black boundary) is approximately 47,500 ac, and the aquatic vegetation-specific study areas (hatched regions) account for approximately 27,500 ac.

Figure 5. Turtle Bayou location map.

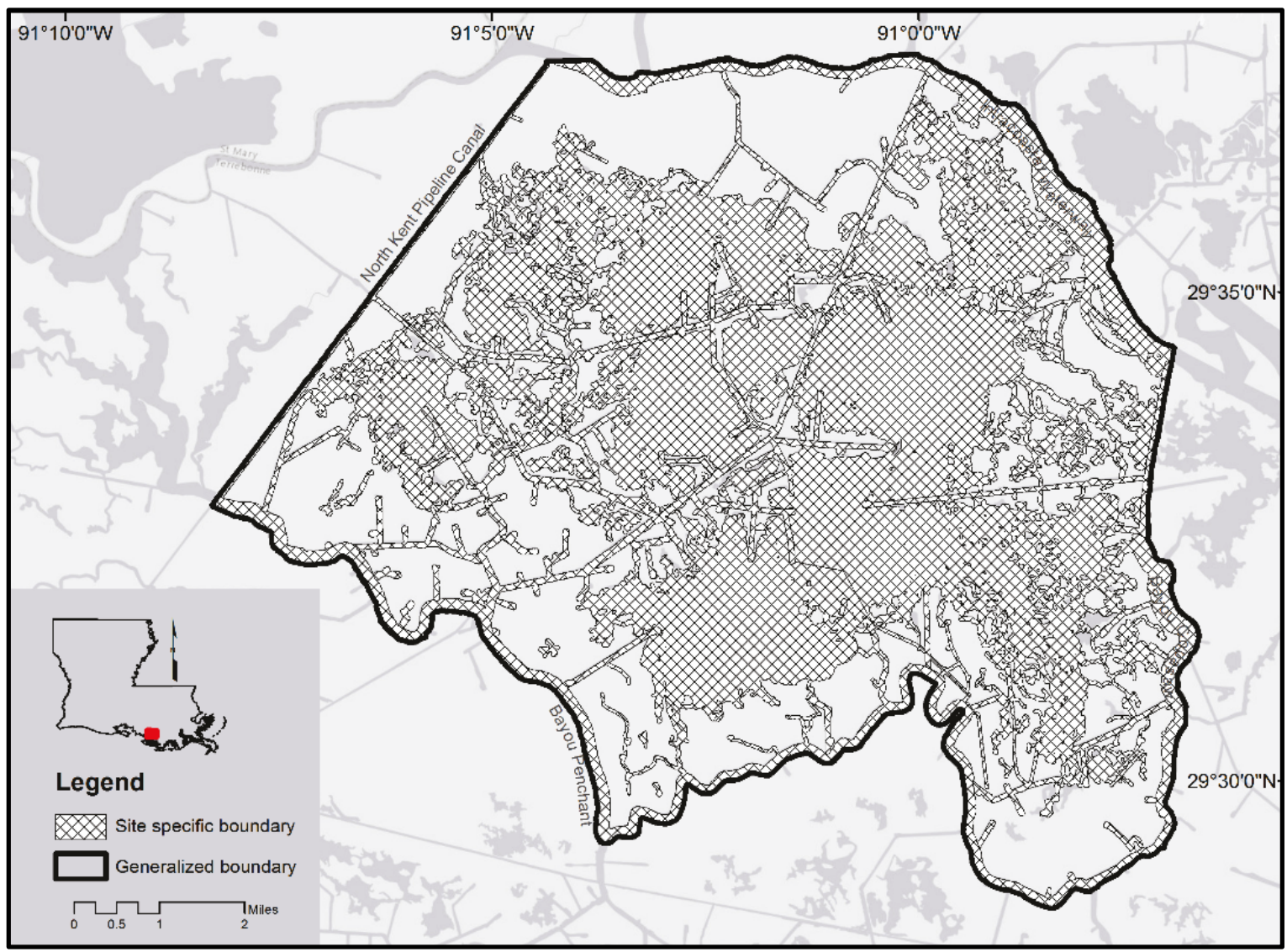




\subsubsection{Lake Long}

The Lake Long study site is located within Lafourche parish in southeastern Louisiana (Figure 6). The Lake Long site extends east from Company Canal to the Allan Ranch Bridge at Bayou L'Eau Bleu, and extends south from Bayou L'Eau Bleu to the Intracoastal Waterway. This site, consisting primarily of forested wetlands and scrub/shrub habitat in the Lafourche Delta, is intermixed with natural bayous, a major channelized waterway, oil and gas access canals, and Lake Long. The shallow, natural coastal lake and its surrounding canals are hydrologically connected to the Intracoastal Waterway and tidally influenced by the Gulf of Mexico (LDWF 2013d). The generalized study site (Figure 6, black boundary) is approximately 8,500 ac, and the aquatic vegetation-specific study areas (hatched regions) account for approximately 2,700 ac.

Figure 6. Lake Long location map.

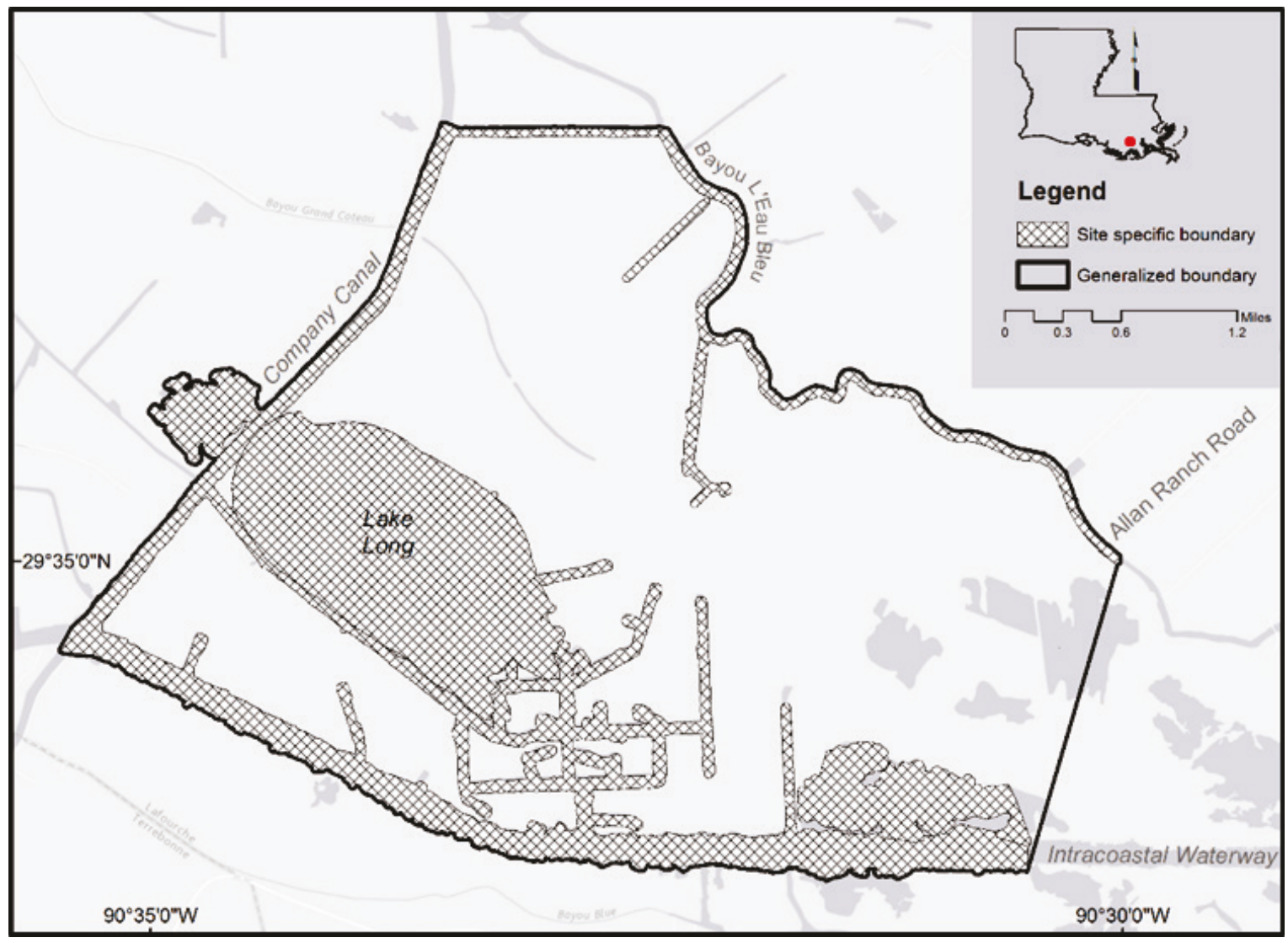




\subsubsection{Des Allemands}

The Des Allemands study site is located within Lafourche and St. Charles parishes in southeastern Louisiana (Figure 7). The study site is bounded by Lac des Allemands to the northwest and Lake Salvador to the southeast and extends south from Humble Canal to Company Canal. This area consists primarily of wetlands and numerous bayous, canals, and channels within the overlapping lobes of the Teche, Atchafalaya, and Lafourche Delta Plains. The erection of flood protection levees along the Mississippi River virtually eliminated freshwater input into the site (Louisiana Coastal Wetlands Conservation and Restoration Task Force [LCWCRTF] 1993). Though rainfall continues to be the dominant source of freshwater into the area, some riverine inflow has returned with the construction of the freshwater diversion at Davis Pond in 2002 (Kral et al. 2012). Low-lying elevation affects the area, allowing for tidal influence from the Gulf of Mexico that result in salinity as high as 15 parts per thousand (ppt) and limit aquatic plant growth in parts of this estuary (Louisiana department of Environmental Quality [LDEQ] 2014; LDWF 2013b). The generalized study site (Figure 7, black boundary) is approximately 26,700 ac, and the AVspecific study areas (hatched regions) account for approximately 13,700 ac. 
Figure 7. Des Allemands location map.

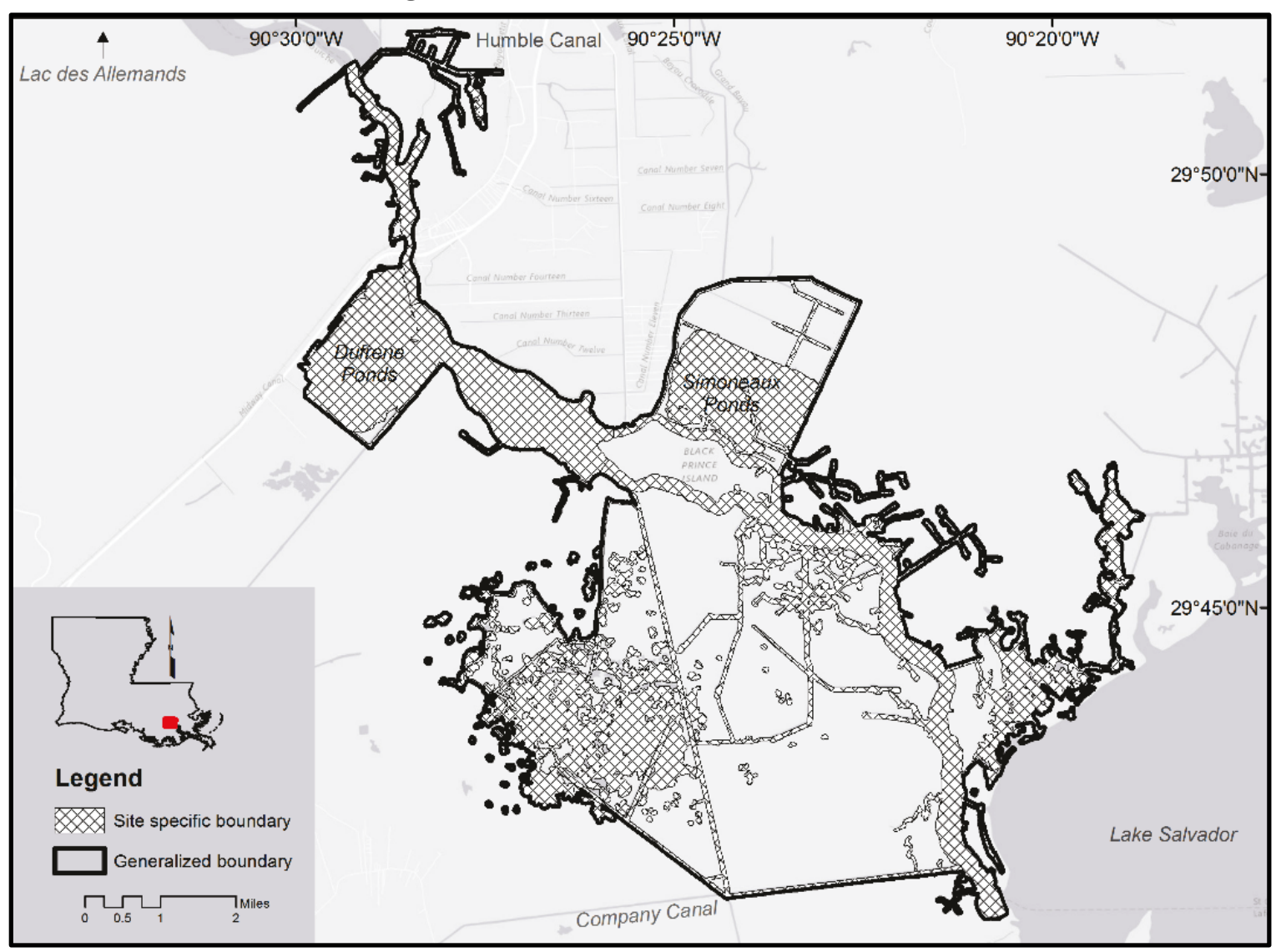




\section{Nuisance Aquatic Vegetation}

\subsection{Background}

Non-native species are species that have been introduced into areas outside of their native range, where they become established and spread (Masterson 2007 and USEPA 2008). While some introduced species are benign, and some beneficial, those that garner the most attention are the species that cause environmental or economic damages or impacts to human health (USEPA 2008). There are multiple stakeholders that use various methods and systems to map and categorize aquatic invasive species in Louisiana. The state management plan for aquatic invasive species in Louisiana categorizes aquatic invasive plants into three primary classes: extensively established species, locally established species, and potential arrivals (Louisiana Department of Wildlife and Fisheries 2005). Extensively established species are those that are found in eight or more of Louisiana's thirteen drainage basins. Those that occur in three to seven drainages are categorized as locally established, and those found in two or fewer drainages are listed as potential arrivals.

Large-scale vegetation surveys have been performed within the coastal zone of Louisiana since 1949 (O’Neil 1949). The more recent, standardized surveys that were completed in 1978, 1988, 1998, 2001, 2007, and 2013, document species composition, abundance, and corresponding marsh type (i.e., fresh, intermediate, brackish, or saline) (Visser et al. 1998). These surveys utilize transects that are oriented in a north-south direction (3 kilometers [km] spacing), with sampling sites located at $0.8 \mathrm{~km}$ spacing along each transect (Sasser et al. 2014). Figure 8 shows the locations of vegetation surveys from 1997, 2001, 2007, and 2013 that previously identified primary nuisance species of concern (described below) in relation to study sites and the primary marsh zones of coastal Louisiana. Many nuisance vegetation species in Louisiana are salinity intolerant. This is observed in Figure 8, which shows nuisance vegetation species existing primarily in fresh marsh zones, with some sprawl into intermediate zones. 
Figure 8. Vegetation surveys (from 1997, 2001, 2007, and 2013) showing locations of previously identified primary nuisance species of concern in relation to vegetation zones of coastal Louisiana. These specific vegetative surveys are not performed outside of Louisiana's coastal zone, and therefore they do not include the Henderson site.

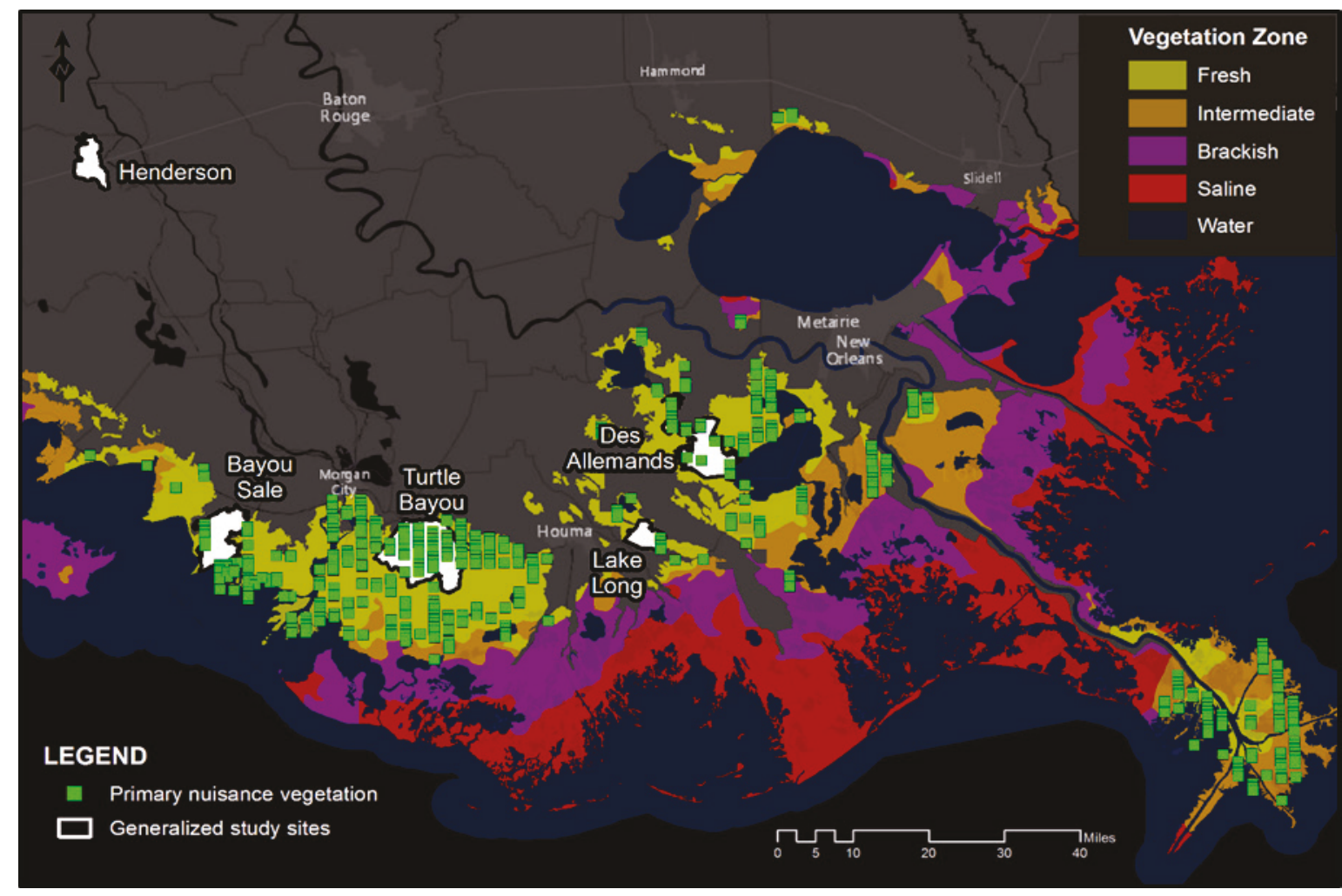

Within the coastal zone of Louisiana, common salvinia (Salvinia minima), Eurasian watermilfoil (Myriophyllum spicatum), giant salvinia (Salvinia molesta), hydrilla (Hydrilla verticillata), and water hyacinth (Eichhornia crassipes) are the primary nuisance invasive species of concern. Species such as sedges (Carex spp.), alligatorweed (Alternanthera philoxeroides), pennywort (Hydrocotyle ranunculoides), and primrose (Ludwigia spp.) present minimal problems (LDWF 2013b, 2013c, 2013d, and 2013e). The focus of this study is the MVN RAG identified hotspot areas that have historically experienced blockage and overgrowth of primary nuisance invasive species. The state management plan for aquatic invasive species in Louisiana describes many of the state's aquatic invasive species (LDWF 2005). Summaries are provided below:

Common Salvinia is a floating fern that typically prefers slow-moving freshwaters such as bayous, cypress swamps, marshes, ponds, and lakes. Common salvinia forms thick mats on the water surface, up to almost 25 centimeters (10 inches) deep in some instances. These mats shade and crowd-out native plants, degrading habitat for fish and birds and negatively affect water quality. 
Eurasian Watermilfoil aggressively out-competes native vegetation and degrades water quality for fish and birds. This species prefers slow-moving waters, such as ponds, lakes, bayous, shallow reservoirs, streams, and lowenergy rivers, but can tolerate brackish waters. It forms thick, dense mats at the water surface and impedes recreational activities such as boating and swimming.

Giant Salvinia was most likely introduced to the United States as an aquarium plant. Giant salvinia expands its range through reproduction, wind transport, and boaters and fishermen who do not rinse their gear. Since its introduction, giant salvinia has expanded into at least 15 locations throughout southern Louisiana. It is a free-floating, rootless plant that reproduces quickly and doubles its biomass every seven to ten days. Giant salvinia chokes bayous and canals and can cover large portions of lakes and reservoirs, degrading water quality, harming wildlife, and impeding boat traffic.

Hydrilla is originally from Asia. It is a rooted, aquatic weed that inhabits both deep and shallow waters. In shallower areas, hydrilla forms thick mats that impede boat traffic and swimming. It adversely affects water quality by shading out native vegetation, lowering dissolved oxygen concentrations, and can result in fish kills.

Water Hyacinth was first introduced to the United States as an ornamental plant at the World's Industrial and Cotton Centennial Exposition in New Orleans in 1884. A South American native, water hyacinth frequently clogs bayous and canals, impedes boat traffic, slows water currents, and blocks light to native submerged aquatic vegetation (SAV), degrading water quality and harming wildlife. Known for its beautiful flowers, hyacinth can be found in almost every drainage basin in Louisiana.

While many aquatic plants are native or were introduced to Louisiana more than 100 years ago, hydrilla and giant salvinia are introductions that are more recent. Hydrilla was introduced in the 1970's and giant salvinia in 1998, but neither appeared in south Louisiana until approximately 2005 (Christopher Mudge, personal communication, 2016).

\subsubsection{Henderson vegetation}

The Henderson study site is located within a large river swamp basin that can be divided into three distinct areas, the northern bottomland hardwood forest, the central cypress-willow-tupelo swamps, and the lower freshwater and brackish marsh (Atchafalaya Basin Program 2014; 
Atchafalaya Basinkeeper 2014). The Henderson study site is located in the central backwater swamp and consists of cypress (Taxodium distichum), willow (Salix nigra), and cottonwood (Populus heterophylla) trees as well as an overabundance of aquatic vegetation (LDWF 2013a). The aquatic vegetation within the study site consists of native coontail (Ceratophyllum demersum), fanwort (Cabomba caroliniana), and American lotus (Nelumbo lutea) as well as invasive species such as hydrilla, common salvinia and water hyacinth (LDWF 2009). These invasive species often reach critical mass, thereby restricting access to many areas in the Basin and exacerbating hypoxic conditions.

The Henderson study site is located beyond the northern bounds of Louisiana's coastal zone, and therefore outside of the coverage of the state's vegetation survey data set. In addition to the NWI data, Figure 9 shows aquatic vegetation data that was surveyed in the fall of 2005. The survey data indicate the primary nuisance aquatic invasive species in the Henderson study site were hydrilla and water hyacinth. Intermixed with the abundant hydrilla and water hyacinth were light and moderate amounts of common salvinia, coontail, duckweed (Lemna minor), primroses, sedges, swamp smartweed (Polygonum hydropiperoides), flatsedge (Cyperus spp.), and filamentous algae (Pithophora spp.) (LDWF 2013a). Figure 9 shows severe infestations (dark green) were located in the lake's shallow flats, moderate infestations (medium green) were located along shorelines and in deeper channels, and light infestations (light green) were located in some small access canals (LDWF 2013a).

Figure 9 also illustrates the 2013 extent of hydrilla (white cross-hatch), these were surveyed along with other nuisance aquatic invasive species. The 2013 survey, which provides estimates of the percent coverage of infestation, shows that hydrilla, water hyacinth, and common salvinia accounted for $50 \%(2,500 \mathrm{ac}), 20 \%$ (1,000 ac), and $10 \%$ (500 ac) coverage of all water features in Henderson Lake, respectively (LDWF 2013a). The 1978 and 1988 NWI data show that the areas of aquatic bed classes (orange regions) are located primarily in the northern half of Henderson Lake and within and along the shorelines of natural and channelized waterways. Density and distribution of aquatic vegetation in this region and many regions of Louisiana are seasonally driven. 
Figure 9. Recent identification and mapping of nuisance aquatic vegetation in the Henderson study area. Henderson Lake hydrilla coverage as of June 2013 (LDWF 2013a).

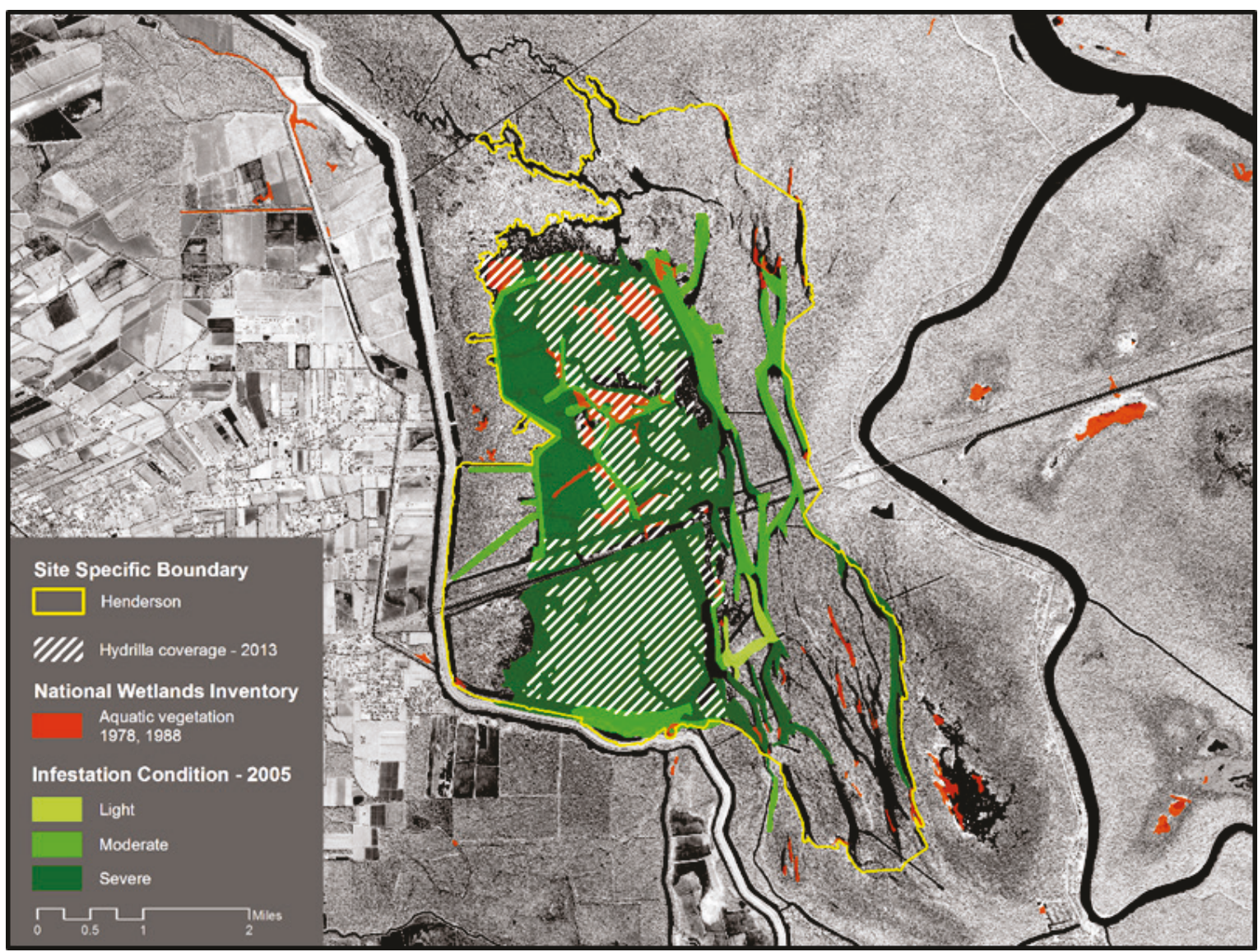

\subsubsection{Bayou Sale vegetation}

The Bayou Sale study site is located within the lower reaches of the Atchafalaya watershed basin. This subsegment consists primarily of inland swamp mixed with fresh water emergent and floating marsh (USACE 1998). The dominant woody vegetation in this study site consists of black willow (Salix nigra), red maple (Acer rubrum), wax myrtle (Morella cerifera), Chinese tallow (Triadica sebifera); while the common marsh plants consist of bulltongue arrowhead (Sagittaria lancifolia), cattail (Typha spp.), Gulf Coast spikerush (Eleocharis cellulosa), seedbox (Ludwigia alternifolia), alligatorweed, broadleaf arrowhead (Sagittaria latifolia), coco yam (Colocasia esculenta), and smooth beggartick (Bidens laevis) (Chabreck and Linscombe 1997).

Although American lotus and hydrilla are also common, water hyacinth is the most abundant nuisance aquatic plant in the Bayou Sale study site. Since no nuisance aquatic vegetation-specific surveys were conducted for 
Bayou Sale, RAG work plans were used to estimate the coverage of water hyacinth within the study site. Between 2003 and 2011, approximately 1,300 ac of water hyacinth per year were identified for control operations. Moreover, the identified areas received chemical control multiple times within a one-year period.

Figure 10 shows the mapped aquatic vegetation and the classified nuisance vegetation within the Bayou Sale study site. The mapped aquatic vegetation (orange regions) consists of the aquatic bed vegetation that were classified as part of the 1978, 1988, and 2008 NWI program. According to the NWI Wetlands and Deepwater Habitats Classification system, aquatic beds include wetlands and deepwater habitats dominated by plants that grow principally on or below the surface of the water for most of the growing season in most years (Cowardin et al. 1979). These classes can consist of algal, rooted vascular, floating vascular, aquatic moss, unknown submergent aquatic, and unknown surface aquatic plants. The NWI data provide a general representation of aquatic vegetation distribution within a lotic system. Figure 10 shows that most of the water features, especially the smaller oil and gas access canals, are inundated with aquatic vegetation (orange regions).

The classified nuisance vegetation (green dots) consists of the primary nuisance invasive species that were identified through the 1997, 2001, 2007, and 2013 vegetation type surveys for coastal Louisiana (Chabreck and Linscombe 1997; Visser et al. 1998; Sasser et al. 2008; Sasser et al. 2014). Since the areas within the Bayou Sale site that are capable of supporting aquatic vegetation are long narrow water features, there are few coinciding survey sites (green dots, Figure 10). Those sites that fall within these water features indicate that the primary nuisance invasive species in the Bayou Sale study site is water hyacinth, with some occurrences of hydrilla. 
Figure 10. Recent identification and mapping of nuisance aquatic vegetation in the Bayou Sale study area.

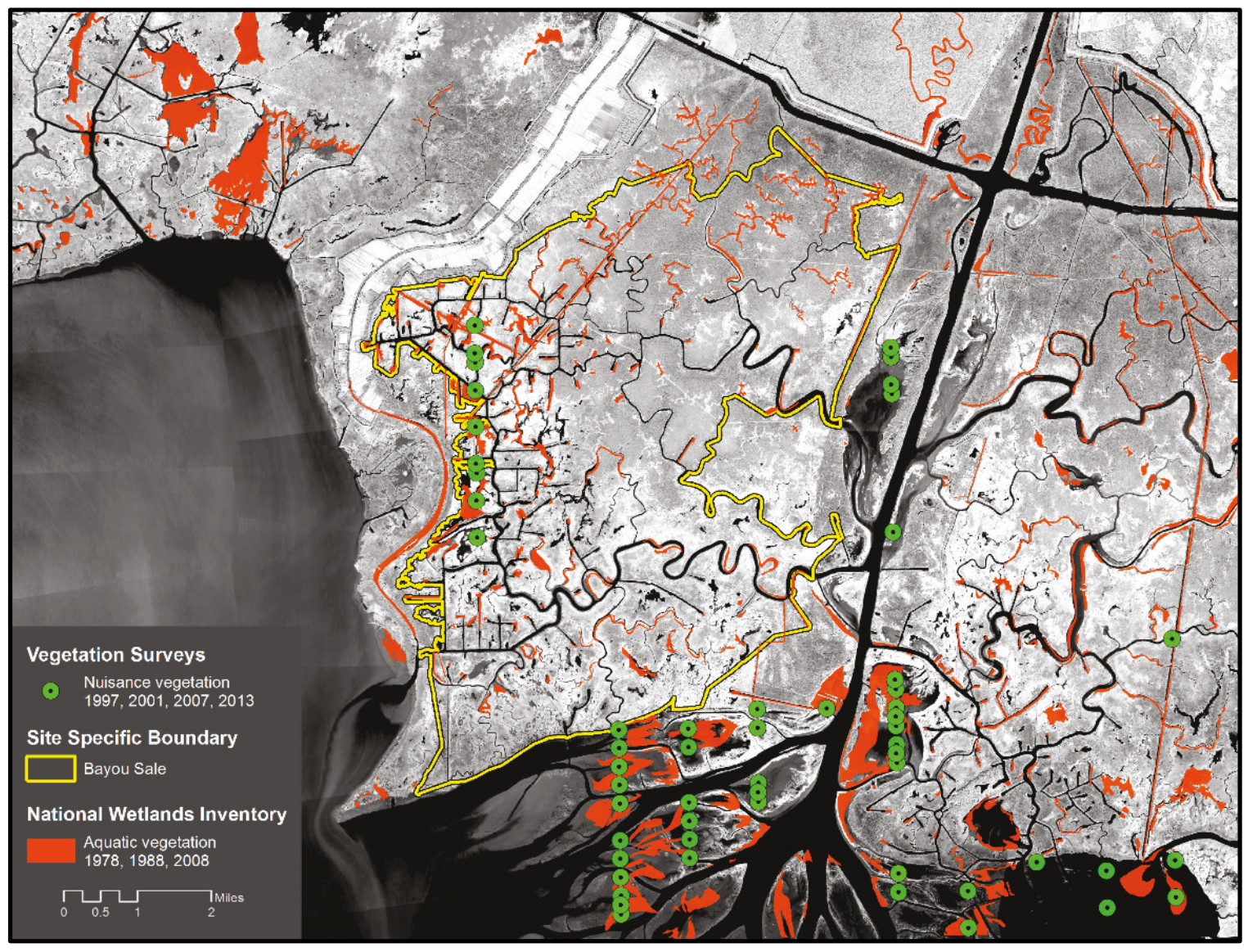

\subsubsection{Turtle Bayou vegetation}

The Turtle Bayou study site is located within the Terrebonne watershed basin. Bayou Penchant marshes are composed mainly of deteriorating, emergent fresh marsh intermingled with areas of broken floating thinmats that are dominated by smooth beggartick and anglestem waterprimrose (Ludwigia leptocarpa) (Chabreck and Linscombe 1997). These landscapes are also heavily surrounded by water hyacinth, southern naiad (Najas quadalupensis), common and giant salvinia, water celery (Vallisneria americana), water lettuce (Pistia stratiotes), coontail, duckweed, and open water areas of hydrilla and yellow waterlily (Nymphaea mexicana) (Chabreck and Linscombe 1997; USDA 2002).

Water hyacinth has been the primary impediment in this area. Winds and tides move these and other floating aquatics through open water features within these fragmented marshes, which themselves, have served as a continuous source of infestation for this region (LDWF 2013e). The LDWF 
estimates that water hyacinth coverage in the Turtle Bayou area averages about 12,000 ac per year. However, in 2013 the LDWF predicted a higher coverage of water hyacinth. Those 2013 predictions include (1) problematic vegetation: water hyacinth (15,000 ac), Hydrilla (3,00o ac), giant salvinia (2,000 ac), alligator weed (2,000 ac), Eurasian watermilfoil $(1,500 \mathrm{ac})$, common salvinia (1,000 ac), and (2) beneficial species: coontail (2,000 ac) and fanwort (750 ac) (LDWF 2013e).

Figure 11 shows the mapped aquatic vegetation (from NWI data) and the classified nuisance vegetation (from Louisiana vegetation survey data) within the Turtle Bayou study site. Aquatic bed classes are located throughout all of the lower energy open water features within the study site and in many of the site's oil and gas "dead-end" access canals. The vegetative plots (green dots) that were surveyed within the Turtle Bayou study site were found to contain a variety of aquatic plants. Over the course of these surveys (1997, 2001, 2007, and 2013), water hyacinth and hydrilla were the most abundant nuisance invasive species present.

Figure 11. Recent identification and mapping of nuisance aquatic vegetation in the Turtle Bayou study area.

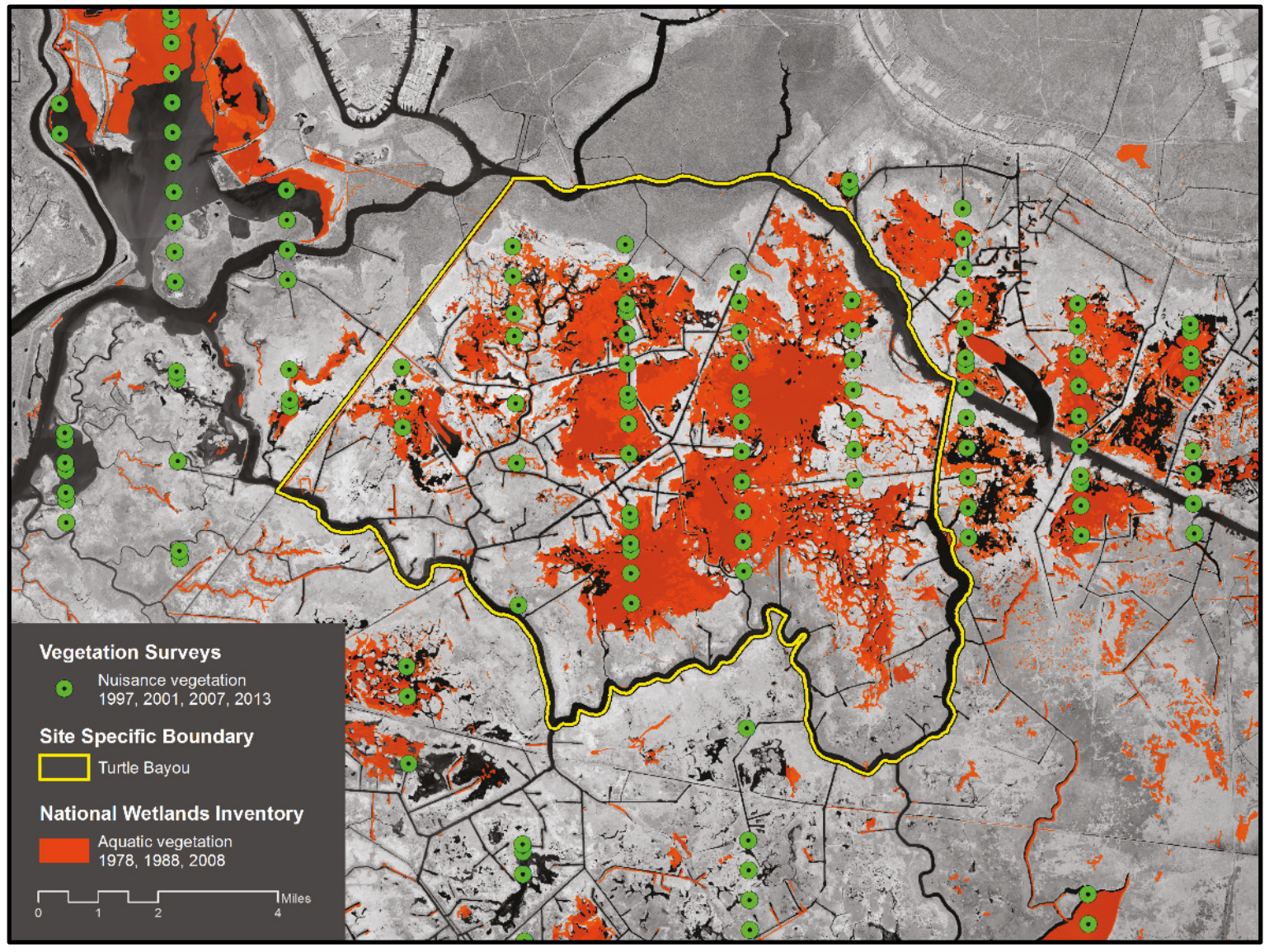




\subsubsection{Lake Long vegetation}

The Lake Long study site is located within the Terrebonne watershed basin. This sub basin is predominantly a fresh marsh estuary that has a long history of nuisance aquatic vegetation (LaCoast 2005; LDWF 2013d). Water hyacinth primarily impacts the very shallow Lake Long. These plants typically enter Lake Long via Company Canal and Bayou Lafourche, and accumulate on the fringe of the lake and in the canal system to the east (LDWF 2013d). Other problematic, as well as beneficial, submersed and floating aquatic species are common to this study site. In 2013, the LDWF predicted the presence and abundance of problematic and beneficial aquatic species in Lake Long. Those predictions include (1) problematic vegetation: water hyacinth (500 ac), sedges (Carex spp., $200 \mathrm{ac}$ ), Eurasian watermilfoil (100 ac), pennywort (100 ac), alligatorweed (8o ac), common salvinia (50 ac), giant salvinia (50 ac), and hydrilla (50 ac); and (2) beneficial vegetation: coontail (100 ac) and fanwort (30 ac) (LDWF 2013d).

Figure 12 shows the mapped aquatic vegetation (from NWI data) and the classified nuisance vegetation (from Louisiana vegetation survey data) within the Lake Long study site. Aquatic bed classes are located primarily along the fringe of Lake Long and Little Lake Long (west of Company Canal), in many of the study site's oil and gas access canals, and within fragmented wetlands to the east.

Due to the relatively small area of the study site, and since the majority of areas that are capable of supporting aquatic vegetation within this study site are long, narrow features, there are few coinciding locations between the study and vegetation survey sites. The few survey sites (green dots) that exist within the study site are located in the fragmented marsh east of Lake Long and were found to contain common salvinia. 
Figure 12. Recent identification and mapping of nuisance aquatic vegetation in the Lake Long study area.

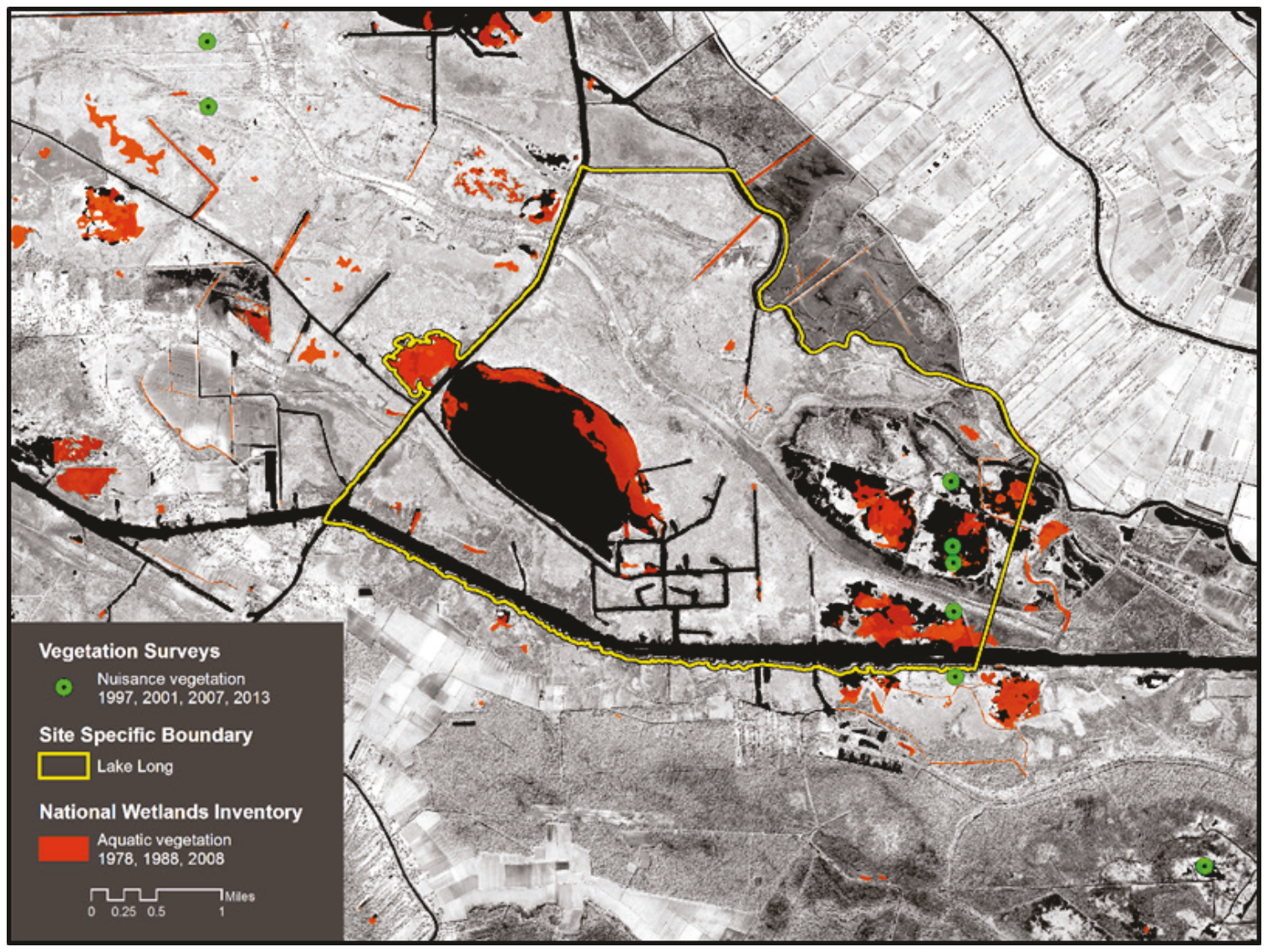

\subsubsection{Des Allemands vegetation}

The Des Allemands study site is located within the Barataria watershed basin. This is predominantly a fresh marsh estuary, regularly consisting of maidencane (Panicum hemitomon), cattail, bulltongue arrowhead, and numerous aquatic plants (LDWF 2013b; LDWF 2015). The basin also consists of over 100,000 acres of tidally influenced waterways that are infested with an estimated 13,000 acres of nuisance aquatic vegetation (LDWF 2013b). As of 2013, of the 13,000 ac of nuisance aquatic vegetation in the system, 6,000 were occupied by water hyacinth, 1,00o by hydrilla, 2,000 by Eurasian watermilfoil, and 4,000 by giant salvinia (LDWF 2013b).

Figure 13 illustrates the recently identified and mapped nuisance aquatic vegetation (1997, 2001, 2007, and 2013 Louisiana vegetation survey data) in the Des Allemands study area. Aquatic bed classes (orange regions) are located primarily in ponds and small waterways, along lake shorelines, and within fragmented wetlands. Most of the larger, higher-energy navigable water features within this site are void of nuisance vegetation. 
Figure 13. Recent identification and mapping of nuisance aquatic vegetation in the Des Allemands study area.

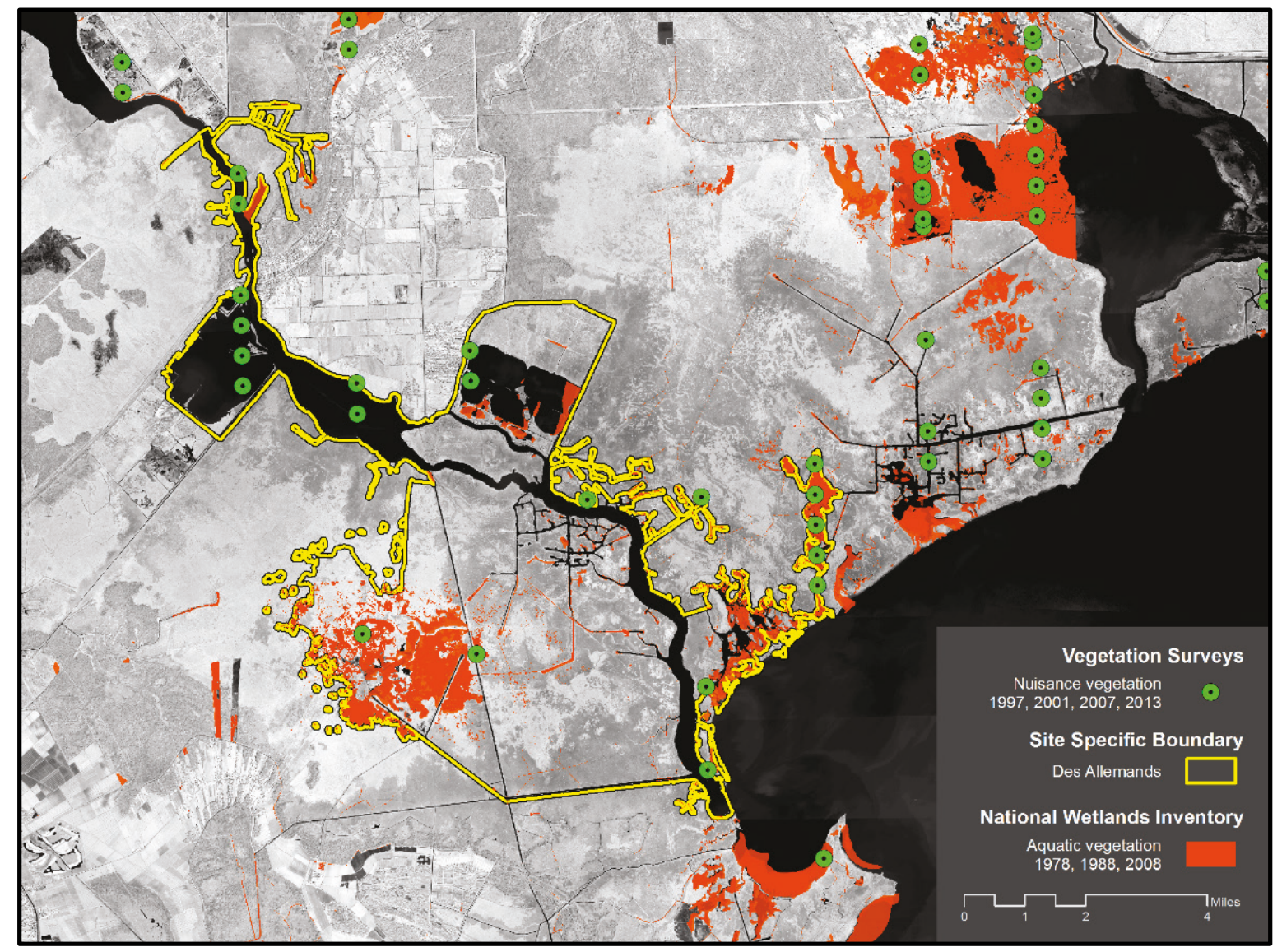

The vegetation survey data shows that of the survey points that fall within the Des Allemands study site, water hyacinth and hydrilla are the most abundant primary nuisance invasive species. The survey data largely correlate with the NWI data, except for portions of Dufrene Ponds and Bayou des Allemands. These sites were identified in the survey data as having primary nuisance invasive species, but were not classified in any of the NWI data sets.

\subsection{Vegetation mapping}

Successful control of nuisance aquatic vegetation requires timely and accurate monitoring (Robles et al. 2006). Traditionally, these vegetation communities have been surveyed and mapped via field-crew-based reconnaissance. However, given the extent of water features and aquatic vegetation distribution throughout coastal ecosystems, time, resources, and cost-intensive nature of field reconnaissance, these methods are often inefficient. Additionally, field surveys of aquatic vegetation communities 
are often impeded by access restrictions (Vis et al. 2003). However, these problems may be overcome with the use of Remote Sensing (RS) data and techniques. RS utilizes data that are more rapidly and efficiently collected (often from satellite sensors) to classify, map, and analyze changes across a geographic area instead of a single location (Jakubauskas et al. 2002; Robles et al. 2010).

Previous studies have demonstrated that RS can be an effective tool for understanding and mapping invasive species (Jensen et al. 1992; Robles et al. 2006; Allen and Suir 2014). RS techniques are increasingly important to invasive species control because they: (1) reduce the time and resources required for mapping locations, densities, and impacts of infestations; and (2) provide information that is critical for the planning, monitoring, and effectiveness of invasive species removal efforts (Jakubauskas et al. 2002; Allen and Suir 2014).

Assessing recent trends in nuisance aquatic vegetation and the effects of environmental drivers and management activities is possible using RS and Geographic Information Systems (GIS) techniques. These tools and techniques ultimately provide capabilities for assessing significant biophysical and ecological parameters, monitoring the short- and longterm effectiveness of eradication projects, and predicting the location and severity of future aquatic plant infestations (Silva et al. 2008; DigitalGlobe 2010; Allen and Suir 2014).

\subsection{Classification methods}

Recent research by Allen and Suir (2014) demonstrate that the moderate resolution Landsat platform is an effective sensor for monitoring large accumulations of aquatic vegetation on water features whose minimum dimension is not less than 30 meters. Given its large spatial extent (swath width $183 \mathrm{~km}$ ), number of multispectral bands, and its revisit frequency (16-day revisit frequency in most areas), the Landsat sensor was selected for use in this study.

This study utilized a modified land-water classification methodology to quantify the relative change in study site aquatic vegetation using Landsat Thematic Mapper (TM) satellite imagery. The methodology is a variant of a classification technique originally developed and modified for the Louisiana Department of Natural Resources Coastal Management Division and United States Geological Survey, respectively to provide Landsat TM 
derived land-water data for coastal land loss studies (Barras et al. 1994; Barras et al. 2003; Morton et al. 2005; Barras 2006; Barras 2007; Barras et al. 2010).

The Landsat 5 TM and Landsat 7 Enhanced TM Plus (ETM+) images were acquired from the USGS Earth Resources Observation Systems (EROS) Data Center. Individual image bands were stacked to create single multilayer files. All image files were then atmospherically and radiometrically corrected (e.g., radiance to reflectance and sun distance).

Density slicing of the Landsat band 5 (near-infrared, $1.55-1.75 \mu \mathrm{m}$ ) produces highly accurate results in delineating water bodies (Allen et al. 2012). Landsat's band 4 (occasionally combined with band 3 to form a Normalized Difference Vegetative Index (NDVI)) provides the best potential for identifying vegetative features. Preliminary assessments using individual bands, and their combination (NDVI), showed that band 4 alone provided the greatest accuracy for classifying aquatic vegetation. Ultimately, a combination of band 5 , band 4 , and the multi-layer images were used for water, vegetation, and cloud detection, respectively.

The band 5 layers were subset from all reflectance corrected files and exported as separate, continuous, and thematic images. Then, an edge enhancement convolution filter was applied to all continuous band 5 files. The non-edge enhanced files provide details necessary to eliminate speckling in larger water features but do not capture smaller water features. Conversely, the edge enhanced files typically over emphasize water when digital number (DN) values are great enough to eliminate speckling in larger water features, particularly when higher levels of turbidity are present. Resulting outputs were continuous and thematic versions of band 5 files, both with and without edge enhancements.

The DN values within these files were then used to perform level slicing to identify the land and water thresholds within all band 5 images. Each DN value represents the population of similar values within the image. Visual assessments were performed to compare $\mathrm{DN}$ values to the source image to determine the land and water threshold. The edge enhanced water DN values were approximately $3 \pm 1$ values higher than the non-edge enhanced images. All processes that were performed on the watersensitive band 5 images were repeated for band 4. Additionally, level 
slicing was performed on all source images to determine $\mathrm{DN}$ values for cloud features.

Recoding of the cloud and band 4 and 5 (with and without edge enhancement) thematic files was performed through an overlay process. Clump and eliminate functions were then performed on each recoded file to reduce noise (Braud and Feng 1998; Suir et al. 2011). A final overlay was performed, in which, the cloud and band 4 and 5 images were aggregated and recoded to single files with land, water, and cloud classes.

\subsection{Classification results}

Visual assessments were performed on 1,041 scenes to determine appropriateness and accuracy of the classification method. Any scenes containing cloud cover within the AV specific boundaries were rejected (462), and those with misclassified land or water features were corrected. The remaining 579 scenes were subset using the AV specific boundary, and summary statistics were generated to quantify water and vegetation acreage for each site. Figure 14 shows the amount of vegetation (acreage) and temporal coverage of satellite imagery for each study site over the 10year period of analysis (2003-2012). The average area of vegetation for each site was 1,281 ac, 1,978 ac, 5,544 ac, 447 ac, and 2,294 ac for Henderson, Bayou Sale, Turtle Bayou, Lake Long, and Des Allemands, respectively. Some sites exhibited narrow ranges of vegetation area across the period of analysis (1,261 to 2,541 for Bayou Sale, and 1,172 to 2,862 for Des Allemands), while others exhibited wide ranges (380 to 2,827 for Henderson, and 1,394 to 8,951 for Turtle Bayou).

Figures $15^{-19}$ show the spatial distribution and frequency of vegetation within each of the five study sites. Since the AV specific boundaries were buffered to ensure maximum coverage of water and aquatic vegetation features, some terrestrial vegetation are captured in the classification process. However, it is assumed that the terrestrial areas are relatively stable across the 10-year period of analysis, and therefore the majority of observed vegetative changes are occurring in aquatic vegetation communities. In general, for all sites, there are lower frequencies (occurrence) of vegetation in the larger, higher-energy natural waterways, and higher frequencies in the smaller open water features and the channelized oil and gas access canals. Figure 15 shows the distribution and frequency of vegetation in the Henderson site. Over the 10-year period of analysis, a majority of the Henderson site contained moderate frequencies 
of vegetation (Figure 15). However, smaller canals and the shoreline and banks of the lake and larger bayous exhibited high frequencies of vegetation. The Bayou Sale site consists primarily of narrow natural and channelized waterways (approximately 30-60 m widths) and the majority of the site contains a large amount and high frequency (red regions) of vegetation (including some terrestrial vegetation due to edge effects) (Figure 16). The Turtle Bayou site is similar to the other study sites in that its larger natural waterways exhibited low frequencies of vegetation, while the smaller access canals and open water areas within fragmented marsh experienced high frequencies of vegetation (Figure 17). Figure 18 shows Company Canal and the Intracoastal Waterway are the only features within the Lake Long site with observed low frequencies of vegetation. Lake Long, Little Lake Long, and all smaller waterways and water features exhibited moderate to high frequencies of vegetation. The larger bayous and ponds within the Des Allemands site have very low frequency of vegetation (green regions, Figure 19). High frequency of vegetation were observed in Des Allemands' smaller access canals, while a range of low to high frequency was observed in the broken marsh and smaller pond areas. 
Figure 14. Landsat derived vegetation area from 2003-2012.

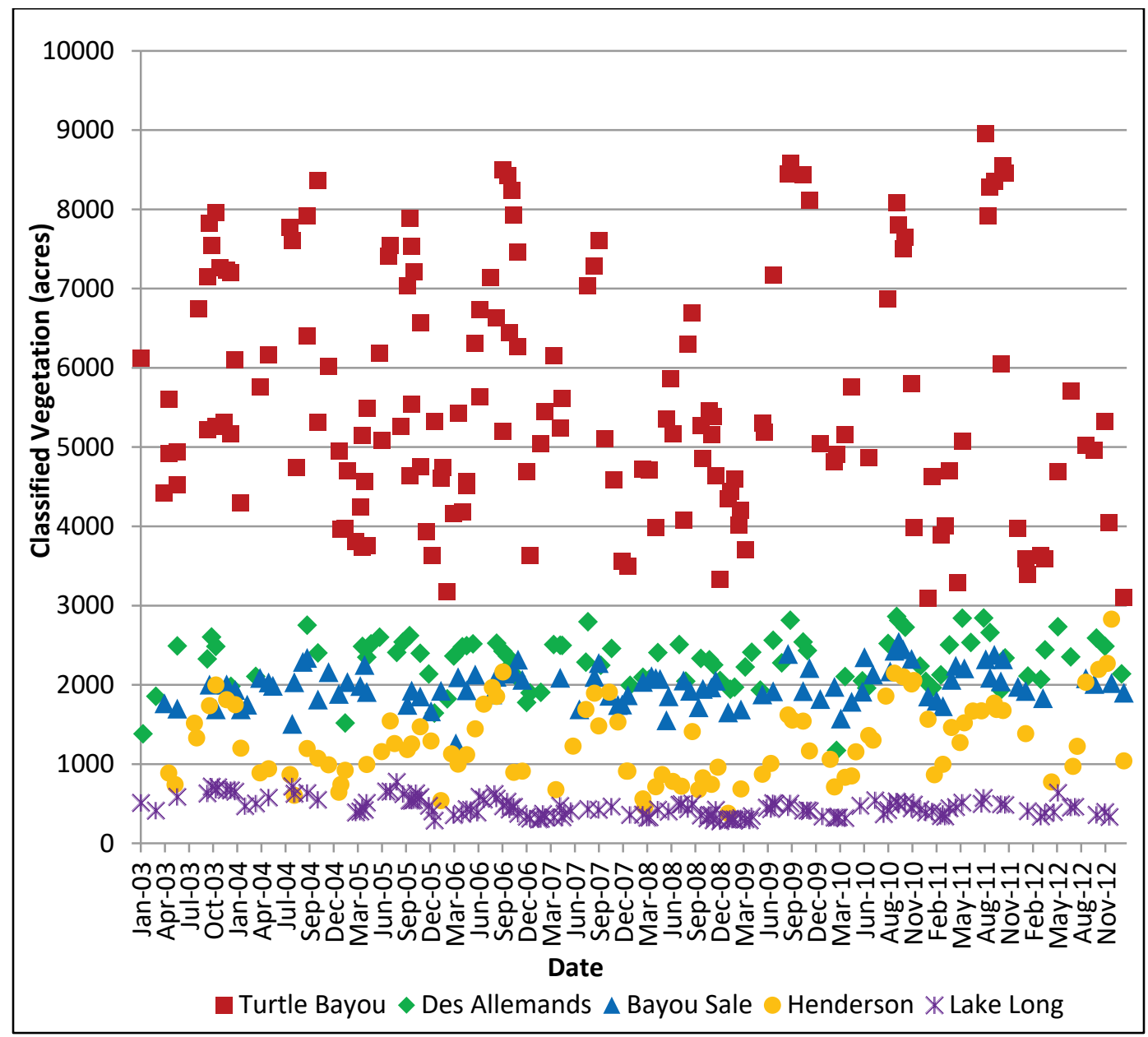




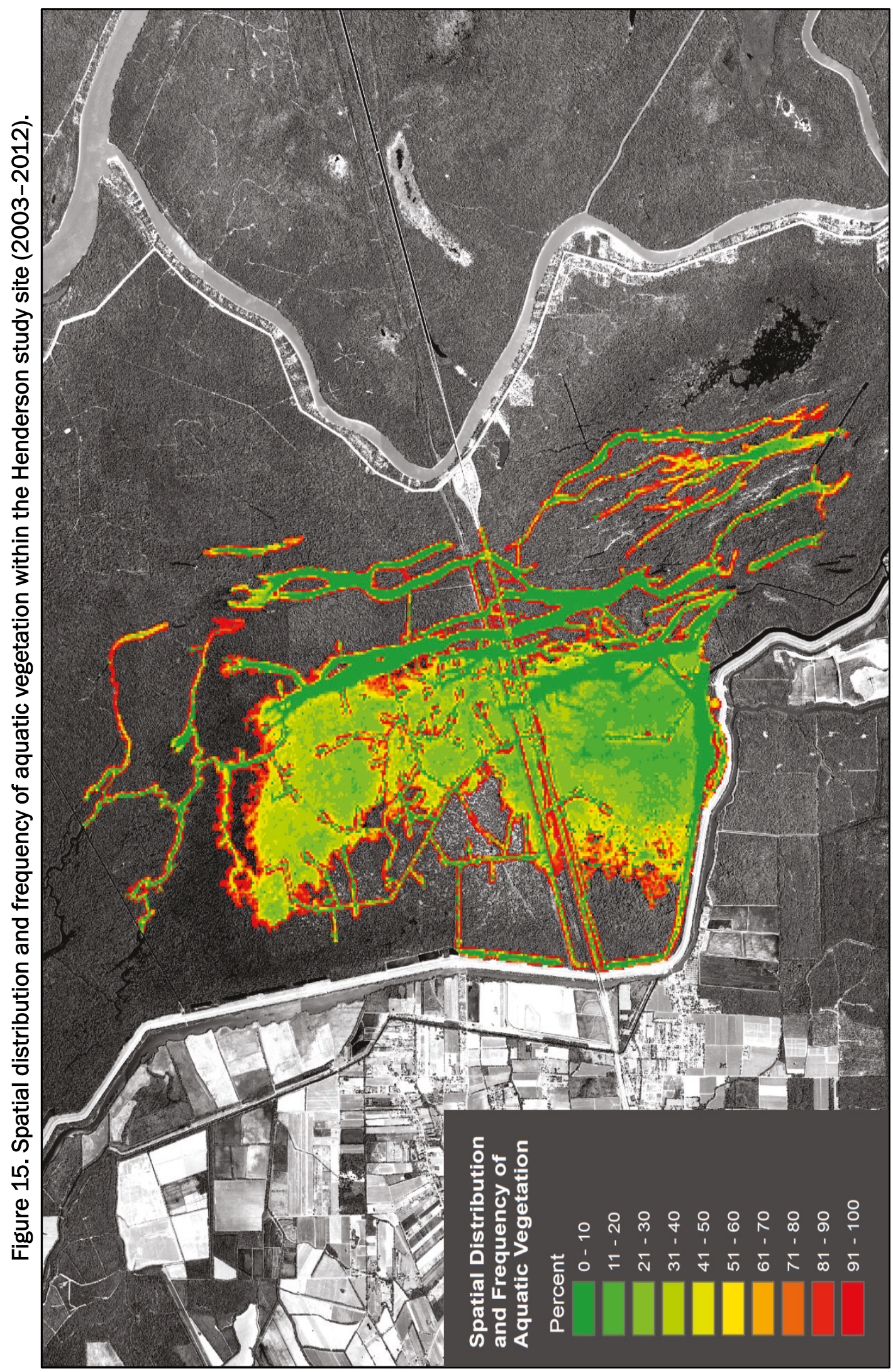




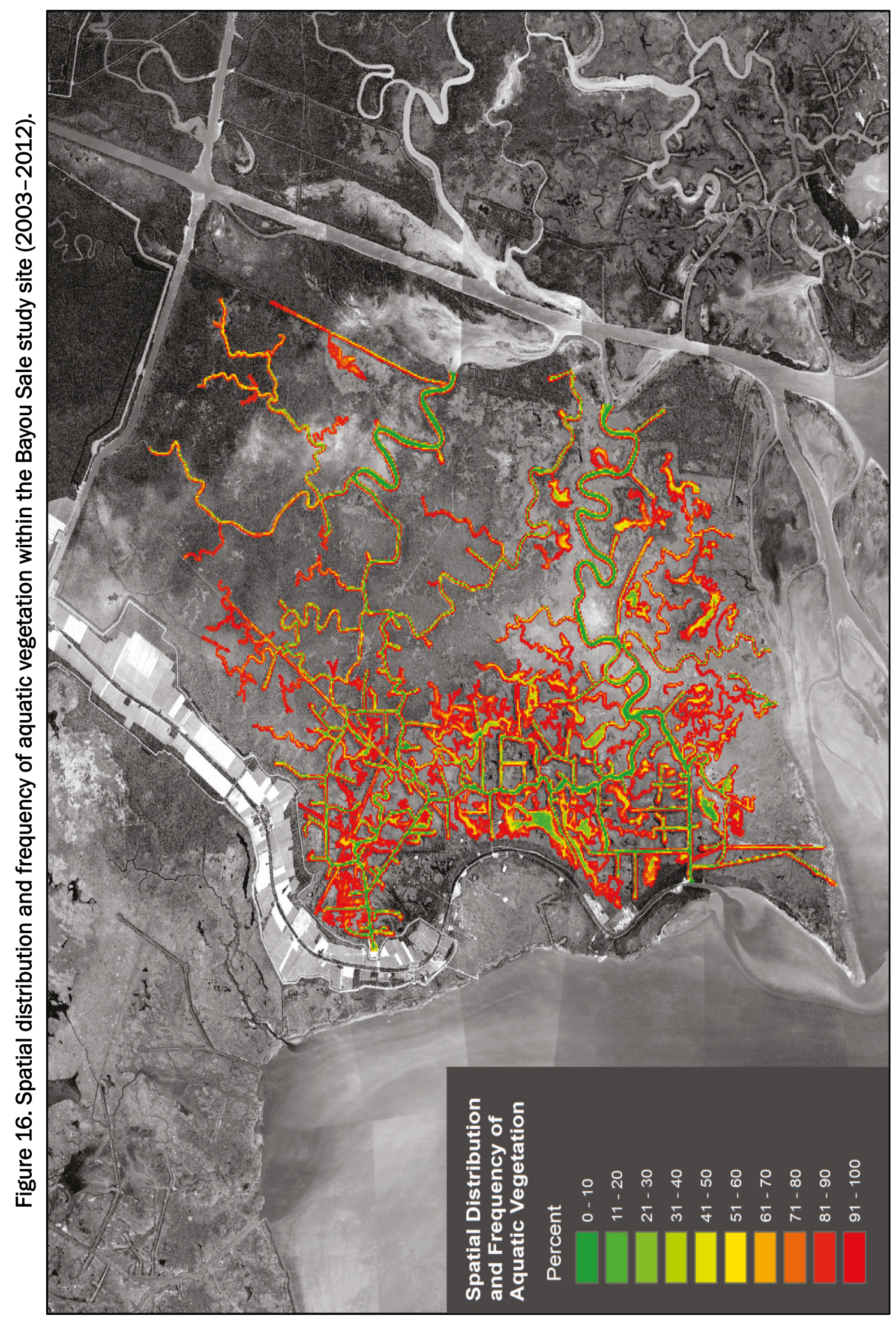




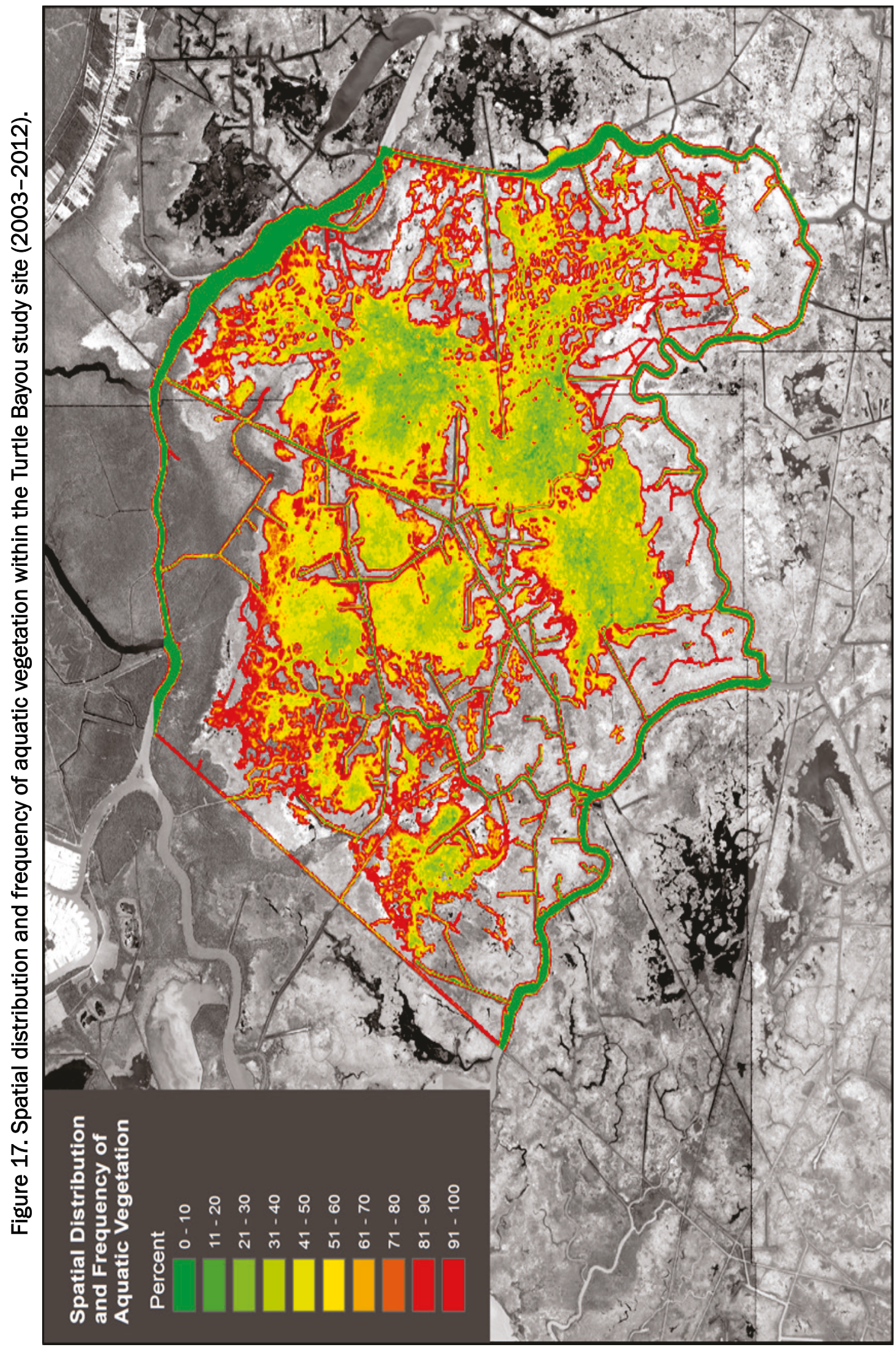




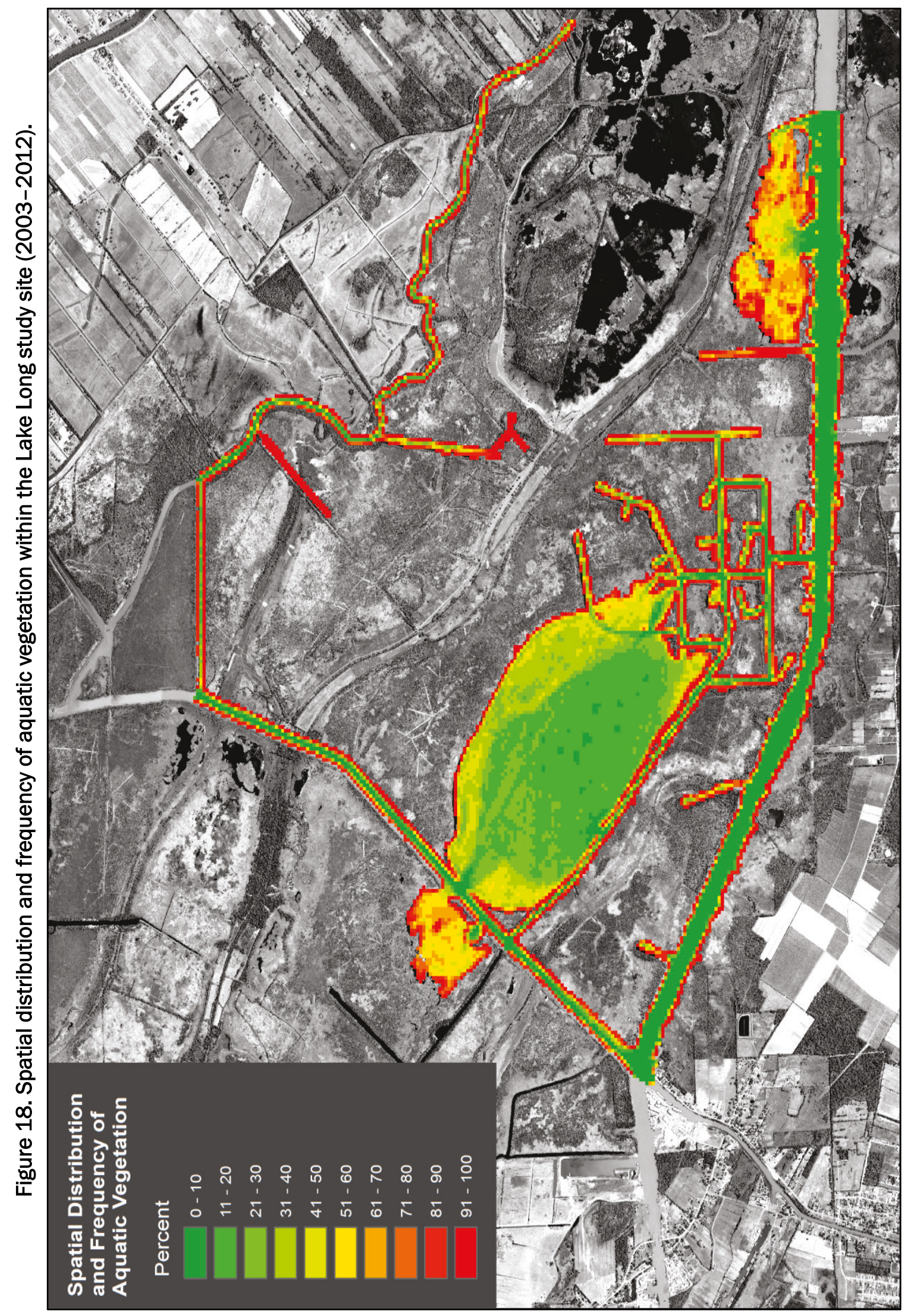




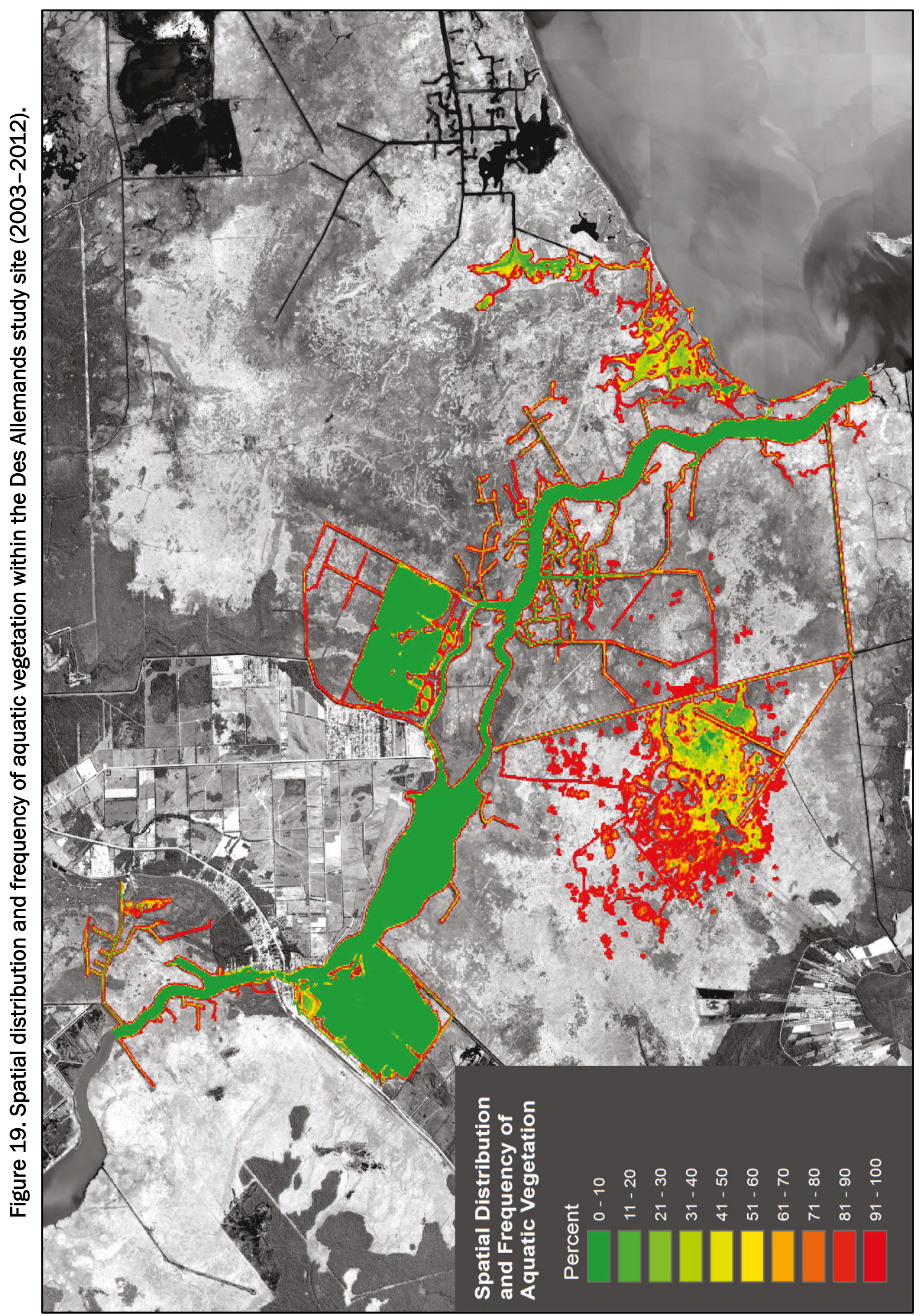




\section{Environmental Variables}

The distribution and abundance of aquatic plants are influenced by variations of environmental factors (Lacoul and Freedman 2006a). Nuisance aquatic plants, and their growth potential, are primarily influenced by factors inherent in limnology, including those related to such physical attributes as geomorphology (geology and topography), sediment, climate, hydrology, water quality constituents, episodic events, and competition (Lacoul and Freedman 2006a; Allen and Suir 2014). Table 1 provides a summary of environmental factors and cofactors that were shown to limit or promote the potential abundance, distribution, growth, and spread of aquatic plants.

Table 1. Factors limiting the potential abundance, distribution, growth, and spread of aquatic plants (modified from Madsen and Owens 2000).

\begin{tabular}{|c|c|c|}
\hline Factor & Cofactor & Reference \\
\hline \multirow{3}{*}{ Light } & Availability & $\begin{array}{l}\text { Duarte et al. 1986; Barko et al. 1982; Madsen and Owens } \\
\qquad 2000\end{array}$ \\
\hline & Transparency & Vant et al. 1986 \\
\hline & Depth & Sheldon and Boylen 1977; Dale 1984 \\
\hline Hydrology & Water level and Velocity & Doyle and Smart 2001; Riis and Biggs 2003 \\
\hline \multirow[t]{2}{*}{ Water Quality } & $\begin{array}{l}\text { Turbidity, Temperature, } \\
\text { Nutrients, Salinity, and pH }\end{array}$ & $\begin{array}{l}\text { Wilde et al. 2013; Adams et al. 1978; Smart 1990; Smart } \\
\text { and Barko 1988; Twilley and Barko 1990; Boyd and } \\
\text { Scarsbrook 1975; Jampeetong and Brix 2009; Kissoon et al. } \\
\text { 2013; Reddy et al. 1990; Room and Thomas 1986; Wilson } \\
\text { et al. 2005; Xie et al. 2004; Van der Heide et al. 2006; } \\
\text { Skubinna et al. 1995; Lacoul and Freedman 2006b }\end{array}$ \\
\hline & $\begin{array}{l}\text { Plant macro-and } \\
\text { micronutrients }\end{array}$ & Barko 1982, Barko 1983 \\
\hline $\begin{array}{l}\text { Sediment } \\
\text { Characteristics }\end{array}$ & $\begin{array}{l}\text { Organic content, particle } \\
\text { size, soil nutrients }\end{array}$ & $\begin{array}{c}\text { Barko and Smart 1981b, 1986; } \\
\text { Carignan and Kalff 1979, 1980; } \\
\text { Anderson and Kalff 1986; Barko and Smart 1983; Barko et } \\
\text { al. } 1986\end{array}$ \\
\hline Climate & $\begin{array}{l}\text { Air temperature, Wind } \\
\text { speed and direction, } \\
\text { Storms, Precipitation }\end{array}$ & $\begin{array}{l}\text { Barko and Smart 1981a; Barko et al. 1982; Lacoul and } \\
\text { Freedman 2006a; McFarland and Barko } 1999\end{array}$ \\
\hline Seasonality & & $\begin{array}{l}\text { Debusk et al. 1981; Haller et al. 1977; Tucker and Debusk } \\
1981\end{array}$ \\
\hline Competition & & McCreary 1991; Thouvenot et al. 2013 \\
\hline \multirow{3}{*}{ Disturbance } & $\begin{array}{l}\text { Abiotic (e.g., wave action, } \\
\text { fetch) }\end{array}$ & Chambers 1987 \\
\hline & Biotic (e.g., herbivory) & Lodge 1991; Coetzee et al. 2007 \\
\hline & Physical (e.g., blockages) & Allen and Suir 2014 \\
\hline
\end{tabular}


Light is typically considered the most significant single factor limiting both distribution and abundance of some aquatic plants, specifically submersed plants (Madsen and Owens 2000). For other macrophytes, a primary factor that controls the establishment and abundance is local hydraulic conditions (i.e., water velocity, depth, hydrologic regime) and their associated disturbance frequencies (Riis and Biggs 2003). With respect to water quality, aquatic plant productivity is primarily limited by turbidity, temperature, salinity, phosphate and nitrogen, although $\mathrm{pH}$ and other nutrients (e.g., inorganic carbon, calcium, and potassium) may also play a role (Skubinna et al. 1995; Xie et al. 2004; Lacoul and Freedman 2006b, Van der Heide et al. 2006; Jampeetong and Brix 2009).

Similar to terrestrial plants, research has also shown connections between sediments and nutrient availability and aquatic plant growth. However, physical properties and disturbances of those sediments may provide as much influence on vegetational change as chemical composition (Barko and Smart 1986). Lacoul and Freedman (2006a) have reported that ambient temperature, wind speed and direction, precipitation, and storms provide significant influence on the physico-chemical, biological, metabolic, and physiological behavior of aquatic ecosystems.

Although environmental factors affect aquatic vegetation differently, most species exhibit some form of seasonal variation. Studies have shown that even when keeping all other variables constant, the composition and growth rates of aquatic vegetation can vary seasonally (Tucker and Debusk 1981). The growth and abundance of plants (individuals and communities) may also be influenced by competition for access to critical resources (Thouvenot et al. 2013). Additionally, herbivory and blockages (e.g., gates, drill stems, and earthen dams) are physical disturbances and barriers that may contribute to growth, density, or loss of submersed, emergent, and floatingleaved macrophytes (Lodge 1991; Allen and Suir 2014).

Ultimately, the interactions between environmental stressors and invasive species, although not well understood, may either directly contribute to the abundance, distribution, growth, and spread of aquatic plants, or indirectly by exacerbating the impacts of climate change on ecosystems, and likewise, enable further invasions (USEPA 2008). 


\subsubsection{Environmental data sources}

A primary objective of this study was to assess aquatic vegetation frequency and distribution, considering environmental drivers and conditions, to predict future growth potential. Environmental and climatic data were acquired from numerous federal- and state-operated monitoring and data collection systems. These systems include the: 1) Coastwide Reference Monitoring System (CRMS), 2) Coastal Wetlands Planning, Protection and Restoration Authority (CWPPRA) monitoring program, 3) Louisiana Department of Environmental Quality (LDEQ) Ambient Water Quality Monitoring Network (AWQMN), 4) Louisiana Office of State Climatology (LOSC) services, 5) National Oceanic and Atmospheric Administration (NOAA) National Weather Service (NWS), 6) USACE Water Control Data System (WCDS), and 7) USGS National Water Information System (NWIS).

- CRMS is a monitoring system that is utilized to evaluate project, region, and coast-wide level vegetation composition and cover, elevation, duration and frequency of flooding, salinity, sedimentation, and erosion (Steyer et al. 2003).

- The CWPPRA monitoring program was developed to provide a standardized approach for monitoring project-specific water quality, hydrology, soils and sediments, vegetative health, habitat mapping, wildlife, and fisheries. CWPPRA data provides a secondary source of hydrologic and water quality data.

- The purpose of the AWQMN is to characterize ambient surface water quality conditions and collect data to make water quality standards attainment decisions (LDEQ 2011). The LDEQ AWQMN program collects and monitors a variety of water quality parameters, including salinity, dissolved oxygen, turbidity, nitrogen, precipitation, total suspended, and dissolved solids.

- LOSC is responsible for climate data archiving and monitoring. LOSC provides access to daily and monthly climate data of interest, specifically air temperature and precipitation.

- NOAA's NWS measures and disseminates hourly surface, tide, and current data. These data provide useful measures such as air temperature, wind speed and direction, and tide levels.

- The WCDS network is a service that USACE uses to collect, store, and disseminate data related to water control operation and maintenance. This network provides historic and real-time river stage and discharge information. 
- The USGS NWIS provides historical and real-time surface-water data that describe stage height, discharge, reservoir and lake levels, surfacewater quality, and precipitation.

Figure 20 shows the primary environmental and climate monitoring stations that were used to generate multiple regression models for each study site. Data from the nearest stations were always utilized in these regressions, however those from more distant stations were included when data gaps existed. Ultimately, data from ten CRMS, four CWPPRA, eighteen LDEQ, five LOSC, nine NOAA, eight USACE, and eight USGS stations were used in conjunction with percentage of aquatic vegetation coverage (from classified satellite imagery) to develop numerical models of aquatic vegetation growth potential.

Figure 20. Study site variable data station location.

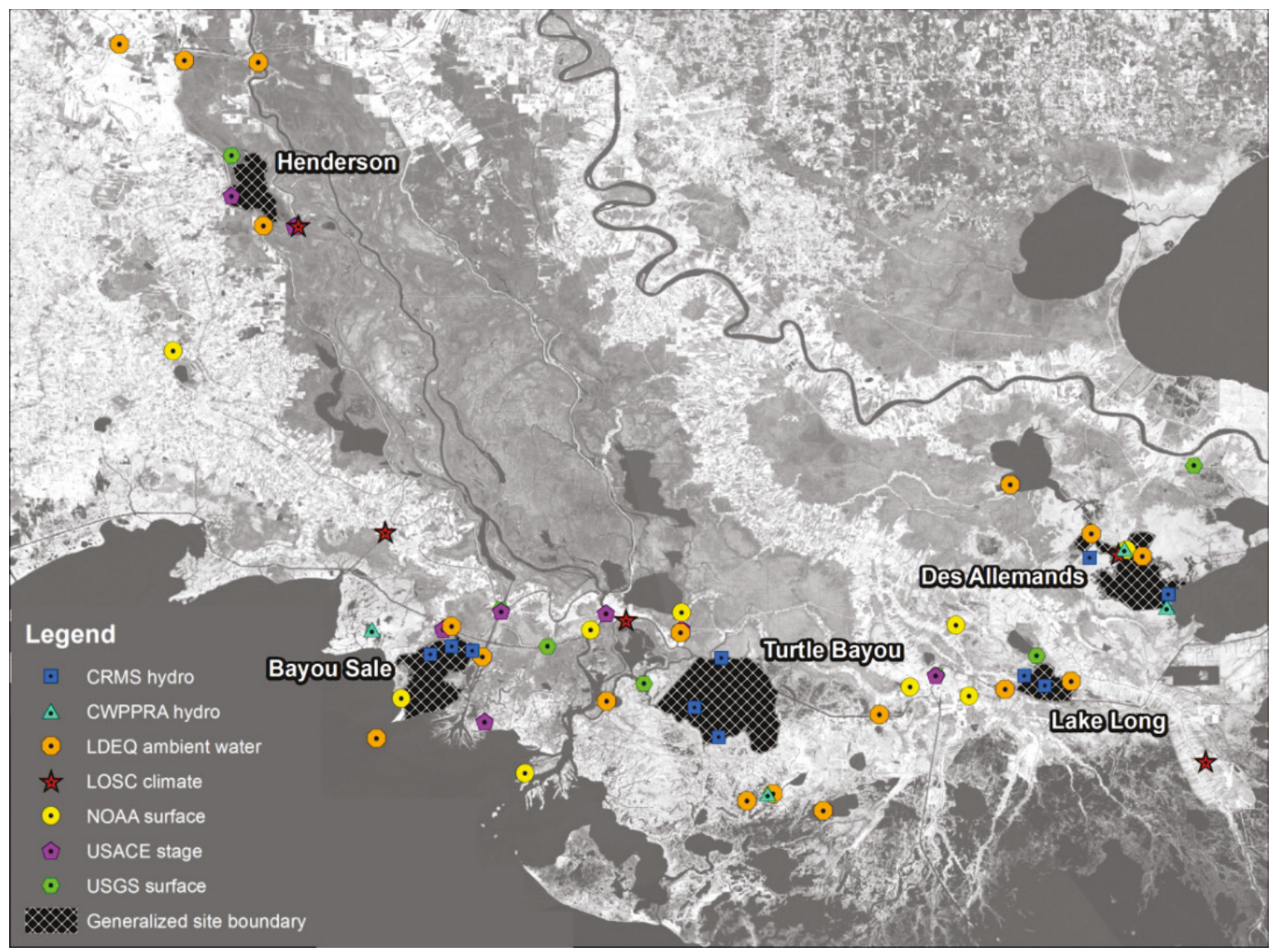




\section{Management Activities}

Since a large majority of federal navigable waterways within the United States are affected by nuisance aquatic vegetation, USACE was tasked with maintaining those waterways through the reduction or eradication of problem species. Removal or control of nuisance plants is typically achieved through integrated pest management (IPM). IPM utilizes deliberate selection, integration, and implementation of weed control measures to reduce nuisance aquatic plant populations (Nelson et al. 2009). Currently, numerous operations, research and development, and technical programs are applying, developing, and supporting IPM activities within USACE. The primary programs of authority are the: (1) Operation and Maintenance (O\&M) Program, (2) Removal of Aquatic Growths (RAG) Program, (3) Aquatic Plant Control (APC) Program, (4) Aquatic Plant Control Research Program (APCRP), (5) Aquatic Nuisance Species Research Program (ANSRP), and (6) Water Operations Technical Support (WOTS) Program (Mobley 2013). To date, the primary IPM mechanisms have been chemical, physical, and biological control. Although significant funding (at least $\$ 100$ million) is spent each year in the control of aquatic plants, much could be done to facilitate the further development and use of aquatic weed control techniques (Rockwell 2003).

\subsection{Chemical control}

Chemical control through proper use of herbicides has long been the most widely used method for managing aquatic weeds (Van et al. 1985). Chemical control typically provides measures that are more time- and resource-efficient than biological and physical control, and in some cases, may be the only practical solution to managing infestations.

However, herbicide treatments can be costly and may provide only shortterm relief from the real problem (Helfrich et al. 2009). Additionally, with improper application, herbicides can negatively impact non-targeted aquatic resources. Historically, USACE and the LDWF have managed chemical control of aquatic vegetation in Louisiana.

\subsubsection{USACE management}

According to Mobley (2013) the USACE MVN RAG program uses chemical control on approximately 30,000 acres of nuisance aquatic plants per year 
(based on 2009-2013 work plans). Approximately 28,000 ac of water hyacinth and alligatorweed were controlled using an aquatic formulation of the systemic herbicide 2,4-D. The remaining acreage primarily consists of giant salvinia, common salvinia, hydrilla, and water lettuce, these were treated using aquatic formulations of the herbicides diquat and glyphosate.

Figure 21 provides the acreage of aquatic vegetation that was chemically treated within each study site from 2003-2011. Total acres sprayed within the entire MVN AOR for each period of control is provided in parentheses (along $\mathrm{x}$-axis) in Figure 21. Figure 21 also provides the percentage of total acres sprayed, considering only the five study sites, as well as the entire AOR (parentheses within pie chart). Considering only the five study sites, Turtle Bayou accounted for $47 \%$ of the acres sprayed, followed by Bayou Sale (21\%), Henderson (12\%), Des Allemands (11\%), and Lake Long (9\%). Respective to all AOR, Turtle Bayou accounted for $31 \%$ of sprayed acres, followed by Bayou Sale (14\%), Henderson (8\%), Des Allemands (7\%), and Lake Long (6\%). Combined, the five study sites accounted for $66 \%$ of all sprayed area within the MVN AOR.

Due to recent funding restraints, field reconnaissance has been limited, and therefore fewer contracts for chemical control have been issued since 2011. Consequently, the Louisiana Department of Wildlife and Fisheries have incorporated many areas that were previously under USACE MVN responsibility into their aquatic vegetation control plans. 


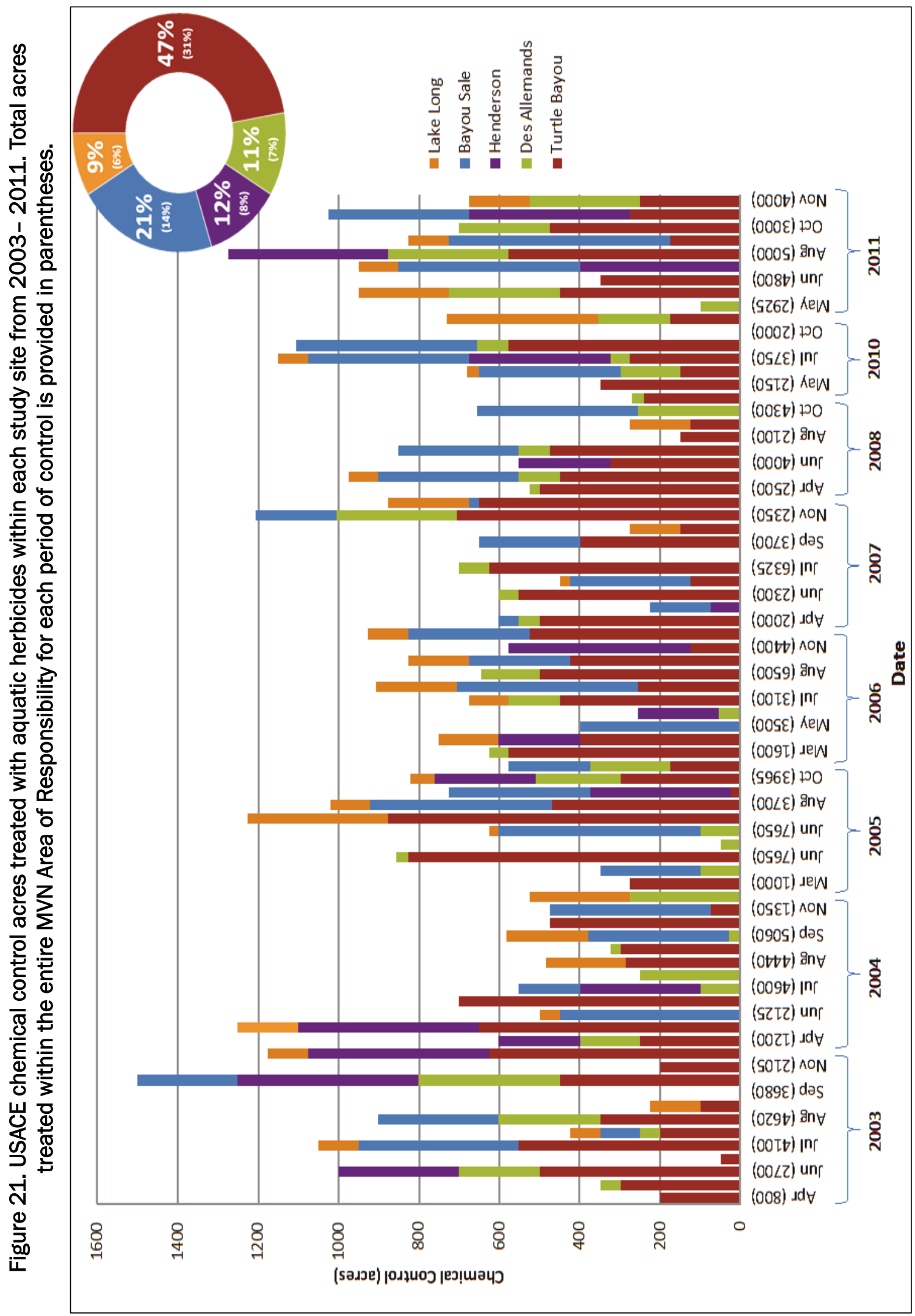




\subsubsection{State management}

The LDWF performs aquatic vegetation control on various regions within the state of Louisiana. Henderson Lake is one region with complex aquatic vegetation conditions. Aquatic vegetation control responsibilities at the Henderson Lake study site are shared by multiple state and federal agencies. Table 2 shows the acres of aquatic vegetation treated by LDWF spray crews in Henderson Lake between 2008 and 2011. LDWF treated a total of 14,485 acres with herbicides to control aquatic vegetation in the Henderson area during that period (LDWF 2013a). Treatment consisted predominantly of 2,4-D applications against water hyacinth, followed by fluridone to control hydrilla, and combinations of glyphosate and diquat on common salvinia. Additionally, the Louisiana Department of Natural Resources (LDNR) treated approximately 4,000 acres of hydrilla in an effort to contain the spread of this invasive species.

In 2013, LDWF assumed responsibility for aquatic vegetation control in the Bayou Sale study site. This site is now part of the LDWF Bayou Teche Aquatic Plant Management Plan. Preliminary plans called for chemical control along the main stem of the bayou in 2013 and 2014, and more extensive control throughout the site in 2015 (Jody David, personal communication, 2014).

Historically, Turtle Bayou and the surrounding Terrebonne marsh were prime targets for USACE spraying efforts. However, due to the aforementioned budget limitations, LDWF assumed management of aquatic vegetation for the entirety of this area in 2012 (LDWF 2013e). LDWF estimated (based on previous efforts by USACE) that approximately 6,000 acres of aquatic vegetation in the Turtle Bayou and Terrebonne marsh areas will require control on an annual basis (LDWF 2013e). The primary target species will remain the overabundant water hyacinth, this is traditionally managed with 2,4-D. Other invasive species or mixed communities of vegetation have typically received diquat or glyphosate treatments (LDWF 2013e).

Lake Long is another USACE RAG AOR that LDWF has recently managed. The main problem in the Lake Long study site is water hyacinth (although other floating species persist), these accumulate on the fringe of the main lake and even more so in the canal system on the southeast side of the lake (LDWF 2013d). In 2012, LDWF chemically treated 1,012 acres of vegetation in Lake Long. LDWF estimates approximately 2,870 acres of aquatic vegetation will require annual control in the Company Canal and Lake Long area. 
Table 2. Acres of aquatic vegetation treated by LDWF spray crews in Henderson Lake - listed by vegetation type and applied herbicide, for the years 2008-2013 (modified from LDWF 2013a).

\begin{tabular}{|c|c|c|c|c|c|c|c|c|}
\hline \multirow{4}{*}{ Vegetation } & \multirow{4}{*}{ Herbicide } & \multicolumn{6}{|c|}{ Year } & \multirow[t]{2}{*}{ Total } \\
\hline & & 2008 & 2009 & 2010 & 2011 & 2012 & 2013 & \\
\hline & & $\begin{array}{c}\text { Area } \\
\text { (acres) }\end{array}$ & $\begin{array}{c}\text { Area } \\
\text { (acres) }\end{array}$ & $\begin{array}{c}\text { Area } \\
\text { (acres) }\end{array}$ & $\begin{array}{c}\text { Area } \\
\text { (acres) }\end{array}$ & $\begin{array}{c}\text { Area } \\
\text { (acres) }\end{array}$ & $\begin{array}{c}\text { Area } \\
\text { (acres) }\end{array}$ & $\begin{array}{c}\text { Area } \\
\text { (acres) }\end{array}$ \\
\hline & & Sum & Sum & Sum & Sum & Sum & Sum & Sum \\
\hline Algae, Filamentous & Diquat & . & . & . & 2 & . & . & 2 \\
\hline \multirow{2}{*}{ Alligatorweed } & $2,4-D$ & . & 28 & 7 & . & 50 & 125 & 210 \\
\hline & Glyphosate & . & . & 10 & . & . & . & 10 \\
\hline Duckweed & Diquat & . & . & 23 & 2 & . & . & 25 \\
\hline Frog's Bit & Diquat & . & 1 & 1 & . & . & . & 2 \\
\hline Hydrilla & Fluridone & . & 3,018 & . & . & . & . & 3,018 \\
\hline \multirow{2}{*}{ Pennywort } & $2,4-D$ & 6 & . & . & . & . & . & 6 \\
\hline & Diquat & . & 4 & 4 & . & . & . & 8 \\
\hline Primrose & 2,4-D & . & 14 & 2 & . & . & . & 16 \\
\hline Salvinia, Giant & Glyphosate & . & . & . & . & 8 & 10 & 18 \\
\hline Sedge sp. & Glyphosate & . & . & . & . & 8 & & 8 \\
\hline \multirow[b]{2}{*}{ Salvinia, Common } & Glyphosate & 15 & 23 & 42 & 26 & 245 & 150 & 501 \\
\hline & Diquat & . & 130 & 148 & . & . & . & 278 \\
\hline \multirow{3}{*}{ Water Hyacinth } & $2,4-D$ & 144 & 153 & 1,041 & 4,400 & 2,715 & 1,750 & 10,203 \\
\hline & Glyphosate & 15 & 7 & 65 & . & . & . & 87 \\
\hline & Diquat & . & 59 & 34 & . & . & . & 93 \\
\hline \multicolumn{2}{|l|}{ Total } & 180 & 3,437 & 1,377 & 4,430 & 3,026 & 2,035 & 14,485 \\
\hline
\end{tabular}

The Des Allemands site accounts for approximately $11 \%$ of the nuisance vegetation that is chemically treated within the Barataria Estuary region. In 2012, water hyacinth accounted for $81 \%$ of the total area that was managed within the Des Allemands site (Table 3). The majority of water hyacinth (1,514 out of $1,535 \mathrm{ac})$, as well as alligatorweed, pennywort, and primrose, were all treated with 2,4-D. In addition, small infestations of pennywort, primrose, giant salvinia, sedge, and water hyacinth have also been treated with glyphosate (LDWF 2013b). 
Table 3. Vegetation sprayed and herbicides used in the Des Allemands study area in 2012 (modified from LDWF 2013b).

\begin{tabular}{|c|c|c|}
\hline Herbicide & Vegetation & Acres Sprayed \\
\hline $2,4-\mathrm{D}$ & Alligatorweed & 261 \\
\hline & Pennywort & 36 \\
\hline & Primrose & 1,707 \\
\hline & Water Hyacinth & 5 \\
\hline Glyphosate & Pennywort & 5 \\
\hline & Primrose & 7 \\
\hline & Salvinia, Giant & 56 \\
\hline & Sedge & 21 \\
\hline Total & Water Hyacinth & 2,100 \\
\hline
\end{tabular}

\subsection{Physical control}

The two most widely used methods of physical control of aquatic vegetation include mechanical harvesting and hydrologic drawdown. Mechanical harvesting typically uses equipment to remove small populations of nuisance plants (LDWF 2014). Though these methods can be effective, they can be costly and negatively impact non-target species (Christopher Mudge, personal communication, 2016). For some species, like hydrilla, drawdowns have been the only mechanism that have demonstrated effective control on quiescent tubers in sediments (Doyle and Smart 2001). Drawdowns are usually conducted during the winter season to expose plants to drying and freezing, and subsequently decreasing aquatic plant infestations (LDWF 2009). Unfortunately, for some lakes and ponds, reducing water levels have negative impacts on recreational and commercial access and can increase likelihood of encroachment from marginal species.

Henderson is the only study site that actively experiences drawdown control. Henderson has reliable sources of inflow and the necessary water control structures to perform drawdowns (LDWF 2014). Table 4 provides the dates, purpose, results, and issues related to drawdown activities in the Henderson Lake study area. The drawdown strategy in Henderson Lake has been relatively ineffective due to rains, high water, and the inability to execute the optimal drawdown management plan (i.e., required frequency and duration) due to public perception and impacts on local economics (LDWF 2014). 
Table 4. Henderson Lake drawdown history (LDWF 2013a).

\begin{tabular}{|l|l|l|l|l|}
\hline Date Opened & Date Closed & Purpose & Results & Issues \\
\hline Fall 1996 & Winter 1997 & Hydrilla control & Unsuccessful & Heavy rains \\
\hline 1997-2000 & $*$ & Hydrilla control & Recommended & No action taken \\
\hline Fall 2000 & Winter 2001 & Hydrilla control & Successful & \\
\hline Fall 2001 & Winter 2002 & Hydrilla control & Unsuccessful & Heavy rains \\
\hline Summer 06 & Fall 2006 & Hydrilla control & $\begin{array}{l}\text { Little success } \\
\text { W/ 2 ft drawdown }\end{array}$ & $\begin{array}{l}1,200 \text { acres } \\
\text { treated }\end{array}$ \\
\hline Summer 07 & Fall 2007 & Hydrilla control & $\begin{array}{l}\text { Little success } \\
\text { W/ 2 ft drawdown }\end{array}$ & $\begin{array}{l}\text { 400 acres } \\
\text { treated }\end{array}$ \\
\hline Summer 08 & Fall 2008 & Hydrilla control & Unsuccessful & High water \\
\hline Fall 2009 & Winter 2010 & Hydrilla control & $\begin{array}{l}\text { No success w/ 2 ft } \\
\text { drawdown }\end{array}$ & $\begin{array}{l}1,000 \text { treated } \\
\text { acres flooded }\end{array}$ \\
\hline Fall 2012 & Still open & Hydrilla control & Unsuccessful & High water \\
\hline
\end{tabular}

* Between 1997 and 2000, LDWF recommended drawdowns, but the public did not support this initiative. Therefore, drawdowns were not conducted.

\subsection{Biological control}

In some areas, chemical and physical controls of nuisance aquatic plants have proven impractical, costly, and ineffective, resulting in rapid recolonization of persistent plants (Tipping et al. 2008). In some cases, these methods have shown to be ecologically disruptive. Alternatively, some introduced or native biological agents have proven to be effective growth inhibitors of aquatic vegetation (Foret et al. 1980). Biological control typically involves the introduction of non-native biocontrol agents (e.g., herbivore, pathogen, or parasite) that interact with the invasive species (LDWF 2005). To date, the most common and effective biocontrol methods utilized against nuisance aquatic vegetation have been herbivorous fishes [primarily triploid grass carp (Ctenopharyngodon idella) stocking] and various insect agents. These biocontrol agents provide a number of advantages over chemical and physical control measures. They are: (1) numerous and diverse, (2) often host-specific, (3) easily disseminated and self-maintaining, (4) capable of limiting populations without eliminating the species, and (5) non-pathogenic to animals (Freeman 1977). Biocontrol can be an effective method for curbing the spread of invasive species, but some control agents, once introduced, can result in additional impairments to the ecosystem (LDWF 2005). One example is the introduction of grass carp to control invasive aquatic vegetation in the United States. While effective, grass carp are not target specific organisms and have depleted native and preferred species, 
ultimately compromising water quality and ecosystem structure (Page and Burr 1991; Nico et al. 2006).

The primary insect biological control species released in Louisiana include: Cyrtobagous salviniae weevil (for giant salvinia), Megamelus scutellaris (for water hyacinth), the Neohydronomous affinis weevil (for water lettuce), and the Agasicles hygrophila flea beetle (for alligatorweed) (Nathan Harms, personal communication, 2014). Primarily, Louisiana State University (LSU), LDWF and USACE have released these insect agents.

Although some biological control applications are site specific, some are basin-level approaches. Since the summer of 2007, approximately 78,000 adult Cyrtobagous salviniae weevils have been released on giant salvinia infestations within the Atchafalaya Basin, while 74,400 weevils were released into 10 different waterbodies throughout the Barataria Basin. Table 5 shows the number of weevils and years of release in the Bayou des Allemands watershed subsegments, both of these encompass the Des Allemands study site. Over a five-year period, 24,800 weevils were released in the Bayou des Allemands area. Lake Long, another site specific biocontrol application area, was also stocked with the Cyrtobagous salviniae weevils in 2011, March 2012, and September 2012 (LDWF 2013d). Although biological agents can have significant long-term impacts on nuisance aquatic vegetation, their effects are difficult to quantify and predict.

Table 5. Number of giant salvinia weevils (Cyrtobagous salviniae) released per water body (LDEQ water feature identification number provided in parentheses) in the Des Allemands through 2012 (LDWF 2013b).

\begin{tabular}{|c|c|c|c|}
\hline Year & Bayou des Allemands (20201) & Bayou des Allemands (20301) & Grand Total \\
\hline 2008 & 3600 & - & 3600 \\
\hline 2009 & 4800 & - & 4800 \\
\hline 2011 & - & - & - \\
\hline 2012 & 2400 & 14000 & 16400 \\
\hline Total & 10800 & 14000 & 24800 \\
\hline
\end{tabular}




\section{Statistical Analyses}

Statistical analyses were conducted in accordance with two primary objectives, these include: 1) identifying the ecological drivers that promote the growth and infestation of the nuisance AV, and 2) developing statistical models to predict the occurrence of AV growth in similar areas given the ecological drivers that are identified in the first objective.

As described in classification methods (Section 2.3), 16-day return imagery data from Landsat-5 TM and Landsat-7 ETM+ between 2003 and 2013 were acquired from the U.S. Geological Survey's EROS Data Center to identify the vegetated areas in open waters and developed navigational channels within the selected five study sites. These 16-day interval Landsat data were summarized into monthly averages for the approximately 10-year study period to generate 132 data points. However, due to cloud cover and other quality issues, the sample size ranged from 86 data points in Des Allemands to 105 in Turtle Bayou (Table 6). The monthly-averaged vegetated areas (as observed from the Landsat imageries), in percent of acres covered, were considered as the dependent variable to formulate predictive multiple regression models with respect to the impact of environmental and available nutrient variables in each of the five study sites.

Data on environmental variables were downloaded from published websites of various federal and state agencies. For example, discharge and water level data (i.e., gage height) were acquired from USGS, whereas stage height and mean sea level (MSL) were collected from USACE and NOAA, respectively. Most of the precipitation records were imported from the Louisiana Office of State Climatology (LOSC), and a few missing precipitation data were filled in from USGS and NOAA's archived records. Data on air and water temperature were assembled from USGS, DEQ, and CRMS websites. Archival records from NOAA's surface data complemented the necessary data on air temperature, wind speed, wind direction, and dew point for the period of study.

Nutrient data were acquired from the Louisiana Department of Environmental Quality (LDEQ) on a monthly collection basis. Scientific literature on factors influencing the growth and infestation of nuisance aquatic vegetation, communications with wetlands research ecologists at the USGS Wetland and Aquatic Research Center (WARC), and the 
availability of data for the study period suggested the use of dissolved oxygen, salinity, turbidity, ammonia, nitrogen, nitrate and nitrite, total dissolved solids, and total suspended solids as major contributors to the spread and growth of AV in the selected five study sites (Table 2).

Although salinity is an important contributing factor for the growth or decline of aquatic vegetation, ecologists suggested substituting specific conductivity for salinity in fresh marsh areas where salinity is minimal or absent. As such, instead of salinity, specific conductivity was considered as a contributing factor in the Henderson site, which is fairly dominated by freshwater marsh.

Original data acquired from the aforementioned sources varied in both time interval and format. For example, water temperature, salinity, and water-level data from CRMS stations were recorded hourly, whereas LOSC precipitation records were provided as monthly totals, and LDEQ data consisted of monthly collections. All data sets were transformed and formatted as comma separated values (CSV) files for statistical analyses. In order to attain comparability among all measurement variables, these files were processed in SAS software version 9.2 (SAS 2010) to obtain monthly average datasets for further analyses. Table 6 illustrates the summary statistics of the collected data from each of the five study sites for the study period. Note that a sample size $(\mathrm{N})$ of 132 indicates that the data were available for each month of the entire period of study. 
Table 6. Sample size (N) and average statistics (Mean) of the measurement variables from the five study sites during 2003-2013 study period.

\begin{tabular}{|c|c|c|c|c|c|c|c|c|c|c|}
\hline \multirow[b]{2}{*}{ Variable (unit) } & \multicolumn{2}{|c|}{ Bayou Sale } & \multicolumn{2}{|c|}{ Des Allemands } & \multicolumn{2}{|c|}{ Henderson } & \multicolumn{2}{|c|}{ Lake Long } & \multicolumn{2}{|c|}{ Turtle Bayou } \\
\hline & $\mathbf{N}$ & Mean & $\mathbf{N}$ & Mean & $\mathbf{N}$ & Mean & $\mathbf{N}$ & Mean & $\mathbf{N}$ & Mean \\
\hline Vegetated Area (Ha) & 96 & 1976.79 & 86 & 2352.31 & 100 & 1341.72 & 94 & 456.62 & 105 & 5453.18 \\
\hline Gage Height (ft) & 132 & 3.49 & 123 & 9.56 & 131 & 9.21 & 124 & 1.83 & 132 & 2.51 \\
\hline Stage Height (ft) & 89 & 1.55 & $\mathrm{~N} / \mathrm{A}$ & $\mathrm{N} / \mathrm{A}$ & 131 & 8.57 & 132 & 3.32 & 132 & 2.90 \\
\hline Discharge (cfs) & 132 & 98476.18 & 96 & 2435.38 & $\mathrm{~N} / \mathrm{A}$ & $\mathrm{N} / \mathrm{A}$ & 115 & 1651.29 & 104 & 3421.63 \\
\hline Precipitation (in) & 132 & 4.81 & 106 & 4.83 & 119 & 5.00 & 132 & 5.23 & 132 & 4.00 \\
\hline Air Temp (deg C) & 81 & 21.00 & 86 & 22.19 & 132 & 21.18 & 132 & 20.80 & 131 & 22.07 \\
\hline Water Temp (deg C) & 119 & 21.59 & 131 & 19.45 & 56 & 20.33 & 124 & 22.46 & 126 & 22.02 \\
\hline Wind Speed (m/s) & 132 & 2.78 & 101 & 2.05 & 132 & 3.71 & 132 & 5.99 & 127 & 3.86 \\
\hline Wind Direction (deg T) & 132 & 166.15 & 102 & 162.82 & 132 & 164.83 & 132 & 160.87 & 127 & 182.94 \\
\hline Dew Point (deg C) & 132 & 14.84 & $\mathrm{~N} / \mathrm{A}$ & $\mathrm{N} / \mathrm{A}$ & 132 & 15.71 & 132 & 15.38 & 127 & 16.73 \\
\hline Mean Sea Level (m) & 91 & 0.95 & 114 & 0.12 & $\mathrm{~N} / \mathrm{A}$ & $\mathrm{N} / \mathrm{A}$ & N/A & N/A & 108 & 0.21 \\
\hline Dissolved Oxygen (mg/L) & 81 & 7.15 & 86 & 6.85 & 44 & 6.80 & 62 & 5.87 & 73 & 7.44 \\
\hline Turbidity (NTU) & 81 & 46.94 & 87 & 24.55 & 56 & 42.36 & 62 & 37.75 & 73 & 29.14 \\
\hline Salinity (ppt) & 125 & 0.69 & 130 & 0.43 & 45 & 0.14 & 122 & 0.34 & 98 & 0.39 \\
\hline Ammonia (mg/L) & 40 & 1.89 & 58 & 023 & 20 & 0.16 & 25 & 0.21 & 40 & 0.18 \\
\hline Nitrogen-Kjeldahl (ppm) & 76 & 1.43 & 78 & 1.30 & 56 & 0.81 & 57 & 1.17 & 65 & 0.94 \\
\hline Nitrate-Nitrite (ppm) & 77 & 0.72 & 47 & 0.15 & 52 & 0.71 & 48 & 0.50 & 66 & 0.51 \\
\hline Total Suspended Solid (ppm) & 80 & 56.27 & 84 & 25.98 & 56 & 41.28 & 62 & 40.82 & 72 & 30.16 \\
\hline Total Dissolved Solid (ppm) & 81 & 600.52 & 87 & 268.25 & 56 & 193.40 & 62 & 400.49 & 73 & 636.17 \\
\hline Specific Conductivity (umhos/cm) & $\mathrm{N} / \mathrm{A}$ & $\mathrm{N} / \mathrm{A}$ & $\mathrm{N} / \mathrm{A}$ & $\mathrm{N} / \mathrm{A}$ & 56 & 276.58 & $N / A$ & $N / A$ & $\mathrm{~N} / \mathrm{A}$ & $\mathrm{N} / \mathrm{A}$ \\
\hline
\end{tabular}




\subsection{Stepwise regressions}

To identify ecological drivers that promote the growth and infestation of nuisance AV in open waters and navigational channels, environmental and nutrient data collected for each of the five study sites were subjected to stepwise regression analyses. Stepwise regression analysis involves a stepby-step iterative process of selecting independent variables while constructing a single most predictive and parsimonious regression model. Such a model can be developed in one of three ways. For example, a model can be developed by testing one independent variable at a time and including it in the model if it is statistically significant (forward selection). A model can also be developed by including all potential independent variables in the model and eliminating those that are not statistically significant (backward elimination), or a model can be developed by a combination of both methods and testing at each step for variables to be included or excluded in the model (stepwise). Statistical significance and the criteria of developing a model depend on the level of significance ( $p$ value) of each independent variable to be included in the model as well as pre-defining $\mathrm{r}^{2}$ (goodness of fit) and $p$-values (significance level) for the selected model to be considered as the best fit. In this study, the level of significance to enter a variable into the model was conservatively adjusted to 0.25 , but for the variable to stay in the model it was set to 0.15 . With these adjustments, any relevant variable will have higher probability to enter into the model, but if there is a collinear variable already included into the model, then the one with lower prediction capability will be dropped out. Subsequently, the resulting model will be a parsimonious one with less multicollinearity (redundancy) among the selected variables. A model with $p \leq 0.05$ was considered statistically significant.

As mentioned earlier, the monthly averaged aquatic vegetation areas identified from the Landsat imagery were considered dependent upon environmental and available nutrient variables. The primary goal of this study is to assist nuisance aquatic vegetation managers by predicting hotspot areas requiring control on a regular basis. Such predictions require monthly data, at a minimum, and stepwise regressions require gap-free data. Nutrient data from the LDEQ, however, were collected only once in three-month intervals within approximately three-year cycles, so the nutrient data were inadequate and excluded from future assessments. The remaining environmental variables identified as potentially impacting the growth of aquatic vegetation-salinity, precipitation, gage and stage heights (water levels), water discharge, air and water temperatures, dew 
point, wind speed and direction, and MSL-met the criteria for collection frequency and were included in the stepwise regression analyses. Vivid outlier data points were eliminated and, where necessary, data were averaged monthly to reduce the effect of extreme values and intermittent gaps in hourly or daily datasets.

All selected environmental variables were included in the initial model of the stepwise regression for each study site. However, the variables selected by the regression analyses were unique to each site. This could be due to site-specific conditions where coastal sites are more prone to salinity, water level, and tidal effects, and inland sites are more susceptible to precipitation and temperature variability.

The stepwise regression process selected variables that were deemed as the most significant at each site. These variables were further analyzed using SAS PROC GLM to obtain the final regression model, the estimates of its $\mathrm{r}^{2}, p$-value, intercept, and the coefficient for each variable. Through this analysis, a generalized linear model (GLM) was produced for each study site, this yields nuisance $\mathrm{AV}$ volume as a percent of total site acreage.

\subsubsection{Henderson statistics}

The Henderson study site falls outside the Louisiana coastal zone and has less oceanic effect from the Gulf of Mexico. As such, this study site occupies mainly fresh marsh and has little or no effect of saltwater intrusion (average salinity $=0.14$ with a range of 0.04 to $0.24 \mathrm{ppt}$ ). Instead of salinity, specific conductivity was included in the stepwise regression procedure along with the other environmental variable described in Table 6 (excluding nutrient variables).

The stepwise procedure selected five variables as the most effective to describe the percent of aquatic acreage covered by nuisance AV in the Henderson study site (Table 7). As observed in the following table, although air temperature seems to have less contribution to AV growth in combination with other factors, it independently shows statistically significant ( $p$-value<0.0135) positive effect. Other environmental variables (i.e., gage height, dew point, wind direction, specific conductivity, etc.) did not show enough contribution to improve the model, thus the process stopped at step 5 . 
Table 7. Henderson Stepwise Selection: Step 5 Variable AirTemp Entered: $r^{2}=0.8434$ and $C(p)=2.6697$.

\begin{tabular}{|c|c|c|c|c|c|c|c|c|}
\hline \multicolumn{7}{|c|}{ Summary of Stepwise Selection HENDERSON } \\
\hline SStep & $\begin{array}{c}\text { Variable } \\
\text { Entered }\end{array}$ & $\begin{array}{c}\text { Variable } \\
\text { Removed }\end{array}$ & $\begin{array}{c}\text { Number } \\
\text { Vars In }\end{array}$ & $\begin{array}{c}\text { Partial } \\
\mathrm{r}^{2}\end{array}$ & $\begin{array}{c}\text { Model } \\
\mathrm{r}^{2}\end{array}$ & $\mathbf{C}(\mathrm{p})$ & $\mathrm{F}$ Value & $\mathrm{Pr}>\mathrm{F}$ \\
\hline 1 & StageHt & & 1 & 0.6102 & 0.6102 & 32.8909 & 51.67 & $<0.0001$ \\
\hline 2 & WindSpd & & 2 & 0.1806 & 0.7908 & 5.2940 & 27.62 & $<0.0001$ \\
\hline 3 & Precip & & 3 & 0.0397 & 0.8305 & 0.7912 & 7.25 & 0.0113 \\
\hline 4 & SpCond & & 4 & 0.0113 & 0.8418 & 0.9357 & 2.15 & 0.1533 \\
\hline 5 & AirTemp & & 5 & 0.0016 & 0.8434 & 2.6697 & 0.30 & 0.4878 \\
\hline
\end{tabular}

The GLM derived from the five selected variables for Henderson is:

$$
\begin{aligned}
& \mathrm{AV}=74.15-1.21 \times \text { StageHt }-7.89 \times \text { WindSpd } \quad \text { Equation } 1 \\
& +0.76 \times \text { Precip }+8.95 \mathrm{E}-3 \times \text { SpCond }+ \text { 0.09 } \times \text { AirTemp } .
\end{aligned}
$$

The above regression model with five factors (Equation 1) exhibited an $\mathrm{r}^{2}$ value of 0.84 and a $p$-value less than 0.0001 , this indicates statistical significance as well as parsimony. Figure 22 illustrates the model goodness-of-fit as model-predicted AV area in percent versus the observed $\mathrm{AV}$ percent from satellite imagery for the period of study. The regression model (Equation 1) indicates that the stage height and wind speed have negative impact on the AV growth, whereas precipitation, specific conductivity, and air temperature have positive impact. 
Figure 22. Goodness-of-fit plot - Model-predicted aquatic vegetation (AV) area in percent versus percentage of observed AV area from the satellite imageries for Henderson study site from 2003-2013.

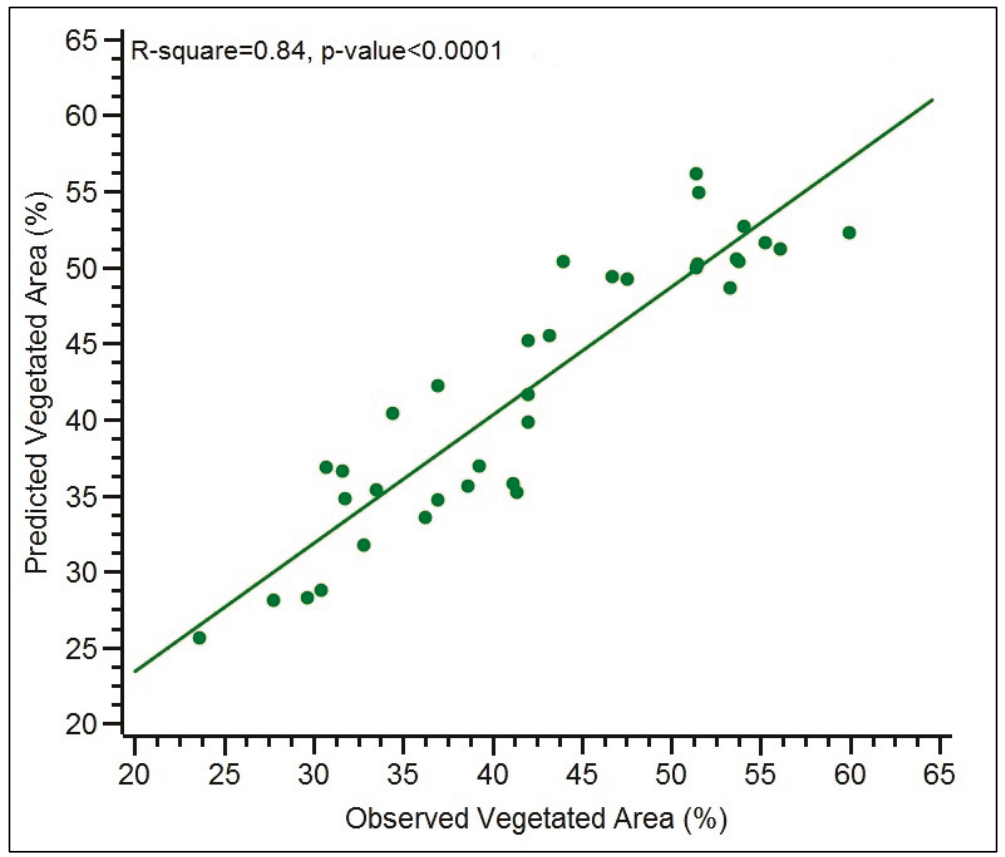

\subsubsection{Bayou Sale statistics}

The stepwise procedure selected eight independent variables to be included in the best possible and parsimonious model for the Bayou Sale study site as described in the following excerpt from the SAS output (Table 8).

Table 8. Bayou Sale Stepwise Selection: Step 8 Variable DewPt Entered: $\mathrm{r}^{2}=0.7252$ and $C(p)=9.0$.

\begin{tabular}{|c|c|c|c|c|c|c|c|c|}
\hline \multicolumn{7}{|c|}{ Summary of Stepwise Selection BAYOU SALE } \\
\hline Step & $\begin{array}{c}\text { Variable } \\
\text { Entered }\end{array}$ & $\begin{array}{c}\text { Variable } \\
\text { Removed }\end{array}$ & $\begin{array}{c}\text { Number } \\
\text { Vars In }\end{array}$ & $\begin{array}{c}\text { Partial } \\
\mathbf{r}^{2}\end{array}$ & $\begin{array}{c}\text { Model } \\
\mathbf{r}^{2}\end{array}$ & $\mathbf{C}(\mathbf{p})$ & F Value & Pr $>$ F \\
\hline 1 & WindSpd & & 1 & 0.6008 & 0.6008 & 11.2855 & 64.73 & $<0.0001$ \\
\hline 2 & MSL & & 2 & 0.0665 & 0.6673 & 4.5778 & 8.39 & 0.0060 \\
\hline 3 & Discharge & & 3 & 0.0212 & 0.6885 & 3.8045 & 2.79 & 0.1027 \\
\hline 4 & Precip & & 4 & 0.0146 & 0.7031 & 3.8876 & 1.97 & 0.1680 \\
\hline 5 & Salinity & & 5 & 0.0051 & 0.7082 & 5.2253 & 0.68 & 0.4161 \\
\hline 6 & WatTemp & & 6 & 0.0028 & 0.7110 & 6.8628 & 0.36 & 0.4500 \\
\hline 7 & StageHt & & 7 & 0.0044 & 0.7154 & 8.2808 & 0.58 & 0.4521 \\
\hline 8 & DewPt & & 8 & 0.0098 & 0.7252 & 9.0000 & 1.28 & 0.2652 \\
\hline
\end{tabular}


The final model included wind speed, MSL, discharge of water, and precipitation as the major contributing factors to the growth and infestation of aquatic vegetation in the Bayou Sale study site. The GLM for the eight selected variables in Bayou Sale is:

$$
\begin{aligned}
& \mathrm{AV}=87.60-5.59 \times \text { WindSpd }+6.64 \times \mathrm{MSL} \quad \text { Equation } 2 \\
& -4.86 \mathrm{E}-05 \times \text { Discharge }-0.21 \times \text { Precip }-1.62 \times \text { Salinity } \\
& -0.41 \mathrm{xWatTemp}+2.14 \mathrm{xStageHt}+0.15 \times \text { DewPt. }
\end{aligned}
$$

The regression model in Equation 2 has an $\mathrm{r}^{2}$ value of 0.73 and a $p$-value less than 0.0001 (Figure 23), this indicates that the variations in the selected eight independent variables explain the $73 \%$ of the total variation in the response (aquatic vegetation). Additionally, each independent variable in the model is statistically significant at $p$-value $\leq 0.10$. The associated numerical coefficient of each independent variable itself may not be easily interpretable. However, in combination, the positive and negative signs indicate: 1) higher wind speed, discharge, precipitation, salinity, and water temperature tend to decrease the vegetation, whereas 2) higher MSL, stage height, and dew point have positive influence on the aquatic vegetation growth in the Bayou Sale study site.

Figure 23. Goodness-of-fit plot - Model-predicted aquatic vegetation (AV) area in percent versus percentage of observed $\mathrm{AV}$ area from the satellite imageries for Bayou Sale study site from 2003-2013.

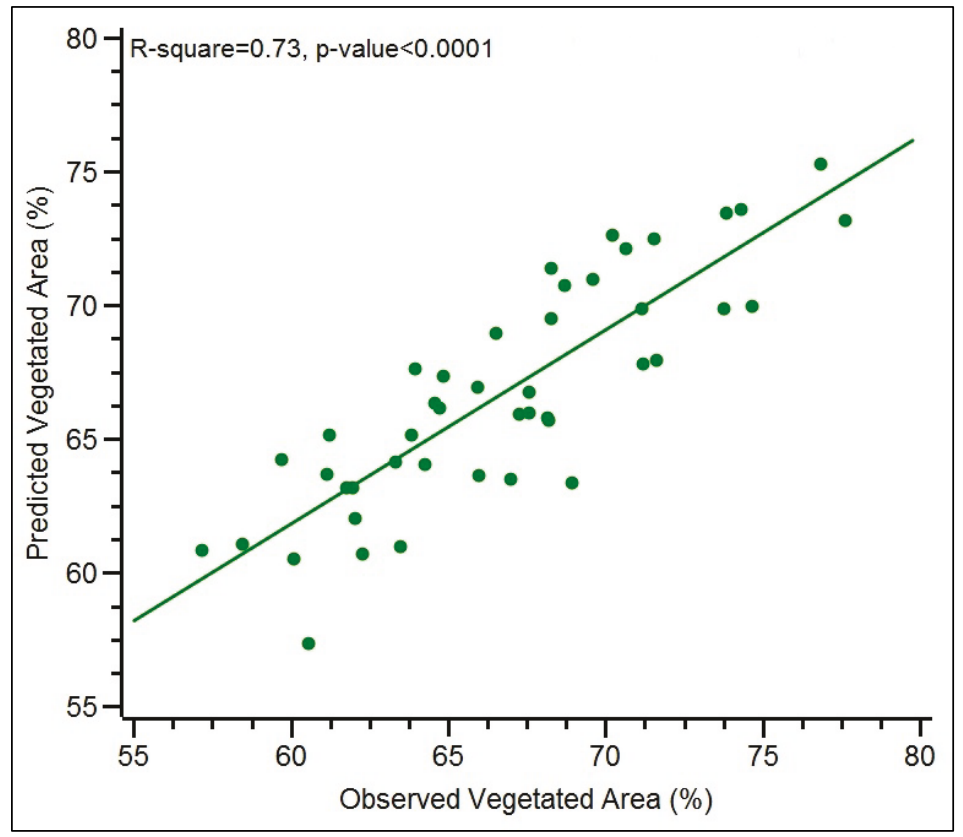




\subsubsection{Turtle Bayou statistics}

Because of its inner-coastal location and close proximity to the Atchafalaya River, the Turtle Bayou study site experiences a fresh and saltwater ecoenvironment. Out of the 11 independent variables included in the initial model, the stepwise procedure selected eight environmental variables as important contributors to the growth or decline of AV in this study site (Table 9).

Table 9. Turtle Bayou Stepwise Selection: Step 8 Variable Salinity Removed: $\mathrm{r}^{2}=$ 0.7962 and $C(p)=8.0028$.

\begin{tabular}{|c|c|c|c|c|c|c|c|c|}
\hline \multicolumn{7}{|c|}{ Summary of Stepwise Selection } \\
\hline Step & $\begin{array}{c}\text { Variable } \\
\text { Entered }\end{array}$ & $\begin{array}{c}\text { Variable } \\
\text { Removed }\end{array}$ & $\begin{array}{c}\text { Number } \\
\text { Vars In }\end{array}$ & $\begin{array}{c}\text { Partial } \\
\mathbf{r}^{2}\end{array}$ & $\begin{array}{c}\text { Model } \\
\mathbf{r}^{2}\end{array}$ & $\mathbf{C}(\mathbf{p})$ & F Value & Pr $>$ F \\
\hline 1 & AirTemp & & 1 & 0.4267 & 0.4267 & 55.6534 & 31.26 & $<0.0001$ \\
\hline 2 & Salinity & & 2 & 0.1205 & 0.5472 & 37.5446 & 10.91 & 0.0020 \\
\hline 3 & WindSpd & & 3 & 0.0630 & 0.6102 & 29.0387 & 6.46 & 0.0150 \\
\hline 4 & StageHt & & 4 & 0.0431 & 0.6533 & 23.8470 & 4.85 & 0.0337 \\
\hline 5 & MSL & & 5 & 0.0937 & 0.7470 & 10.2077 & 14.08 & 0.0006 \\
\hline 6 & Precip & & 6 & 0.0374 & 0.7845 & 5.9610 & 6.43 & 0.0156 \\
\hline 7 & Discharge & & 7 & 0.0085 & 0.7930 & 6.5428 & 1.48 & 0.2320 \\
\hline 8 & DewPt & & 8 & 0.0032 & 0.7962 & 8.0028 & 0.56 & 0.4609 \\
\hline
\end{tabular}

Subsequently, the selected eight variables were used to produce the following GLM for Turtle Bayou:

$$
\begin{aligned}
\mathrm{AV} & =47.38+0.99 \times \text { AirTemp }+6.34 \times \text { Salinity } \quad \text { Equation } 3 \\
& +2.49 \times \text { WindSpd }-11.56 \times \text { StageHt }+12.38 \times \mathrm{MSL} \\
& -0.73 \times \text { Precip }-1.01 \mathrm{E}-5 \times \text { Discharge }+0.51 \times \text { DewPt }
\end{aligned}
$$

The regression model in Equation 3 is statistically significant with $p$-value less than 0.0001 and an $\mathrm{r}^{2}$ value of 0.80 (Figure 24). Although discharge may be related to stage height and precipitation, all three have negative influence, whereas air temperature, dew point and MSL have positive relation to the percent growth of $\mathrm{AV}$. 
Figure 24. Goodness-of-fit plot - Model-predicted aquatic vegetation (AV) area in percent versus percentage of observed AV area from the satellite imageries for Lake Long study site from 2003-2013.

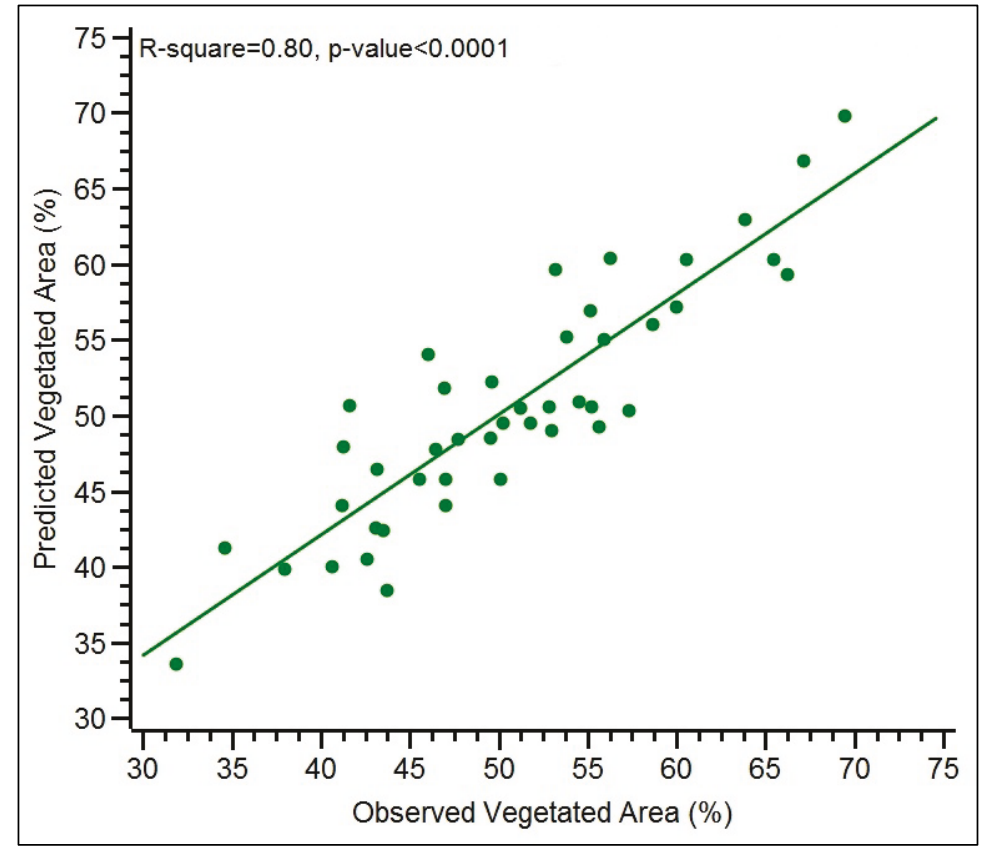

\subsubsection{Lake Long statistics}

The Lake Long study site experiences both river and marine influences. The stepwise regression procedure selected the following six variables as contributors to the growth or decline of the AV in this study site (Table 10).

Table 10. Lake Long Stepwise Selection: Step 6 Variable Precip Entered: $\mathrm{r}^{2}=0.7238$ and $C(p)=6.0007$.

\begin{tabular}{|c|c|c|c|c|c|c|c|c|}
\hline \multicolumn{7}{|c|}{ Summary of Stepwise Selection LAKE LONG } \\
\hline Step & $\begin{array}{c}\text { Variable } \\
\text { Entered }\end{array}$ & $\begin{array}{c}\text { Variable } \\
\text { Removed }\end{array}$ & $\begin{array}{c}\text { Number } \\
\text { Vars In }\end{array}$ & $\begin{array}{c}\text { Partial } \\
\mathbf{r}^{2}\end{array}$ & $\begin{array}{c}\text { Model } \\
\mathbf{r}^{2}\end{array}$ & $\mathbf{C}(\mathrm{p})$ & F Value & Pr $>$ F \\
\hline 1 & WindSpd & & 1 & 0.5442 & 0.5442 & 41.5454 & 90.73 & $<0.0001$ \\
\hline 2 & DewPt & & 2 & 0.0560 & 0.6002 & 29.3438 & 10.51 & 0.0018 \\
\hline 3 & Salinity & & 3 & 0.0828 & 0.6830 & 10.3519 & 19.33 & $<0.0001$ \\
\hline 4 & Discharge & & 4 & 0.0233 & 0.7064 & 6.4344 & 5.80 & 0.0185 \\
\hline 5 & AirTemp & & 5 & 0.0084 & 0.7148 & 6.2960 & 2.13 & 0.1488 \\
\hline 6 & Precip & & 6 & 0.0091 & 0.7238 & 6.0007 & 2.33 & 0.1315 \\
\hline
\end{tabular}


The GLM produced for Lake Long by using the six selected variables is:

$$
\begin{gathered}
\mathrm{AV}=44.53-1.28 \times \text { WindSpd }+0.84 \times \text { DewPt } \\
+4.40 \times \text { Salinity }-1.31 \mathrm{E}-3 \times \text { Discharge } \\
-0.30 \times \text { AirTemp }-0.20 \times \text { Precip }
\end{gathered}
$$

The above model (Equation 4) is statistically significant ( $p$-value $<0.0001$ ) with an $\mathrm{r}^{2}$ value of 0.72 (Figure 25). Reviewing the analysis of variance (ANOVA) model output, even though negative, precipitation and air temperature have lesser impact ( $p$-value $<0.15$ ) than wind speed $(p$ value $<0.0001)$. Conversely, dew point and salinity were indicated as having a positive impact on AV growth in the Lake Long study site. All six variables were statistically significant at or below 0.15 level of significance.

Figure 25. Goodness-of-fit plot-Model-predicted aquatic vegetation (AV) area in percent versus percentage of observed $A V$ area from the satellite imageries for Lake Long study site from 2003-2013.

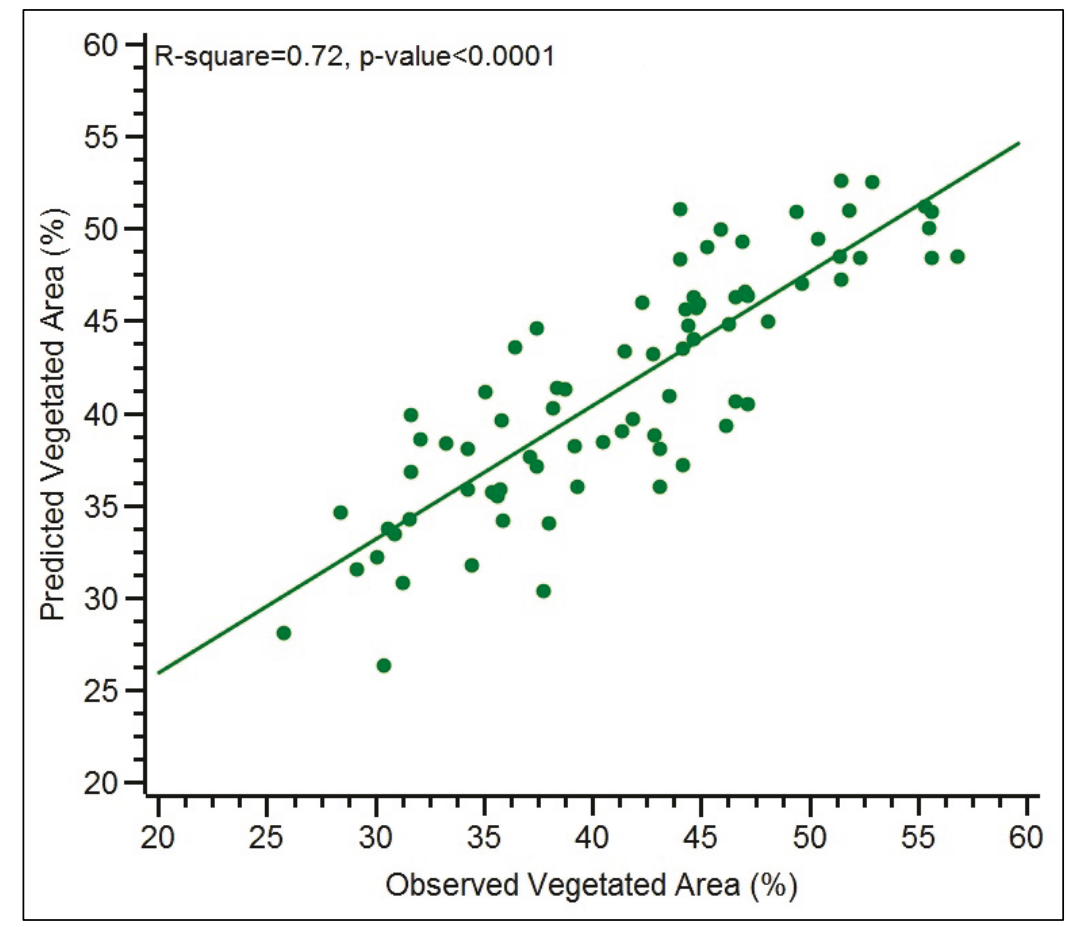

\subsubsection{Des Allemands statistics}

The stepwise regression procedure selected five independent environmental variables to be included for the best parsimonious model in Des Allemands study site (Table 11). Wind direction was initially entered through the stepwise selection, however, since its contribution to improve 
the model was not significant (partial $\mathrm{r}^{2}=0.0027, p$-value $>0.5$ ), it was excluded from the model.

Table 11. Des Allemands Stepwise Selection: Step 7 Variable WindDir Removed: $r^{2}=$ 0.8350 and $C(p)=3.8596$.

\begin{tabular}{|c|c|c|c|c|c|c|c|c|}
\hline \multicolumn{7}{|c|}{ Summary of Stepwise Selection DES ALLEMANDS } \\
\hline Step & $\begin{array}{c}\text { Variable } \\
\text { Entered }\end{array}$ & $\begin{array}{c}\text { Variable } \\
\text { Removed }\end{array}$ & $\begin{array}{c}\text { Number } \\
\text { Vars In }\end{array}$ & $\begin{array}{c}\text { Partial } \\
\mathrm{r}^{2}\end{array}$ & $\begin{array}{c}\text { Model } \\
\mathrm{r}^{2}\end{array}$ & $\mathrm{C}(\mathrm{p})$ & F Value & Pr > F \\
\hline 1 & WatTemp & & 1 & 0.7569 & 0.7569 & 6.2060 & 87.18 & $<0.0001$ \\
\hline 2 & GageHt & & 2 & 0.0378 & 0.7947 & 3.1946 & 4.98 & 0.0342 \\
\hline 3 & MSL & & 3 & 0.0194 & 0.8141 & 2.6274 & 2.71 & 0.1117 \\
\hline 4 & Precip & & 4 & 0.0140 & 0.8281 & 2.7769 & 2.03 & 0.1665 \\
\hline 5 & Salinity & & 5 & 0.0069 & 0.8350 & 3.8596 & 1.01 & 0.3256 \\
\hline 6 & WindDir & & 6 & 0.0027 & 0.8377 & 5.4977 & 0.39 & 0.5399 \\
\hline 7 & & WindDir & 5 & 0.0027 & 0.8350 & 3.8596 & 0.39 & 0.5399 \\
\hline
\end{tabular}

The five environmental variables selected by the stepwise procedure were processed into the following GLM for the Des Allemands study site:

$$
\begin{aligned}
\mathrm{AV} & =52.72+0.41 \times \text { WatTemp }-1.41 \times \text { GageHt } \quad \text { Equation } 5 \\
& +2.80 \times \text { MSL }-0.18 \times \text { Precip }-1.41 \times \text { Salinity }
\end{aligned}
$$

The multiple regression model described in equation 5 has an $\mathrm{r}^{2}$ value of 0.84 and a $p$-value less than 0.0001 , this indicates the five independent variables included in the model explain $84 \%$ of the total variation of the percentage growth in aquatic vegetation (Figure 26). This model indicates that gage height (water level), precipitation, and salinity have a negative effect, whereas water temperature and MSL have a positive effect on AV growth in the area. It is not well understood why the two water level variables (i.e., MSL and gage height) exhibit opposing influence, although, this could potentially be attributed to MSL providing marine influence and gage height providing riverine influence. 
Figure 26. Goodness-of-fit plot - Model-predicted aquatic vegetation (AV) area in percent versus percentage of observed AV area from the satellite imageries for Des Allemands study site from 2003-2013.

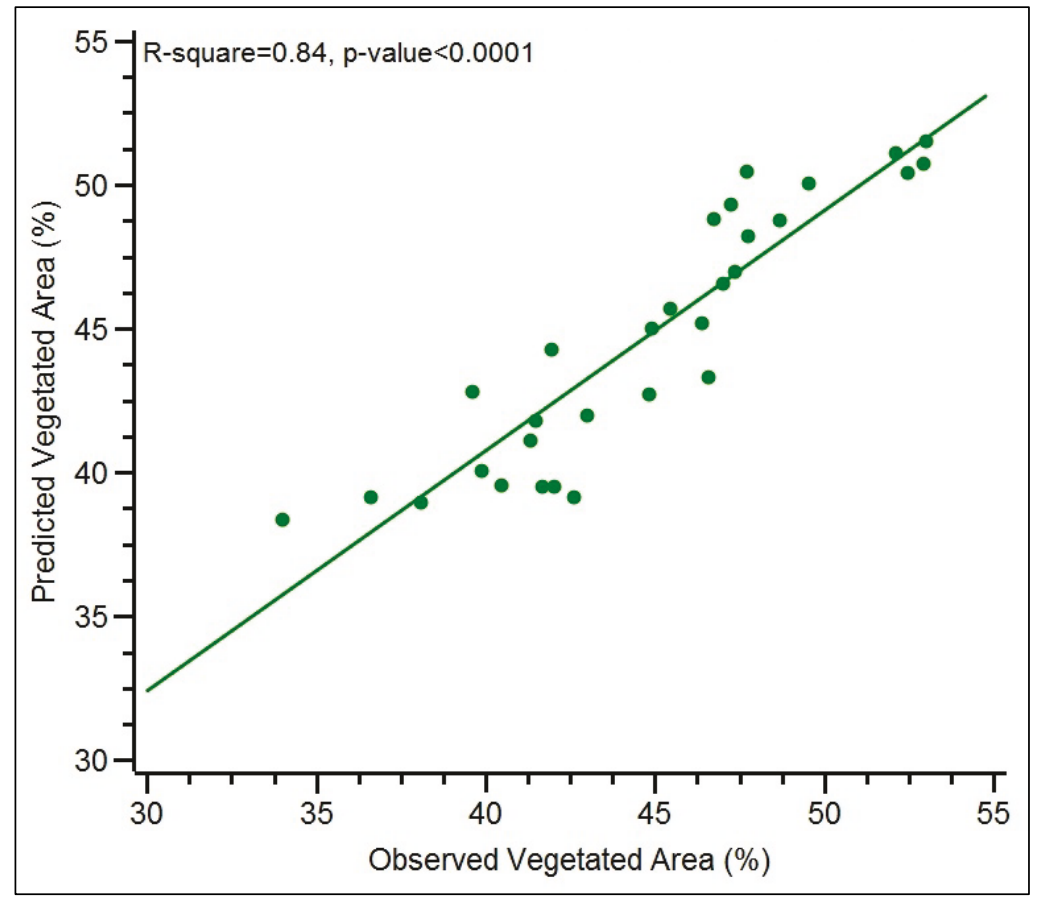

\subsection{Other statistical assessments}

Besides stepwise multiple regression models, other statistical methods were also evaluated, including principal component and factor analysis, seasonal variations, 1-2-3-month lags between collection of predictor variable data and vegetation growth (i.e., Landsat aerial data), and a directional wind field model using Arc-Tan2 transformation.

\subsubsection{Principal component and factor analysis}

To capture maximum variation on the response variable (i.e., vegetated area) while using fewer linear combinations of the predictor variables, the principle component analysis (PCA) and its surrogate factor analysis (FA) methods were assessed. Among the 20 predictor variables described in Table 8, measurements on water depth (i.e., gage height, stage height, and MSL) were too highly correlated to incorporate as separate independent variables, so only gage height was used. Additionally, due to lack of sufficient data, only discharge, stage height, precipitation, air temperature, wind speed, wind direction, water temperature, dew point, salinity, dissolved oxygen, turbidity, nitrogen, nitrate and nitrite, total suspended solids, and total dissolved solids were introduced in PCA and FA models. 
These PCA and FA models were carried out using PROC PRINCOMP and PROC FACTOR with the maximum likelihood option in SAS 9.3.

In the Turtle Bayou site, the eight values indicated that two components cumulatively provide only $64 \%$ of the total variance, and three components explained $71 \%$ of the total variations. The other study sites required more than three components to attain over $70 \%$ of the total variance of the response variable. Factor analysis procedures with maximum likelihood Heywood, restricting communality to one, and Varimax, which ascertains maximum variance using orthogonal rotations, options turned on, were also exploited. However, none of the study sites could provide sufficient explanation without considering three or more factors. PCA and FA both needed all the predictor variables to be included in the model to create components (or factors). Additionally, the data did not generate sufficient explanation with less than three components. Therefore, no further PCA and FA techniques were pursued.

\subsubsection{Arc-Tan transformation}

A wind field equation taking into account the average direction and the average wind speed was considered to describe the relative wind direction. For example, instead of a simple directional average, both average wind speed and the directional vector were used in the ArcTan2 function to extract average wind direction. The $\arctan 2$ function $[\operatorname{atan} 2(\mathrm{y}, \mathrm{x})=\arctan$

$\left.\left(\frac{y}{x}\right)\right]$, with variations in the formula due to limits and ranges on $y$ and $x$, may perhaps be highly suitable and realistic in short-term cyclonic effects on vegetation and other circumstances. Use of arctan2 function to define relative direction of wind speed did not improve predictive strength on the infestation of aquatic vegetation in this 10-year monthly average data. Therefore, wind speed and wind direction were evaluated as separate variables in the stepwise multiple regression models.

\subsubsection{Seasonality and monthly lag}

Except for the Henderson site, all study sites were located in south Louisiana coastal areas where three seasons (i.e., winter, spring, and summer) are dominant. Ten years' average monthly data of all predictor and response variables were separated into these three seasons, and multiple regression models (with and without stepwise procedure) were conducted for each site. Apart from salinity level and dew point temperature, there was no significant change in selecting predictor 
variables across the four coastal sites due to seasonal effect. Increased salinity in summer periods had a negative effect on vegetation growth, whereas increased dew point and temperature encouraged positive growth in the coastal sites. The Henderson site showed positive vegetation growth due to winter and spring precipitation, but negative growth due to excessive waterlogging (i.e., increase in stage height) in summer. Higher stage height and wind speed (i.e., tropical storms in summer) had negative effect on vegetation growth in the Henderson area. Seasonally-aware models for all five sites showed an increase or decrease on many of the estimated coefficients of the predictor variables, but the predictive strength of the model (as evaluated by $\mathrm{r}^{2}$ ) remained similar to the simpler annual models.

As in the seasonal assessment mentioned above, multiple regression models were performed using 1-, 2-, or 3-month lags between the predictors (environmental variables) and the response variable (vegetated area). Apart from small increases or decreases in the estimated coefficients, the $\mathrm{r}^{2}$ values and the slopes from the predicted response and the observed vegetated areas were very robust when applying a 1-month lag. However, substantial decrease in model's predictive strength (as observed by $\mathrm{r}^{2}$ value) was observed with the 2- and 3-month lags. Consequently, predictions of aquatic vegetation conditions were restricted to one-month forecasts. 


\section{Predictive Tool}

Using the regression models developed for the five selected study sites, a spatial predictive tool was developed to deliver a monthly report highlighting areas of highest potential for nuisance AV growth. At a basic level, software for a predictive tool can be separated into three primary areas: 1) reading input files and parameters, 2) executing the model logic, and 3) creating output files. To automate the regular execution of such a tool, additional points to address include gathering input data and delivering output to end users (Figure 27).

Figure 27. Predictive tool automated workflow, including actions taken and technologies used for each step.

\begin{tabular}{|c|c|c|c|c|}
\hline $\begin{array}{c}\text { External input } \\
\text { data acquisition }\end{array}$ & $\begin{array}{c}\text { Input data } \\
\text { pre-processing }\end{array}$ & $\begin{array}{l}\text { Model logic } \\
\text { execution }\end{array}$ & $\begin{array}{c}\text { Output } \\
\text { generation }\end{array}$ & $\begin{array}{l}\text { Output } \\
\text { delivery }\end{array}$ \\
\hline $\begin{array}{l}\text { - Web service } \\
\text { requests } \\
\text { - Web scraping }\end{array}$ & $\begin{array}{l}\text { - Temporal scaling } \\
\text { - Unit conversion }\end{array}$ & $\begin{array}{c}\text { - Stored procedure } \\
\text { call }\end{array}$ & $\begin{array}{l}\text { - Classified map } \\
\text { template population } \\
\text { - PDF file creation }\end{array}$ & $\begin{array}{c}\text { - Printable map } \\
\text { - Web map }\end{array}$ \\
\hline $\begin{array}{l}\text { ASP.NET web } \\
\text { services }\end{array}$ & $\begin{array}{l}\text { ASP.NET web } \\
\text { services }\end{array}$ & $\begin{array}{c}\text { SQL relational } \\
\text { database }\end{array}$ & $\begin{array}{l}\text { Python/ESRI } \\
\text { arcpy script }\end{array}$ & $\begin{array}{c}\text { Windows Server } \\
2012\end{array}$ \\
\hline
\end{tabular}

The first step in translating the five study site models into a regional predictive tool was to identify an appropriate spatial scale and resolution. After examining the spread of available stations reporting the necessary environmental data within the current and past AOR for the MVN RAG program, the decision was made to use standard subwatershed regions described using 10-digit Hydrologic Unit Codes (HUC). A total of 61 HUCs intersecting MVN's historical AOR (Figure 1) were selected and assigned an analog study site model based on a combination of proximity and hydrologic similarity, specifically with respect to the influence of tides and rivers (Figure 28). 
Figure 28. Classified map of study site models selected for use in each of 61 HUCs.

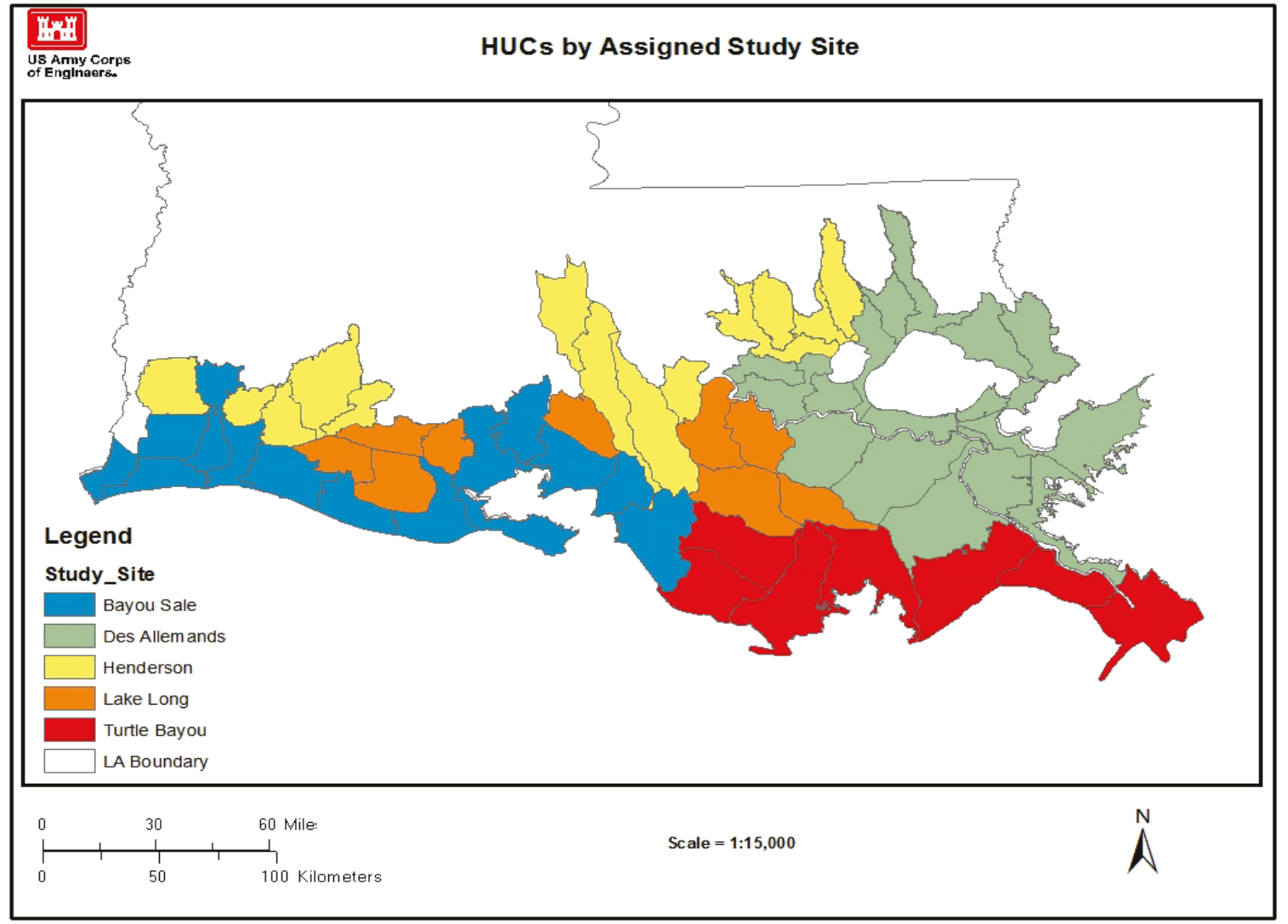

Once each HUC was assigned an analog model, the next step was to identify sources to provide regularly updated data for the environmental variables that comprised the models. Locations of environmental monitoring stations from various agencies were mapped on top of HUC polygons. Stations were then selected based on proximity to an HUC, ability to capture regular readings of environmental data relevant to the analog model assigned to that HUC, and availability as a machinereadable online data feed. Based on these selections, an automated monthly workflow was designed to: 1) retrieve environmental data online for each selected station, 2) store those data within a relational database, 3) execute the logic of the five models against those data to produce a predicted percentage of AV coverage per HUC, 4) create maps from these predictions, and 5) make these maps available to end users online.

\subsection{Input data collection and preparation}

To execute the five analog models across the spatial domain, input data was gathered for 12 environmental variables across more than 200 stations from five different online data sources (Table 12). To collect these 
data, a series of ASP.NET Web API 2 services were developed using C\#.NET in Visual Studio 2013. Each service was designed to poll one of the five online data sources and retrieve monthly averaged data for each station. These services performed a wide range of operations, from simple web service GET requests to scraping through HTML pages for specific elements of the document object model. All services were deployed to a machine running Microsoft Windows Server 2012 and Internet Information Services (IIS) 8.

Table 12. Online data sources and variables collected from each source by the automated predictive tool.

\begin{tabular}{|c|c|c|}
\hline Data source & Variables collected (units) & Root URL(s) \\
\hline NOAA* & $\begin{array}{l}\text { Air temperature }\left({ }^{\circ} \mathrm{C}\right) \\
\text { Dew point }\left({ }^{\circ} \mathrm{C}\right) \\
\text { Mean sea level }(\mathrm{ft}) \\
\text { Wind direction }\left({ }^{\circ}\right) \\
\text { Wind speed }(\mathrm{mph})\end{array}$ & $\begin{array}{l}\text { http://tidesandcurrents.noaa.gov/a } \\
\text { pi/datagetter } \\
\text { http://www.wunderground.com/hist } \\
\text { ory/airport/ } \\
\text { http://www.wunderground.com/we } \\
\text { atherstation/WXDailyHistory.asp }\end{array}$ \\
\hline USACE & Stage $(\mathrm{ft})$ & $\begin{array}{l}\text { http://rivergages.mvr.usace.army.mi } \\
\text { l/WaterControl/yearly_tables2.cfm }\end{array}$ \\
\hline $\begin{array}{l}\text { USGS National Water } \\
\text { Information System }\end{array}$ & $\begin{array}{l}\text { Discharge (ft3/s) } \\
\text { Gage height (ft) }\end{array}$ & http://waterdata.usgs.gov/nwis/dv \\
\hline $\begin{array}{l}\text { Coastwide Reference } \\
\text { Monitoring System }\end{array}$ & $\begin{array}{c}\text { Salinity (ppt) } \\
\text { Specific conductance } \\
(\mu \mathrm{S} / \mathrm{cm}) \\
\text { Water temperature }\left({ }^{\circ} \mathrm{C}\right)\end{array}$ & $\begin{array}{l}\text { http://lacoast.gov/crms2 } \\
\text { http://cims.coastal.la.gov/DataDow } \\
\text { nload/DataDownload.aspx?type=hy } \\
\text { dro_monthly }\end{array}$ \\
\hline $\begin{array}{l}\text { Louisiana Office of State } \\
\quad \text { Climatology (LOSC) }\end{array}$ & $\begin{array}{l}\text { Air temperature }\left({ }^{\circ} \mathrm{C}\right) \\
\text { Precipitation (in) }\end{array}$ & $\begin{array}{l}\text { http://www.losc.lsu.edu/products/ } \\
\text { monthly/ }\end{array}$ \\
\hline
\end{tabular}

* Weather data for some NOAA stations were collected via the Weather Underground website.

A C\#.NET console script was developed to automate the monthly acquisition of data from these services. The script was capable of accepting a month and year as command-line input parameters. Absent these, the script detected the current month and year, then operated against the preceding month (e.g., if executed in November 2015, the tool operated against October 2015). The script was scheduled to execute monthly as a 
Windows service on the same server as the web services. Upon execution, the script established an HTTP connection to each web service and passed as parameters the selected month and year. In turn, each web service retrieved a list of stations and variables from a database (described in section 6.2), polled the online data feed for each station, retrieved (or calculated from daily data) a monthly average value for each appropriate variable reported by that station, inserted that value into the database, and logged the success or failure of each connection.

Generating reliable predictions from the linear regression models being used in this tool largely depends on data availability. A study site model operating without a monthly average value for one or more component environmental variables will produce a biased prediction, with the scale of bias dependent on the absolute size of the missing value and its model coefficient. No matter the scale, the absence of important environmental data will result in lower confidence in the output. Because the predictive tool uses data from online sources of various robustness and stability, which in turn rely on physical monitoring stations subject to weather, loss of power, and other issues, the automated system must account for the possibility of missing data.

Several fallback approaches were taken when building the predictive tool to deal with missing environmental station data. In the case of stations with long-term outages (three months or greater) and those that seem to have stopped reporting altogether during the tool development period, a second nearby station was identified to provide backup data. Although the secondary station may be farther from the center of the related HUC and therefore less ideal as a data provider, its data was still considered to be more reliable than that produced by interpolation or other modeling routines. For those stations with short-term outages (less than three months), a rough, first approach was to replace unreported variable values each month with an average of reported values from nearby HUCs with the same assigned analog model. This approach proved acceptable for variables with low regional variability, such as temperature, but failed for variables with more highly localized variability like salinity and discharge. In response to this result, a second approach was developed to account for local variability. Instead of replacing missing values with averages from nearby stations, the tool instead used an average of reported values in the past five years for the same station in the same month. For example, if salinity data was missing from one station in October 2015, then that gap 
was filled by averaging the monthly averages of salinity recorded by that station from the month of October in 2010-2014. This approach ensured that values used in place of missing data were realistic on a local scale. Although it introduces the assumption that environmental data reported by a station in any one month will be similar to data from that month in the past five years, the level of error inherent in this assumption was found to be acceptable for the sake of this modeling effort.

\subsection{Data storage and model execution}

A Microsoft SQL Server 2012 relational database acted as the central hub for the predictive tool. The database stored monthly environmental data alongside information about each HUC, study site, analog model, and station, and the information about how to link these pieces together (Figure 29).

Figure 29. Diagram of relational database central to predictive tool.

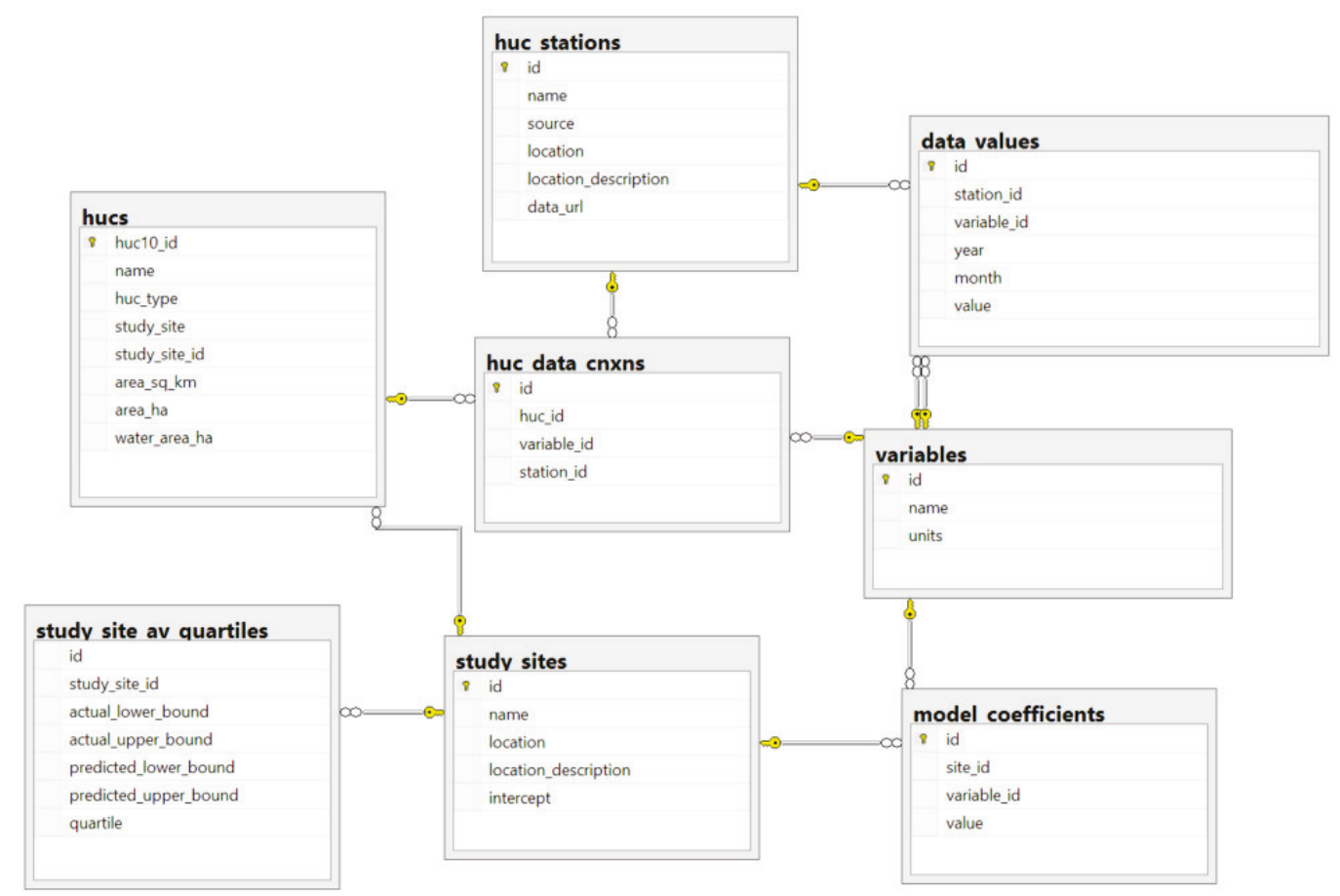

The database also contains the coefficients that define the influence of each environmental variable within the analog models, and the algorithm for applying those coefficients to the monthly environmental data retrieved via the web services of the predictive tool. This algorithm is held within the database as a Transact-SQL stored procedure. When called with a specific month and year as parameters, the stored procedure uses the 
appropriate model coefficients and environmental data to calculate the percentage of water area within each HUC that is forecasted to be covered by nuisance aquatic vegetation.

Each forecasted percentage is then classified in one of four quartiles, labeled Low, Medium-Low, Medium, and High, to make results more easily comparable across models and improve end-user efficiency in identifying hotspot areas. The names given to the classes refers to the percentage of forecasted coverage in relation to historic coverage over the same area. Quartile boundaries were calculated (method discussed in Section 6.3) and stored in the database, this allowed the stored procedure to perform a straightforward classification of monthly forecasted percentages for each HUC based on the assigned study site. Once the forecasted percentages are classified, the stored procedure returns a table to the calling program-in this case, a Python script (see Section 6.3)with each row in the table containing a 10-digit HUC ID and the quartile, in which, the forecasted percentage for that HUC falls.

\subsection{Output generation and delivery}

The ultimate purpose of the predictive tool is to use the monthly predictions calculated by the models to create classified maps, and to deliver these maps to end users for potential use in decision-making. To create monthly maps, a Python script was written and scheduled as a Windows service to occur once the appropriate data were collected each month. The script determines the month preceding the current one, then executes a call to the stored procedure in the database with that month and year as parameters, and receives the result table. Results are then inserted into an ESRI ArcMap (version 10.3) map template by using the ESRI arcpy library. Along with typical background information, the map template contains a layer of polygons representing the boundary of each HUC selected for inclusion in the predictive tool. The Python script uses the 10-digit HUC ID to perform a spatial join of the forecasted monthly AV quartile in the result table to the HUC layer in the map template. Quartiles are represented visually on the map, ranging from Low to High, as green, yellow, orange, and red. The Python script uses the arcpy rendering engine to create an image from the classified map template, this is stored as a Portable Document Format (PDF) file on the Windows Server 2012 machine for end-users to use at a later time. 
Initial maps generated from the predictive tool were found to have a disproportionately large number of HUCs classified as High when compared with expected results (see Figure 30). Among other factors, the maps did not illustrate a progression in forecasted coverage as the maps moved from cooler to warmer months. Investigation of this outcome revealed two primary concerns. The linear regression models were developed using smaller study sites within the MVN AOR but applied to larger HUCs across the Louisiana coastal zone. Although this localized approach allowed for the detailed study of historical AV growth necessary for the regression analysis, it did not introduce an appropriately high level of variance in environmental data to account for the differences encountered in HUCs across the coastal landscape, especially within the historical AOR. The largest impact of this tradeoff was witnessed in salinity, whereas, historical salinity values in several study sites ranged between 0-2 ppt, certain HUCs assigned analog models from these study sites had salinity ranges of 10-18 ppt. When combined with the larger values of the latter range, the model coefficients developed against the smaller values of the former range, this resulted in salinity exhibiting an outsized impact on the final forecasted percentages of coverage. This analysis led to a restriction of the focus of the predictive tool to only the current AOR (Figure 1), lowering the number of HUCs from 61 to 22. 
Figure 30. Map images for January, April, and July 2015 detailing preliminary classified monthly AV growth potential in each HUC.
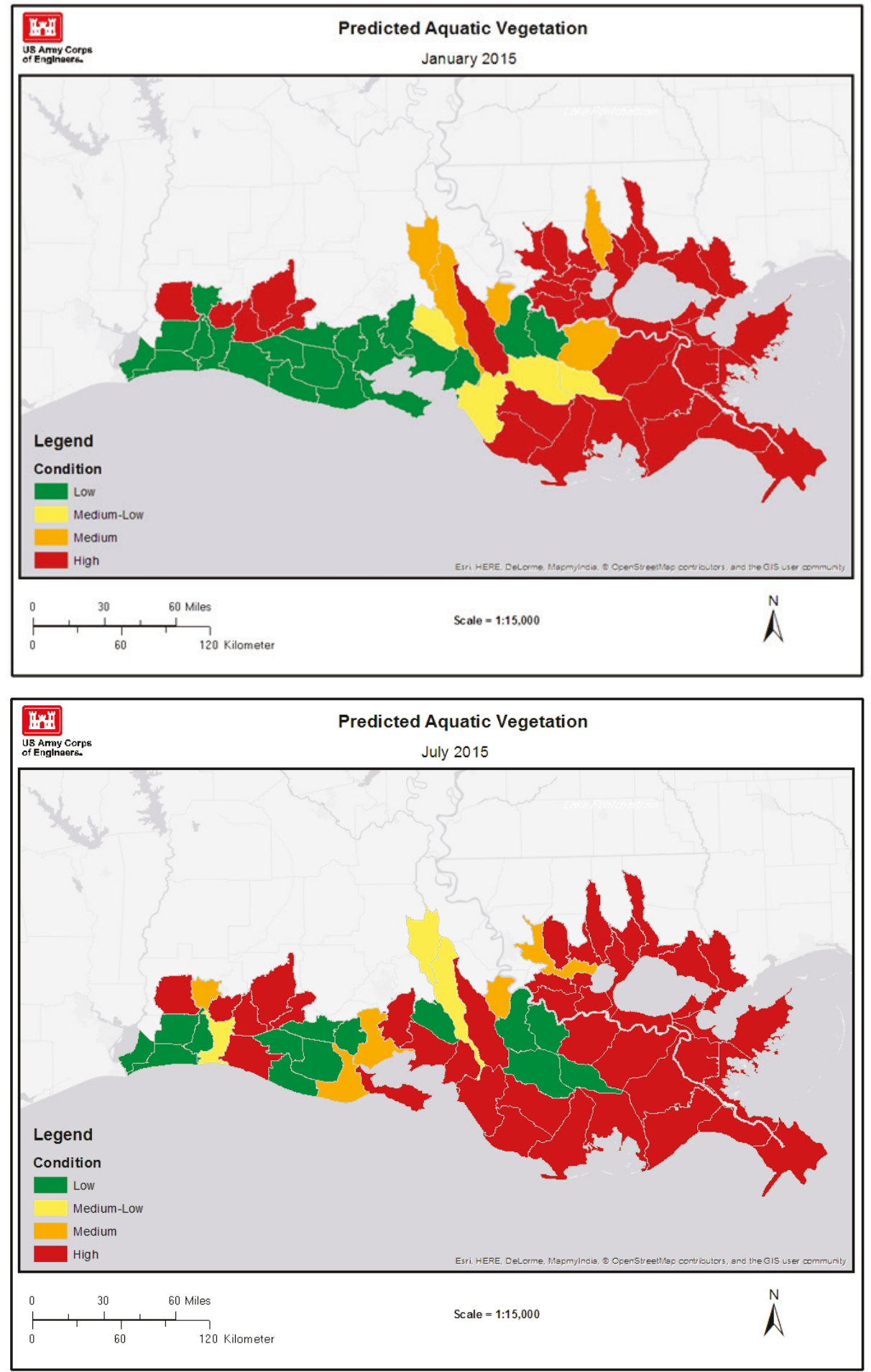


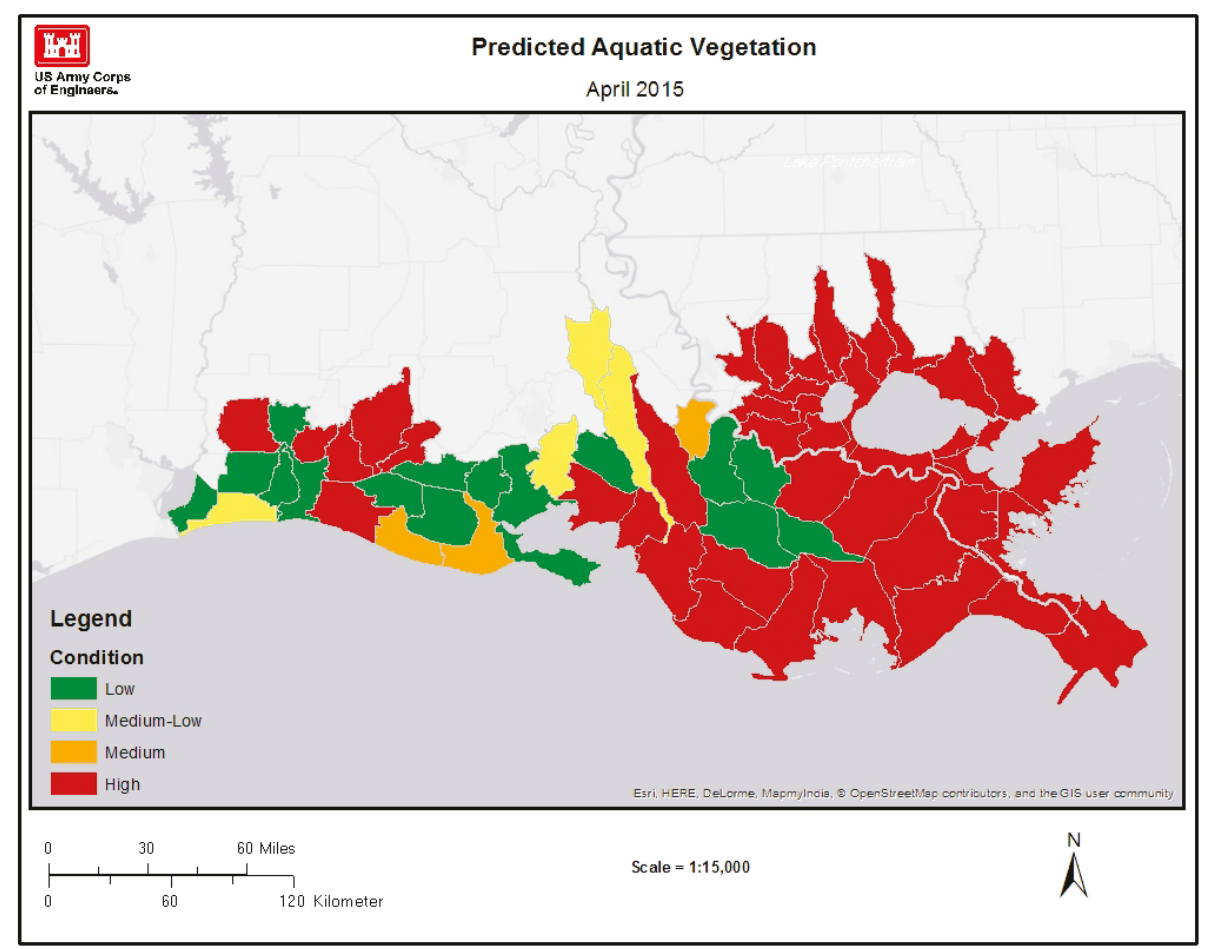

Second, the method of generating quartiles for classification of forecast percentages was tied too tightly to the history of the study site. Low-tohigh map classifications were first developed for each analog model by converting ten years of previously classified, monthly AV acreage in each study site into percentages of water area covered, and then performing a standard quartile analysis. Forecasted output from each HUC was then classified by the quartiles calculated for the analog model assigned to that HUC. Such classification was not sensitive to the history of nuisance AV growth within each HUC, only within each study site, nor did it account for differences between each HUC and its related study site. In other words, the maps did not provide classified output in relation to the typical growth patterns in each HUC. Whereas 50\% coverage may be considered high within one study site or HUC, relative to typical conditions, it may just as easily be considered low in another HUC. In practice, the quartiles developed for several of the study sites were unrealistically small, this resulted in a number of HUCs receiving inappropriately high classifications. To address this issue, it was determined that monthly forecasts for each HUC should be classified by quartiles developed against that HUC, not against the analog study site. Achieving this across the spatial domain of the 22 HUCs with remotely sensed image classification was not feasible within the scope of this project, so quartiles were instead calculated against modeled values. The analog model assigned to each 
HUC was executed against monthly environmental data from the past five years, as reported by the stations identified in an earlier step. A standard quartile analysis was then performed against the hindcasted percentages, this resulted in new quartile boundaries for each HUC. After implementing corrections for these two issues, classified maps of forecasted output more closely aligned to expected results than the initial maps were created that exhibited a natural increase in potential growth in warmer months (Figure 31).

Figure 31. Updated map images for January, April, and July 2015 detailing classified monthly AV growth potential in current MVN AOR HUCs in relation to local historic growth patterns.

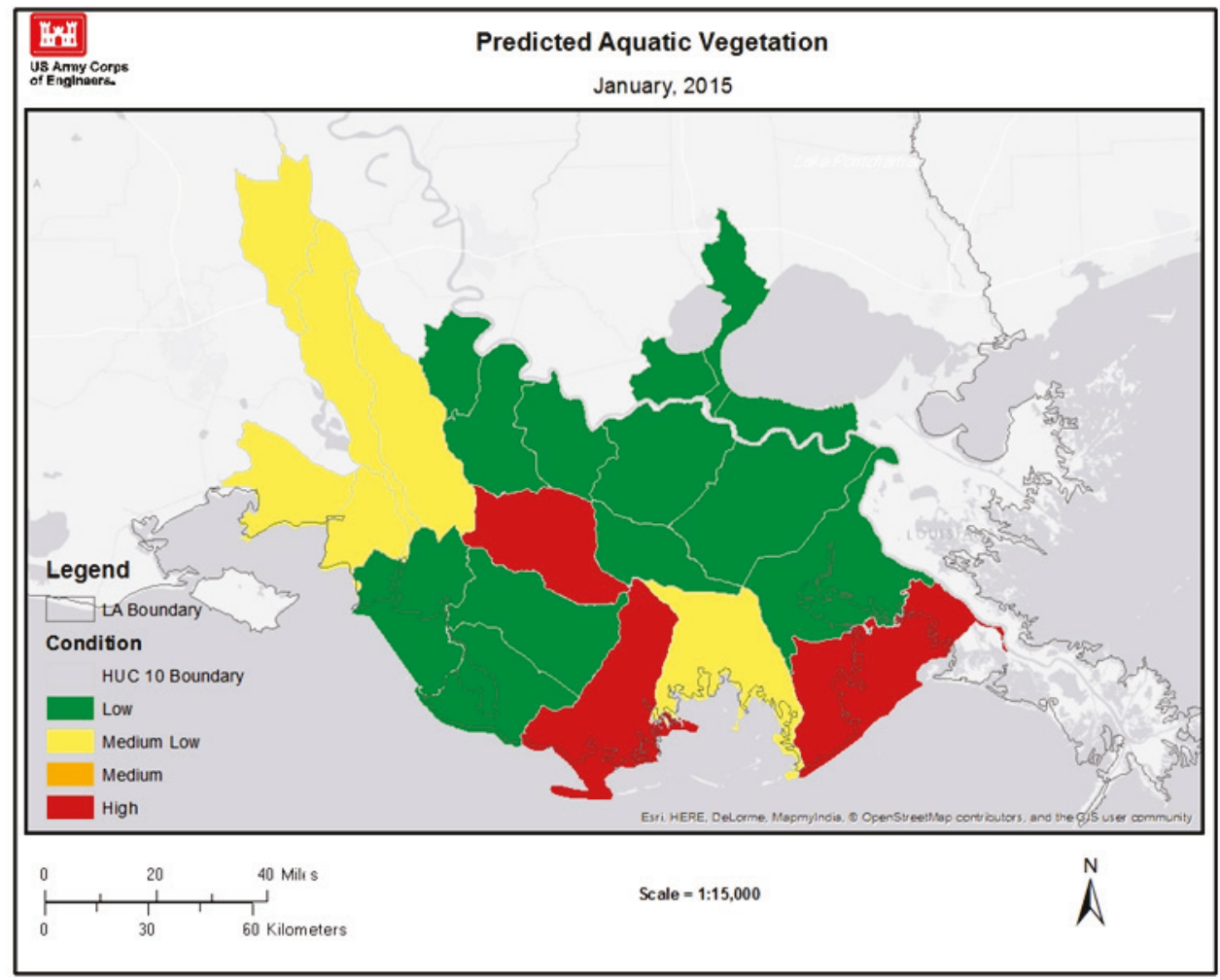



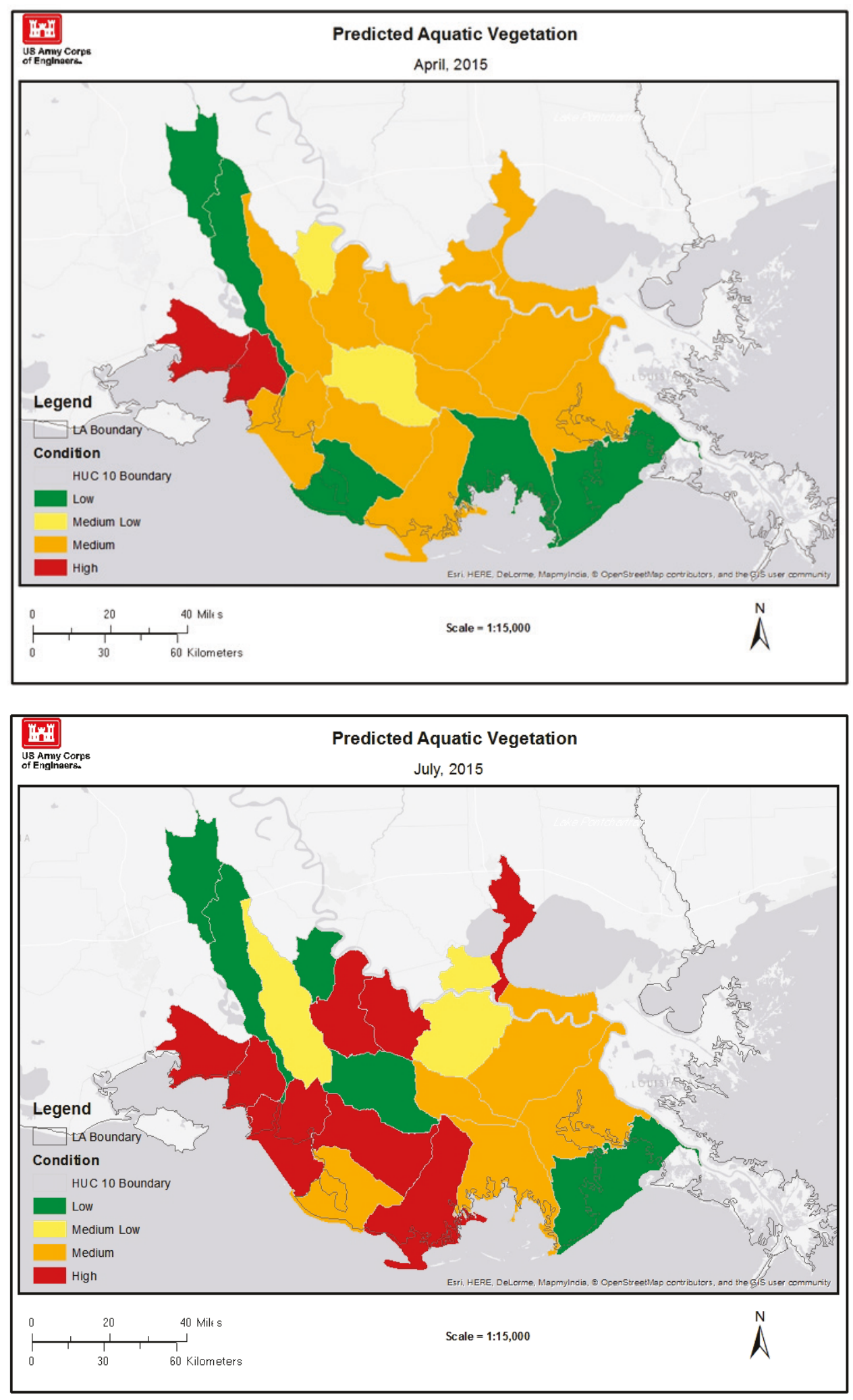
Map products generated by the system are available to end users through a protected online map gallery. As described above, the automated predictive tool is scheduled to execute on a monthly basis. Upon generation of a new map, the tool saves the map in a standard location on a web server. When an end user logs in to the online map gallery, that location is polled and all available maps are presented to the user in a thumbnail gallery. Map thumbnails can be expanded individually or sideby-side for temporal comparisons, downloaded, or printed for offline use.

\subsection{Validation of output}

To evaluate the accuracy of the models, predicted aquatic vegetation cover (percentage) was compared to actual cover (from classified imagery). A two-year period consisting of fourteen data points were used to evaluate trends and differences in cover and quartile classes for all study sites. Figures $32-36$ show the actual (black solid lines) versus predicted (gray dashed lines) percentages of aquatic vegetation from 2010 to 2012. The differences in actual and predicted AV ranged from 0.5\% in August 2011 at the Henderson site to 32.5\% in August 2011 at the Turtle Bayou site. The average difference in predicted and actual AV was 9\%, 21\%, 13\%, 6\%, and $4 \%$ for the Henderson, Bayou Sale, Turtle Bayou, Lake Long, and Des Allemands sites, respectively. The average difference between predicted and actual AV across all sites was $<10 \%$. The larger differences in AV percentages occurred at the Bayou Sale and Turtle Bayou sites. Those sites have more complex hydrology (receiving substantial riverine and marine influences) than the other sites, and are therefore more difficult to predict AV growth potential.

Since the sources of environmental data differ between the study sites and the HUCs, and since the quartile classes were established independently (sites based on satellite-derived AV and HUCs based on range of predicted $\mathrm{AV}$ ), precise matching of the actual to the predicted AV values is not expected. What is expected are similar trends (relative increases and decreases) in actual and predicted AV values and quartile classes. Generally, similar slopes and trends (i.e., increases and decreases) in AV percentages were observed across the period of analysis for all sites (Figures 32- 36). Of the 70 predictions, 29 (41.4\%) had quartile classes that matched the satellite-derived classes. Of the remaining 41 predictions, approximately 28 (40\%) were within one class, 12 (17.1\%) were within two classes, and only one (1.4\%) was off by more than two classes. 
Figure 32. Actual versus predicted percentages of aquatic vegetation in the Henderson study area and HUC from 2010-2012.

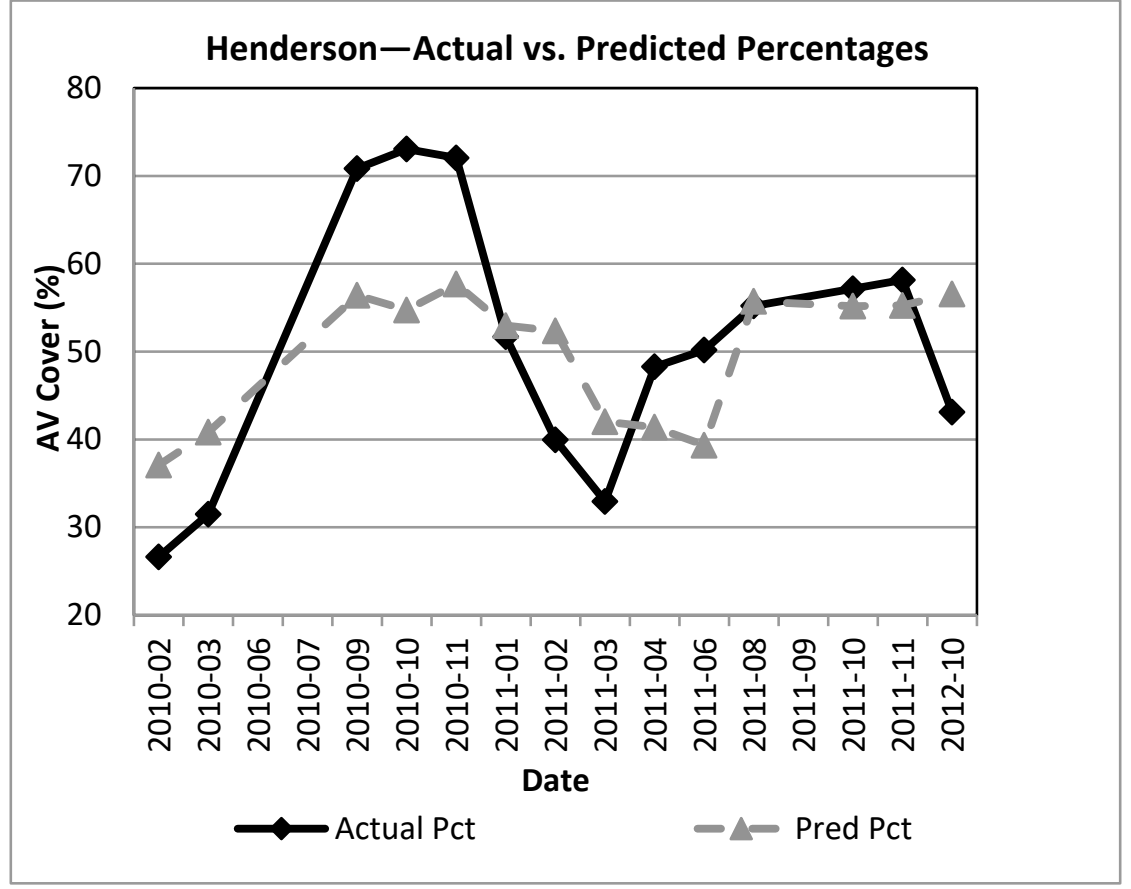

Figure 33. Actual versus predicted percentages of aquatic vegetation in the Bayou Sale study area and HUC from 2010-2012.

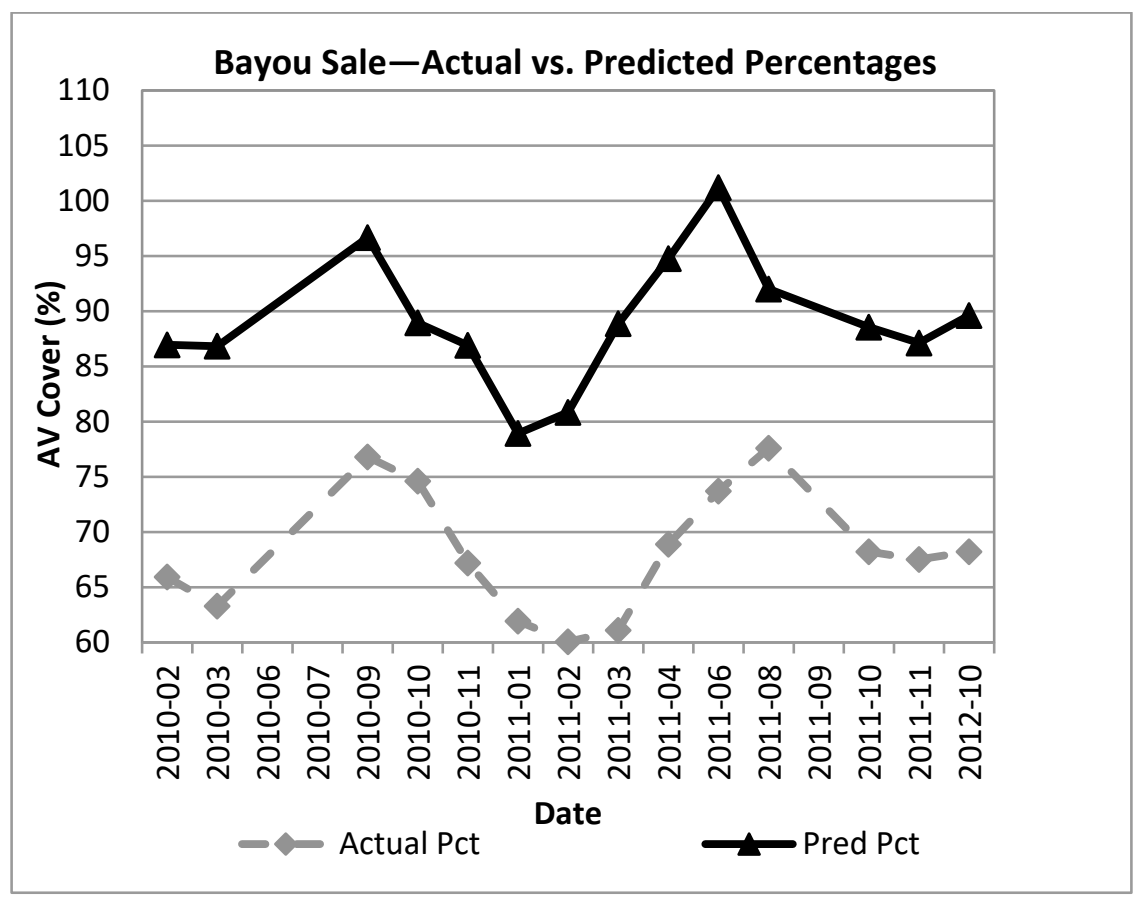


Figure 34. Actual versus predicted percentages of aquatic vegetation in the Turtle Bayou study area and HUC from 2010-2012.

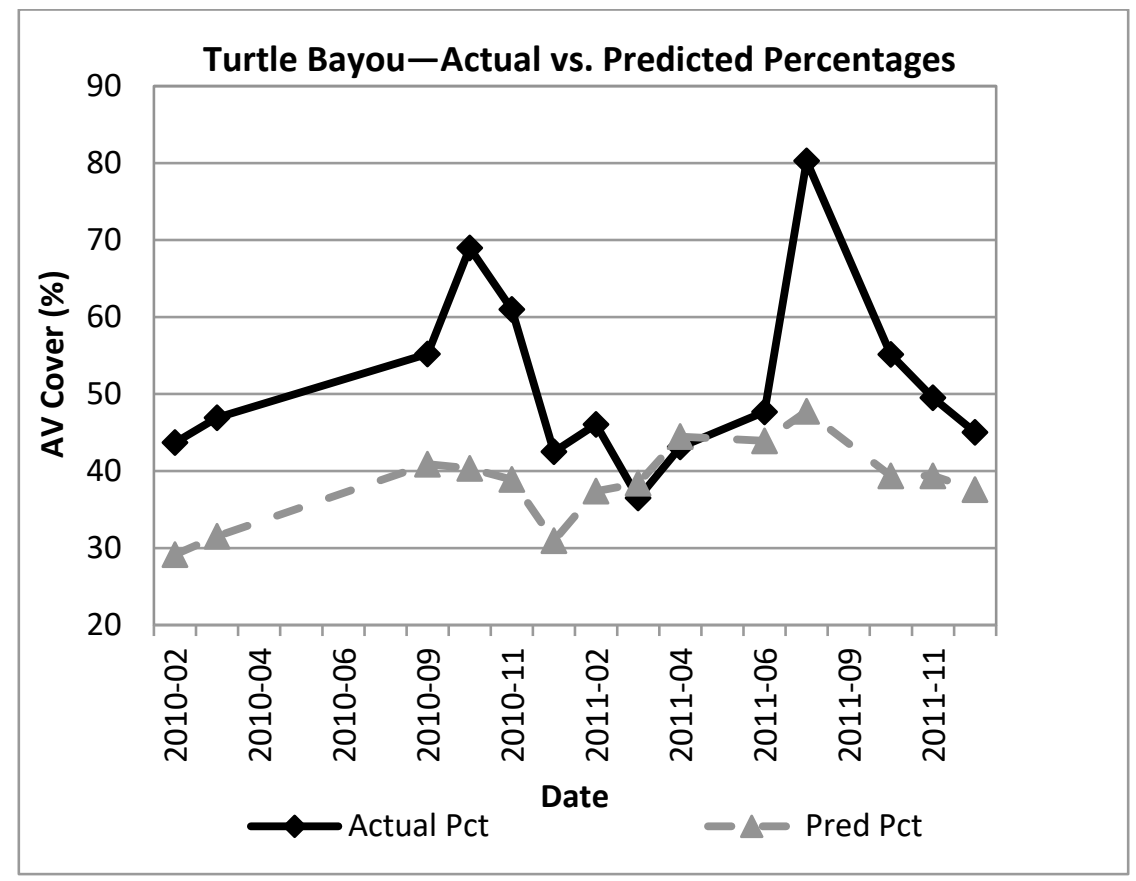

Figure 35. Actual versus predicted percentages of aquatic vegetation in the Lake Long study area and HUC from 2010-2012.

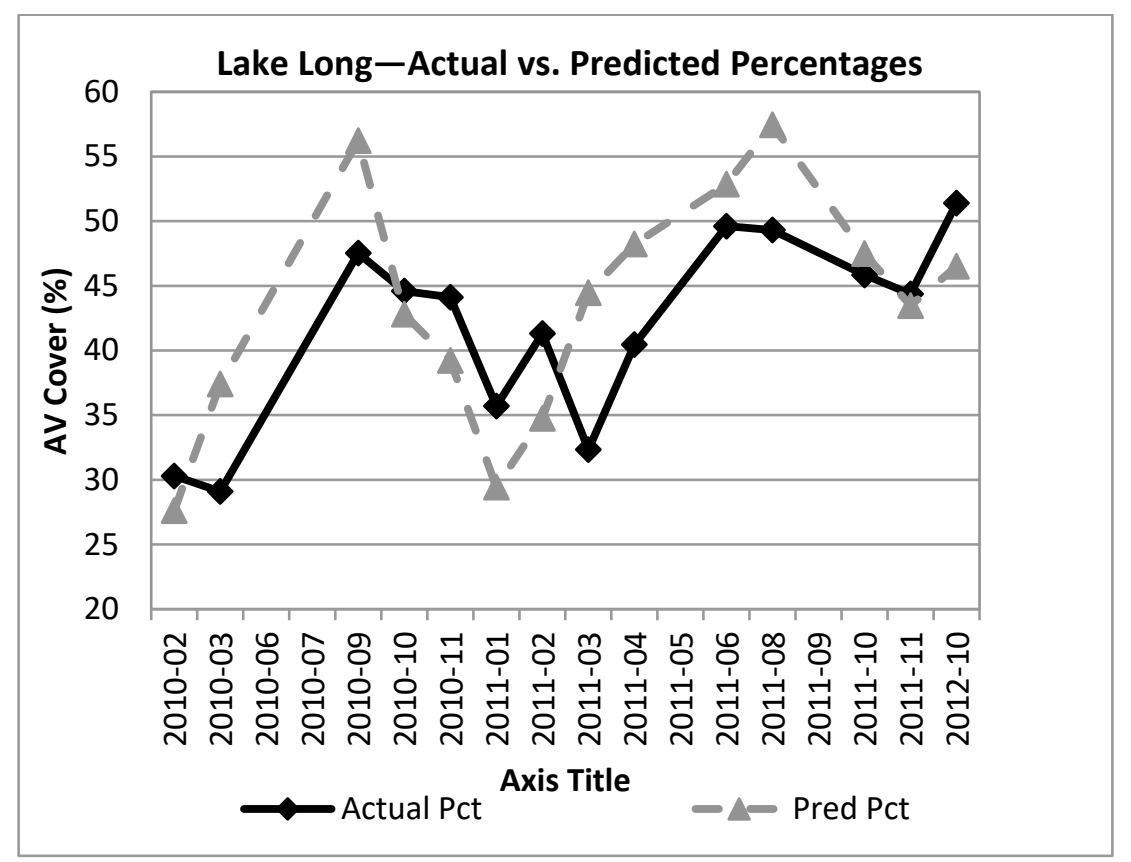


Figure 36. Actual versus predicted percentages of aquatic vegetation in the Des Allemands study area and HUC from 2010-2012.

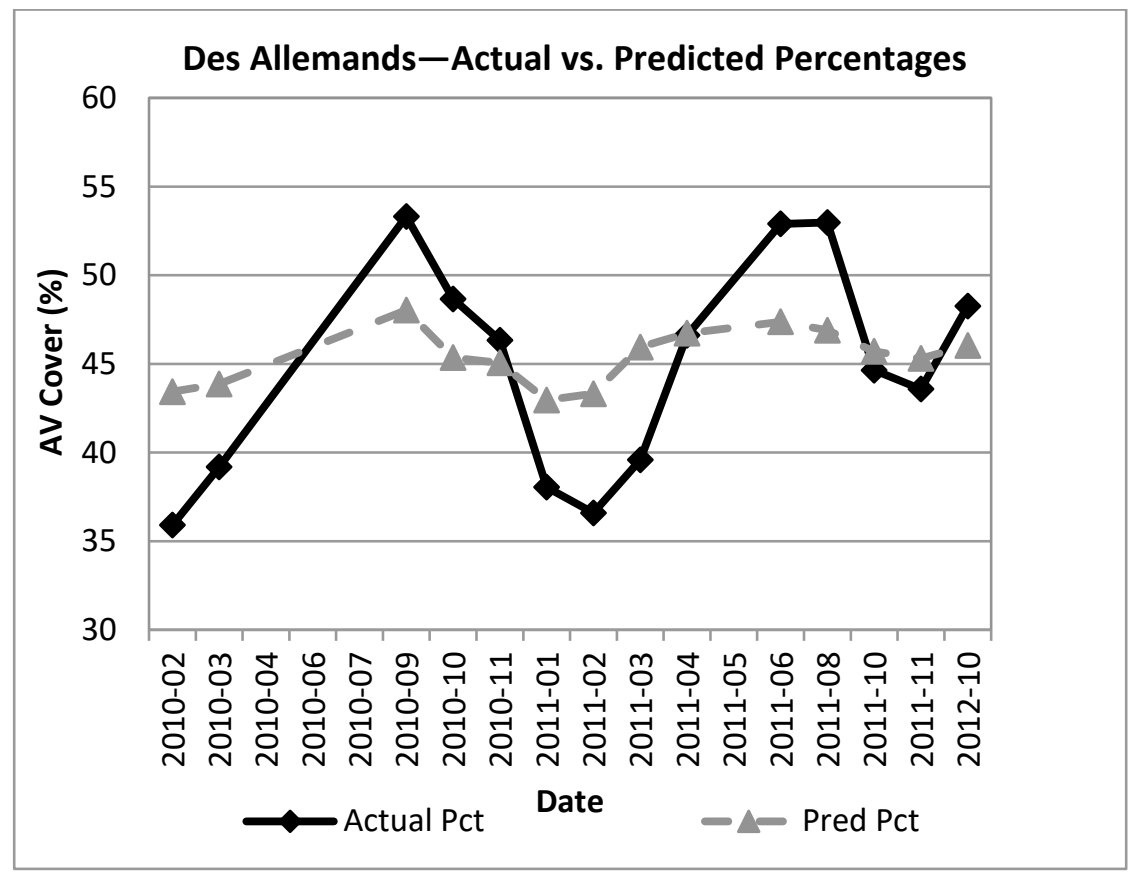




\section{Conclusion}

Given increasing distributions of aquatic nuisance vegetation and reductions in resources required to manage those infestations, methods and tools capable of efficiently mapping and predicting areas of high density or growth potential are essential. This predictive tool element, the second of a two part study (Allen and Suir 2014), used satellite imagery to classify and track aquatic vegetation occurrence over time and correlate environmental drivers to establish numerical models capable of forecasting aquatic vegetation condition in southeastern coastal Louisiana. The predictive tool, consisting of numerical models, software (input, storage, and execution code), and product delivery services, provide aquatic nuisance vegetation condition forecasts based on subwatershed units within the USACE New Orleans District's Removal of Aquatic Growth Area Of Responsibility. The numerical models' predictive strengths (as observed by $\mathrm{r}^{2}$ value) ranged from 0.72 to 0.84 . This study provides methods for efficient monitoring and possible early detection of the extent of aquatic nuisance vegetation distribution, density, blockage, and growth potential. Ideally, these measures will provide useful guidance for aquatic vegetation management and assessments of long- and shortterm efficacy, however they are not without limitations.

Classifying and mapping aquatic vegetation using moderate resolution Landsat satellite imagery provide adequate temporal coverage, but Landsat images are limited to features that are larger (or wider) than $30 \mathrm{~m}$. Also, most environmental changes have short-term effects on aquatic vegetation growth, but because some environmental drivers (i.e., temperature) have been shown to have extended influence on growth, there is a need to assess longer-term trends and impacts on growth potential and predictive capabilities. Additionally, since the numerical models were based on ranges of conditions at "hotspot" study sites, their applications are region specific. However, the models could be modified for other areas/systems, if the necessary data are available.

The linear nature of the models developed as part of this study may limit the effectiveness of predictions made against data with high variability. Although the collective formulation of each model may closely represent actual nuisance AV growth patterns, the coefficient of each individual variable obtained in the ANOVA output may not reflect the exact relationship between a particular variable and the growth or reduction of 
$\mathrm{AV}$. Applying the models to environmental variable data beyond the range of those observed in the ten-year study period may increase uncertainty with the predictions.

Incorporating other statistical techniques may improve the predictive strength of the automated tool, albeit, at the expense of explanatory strength. Although the stepwise linear regression models developed for each study site balance predictive strength giving it the ability to explain the influence of independent variables on prior aquatic vegetation growth, a method such as applying the least absolute shrinkage and selection operator to multiply-imputed datasets (i.e., the MI-LASSO method) may better account for missing environmental data and select variables that produce a model with a tighter fit between predictions and actual future percent coverage. The predictive tool could also benefit from new cloudbased geospatial services that are offered through the Google Earth Engine Application Program Interface (API). These services may provide automated aquatic vegetation calculations from Landsat sensors for future monitoring and model verifications.

This study element, in addition to the previous element (Allen and Suir 2014), provides moderate temporal and spatial resolution data for effective monitoring and predicting of aquatic vegetation extent and growth potential in south Louisiana. These methods and tools have the potential (with modifications) to markedly enhance aquatic vegetation management throughout the southeastern U.S. and other USACE districts nationwide where growth of aquatic vegetation is a concern. 


\section{References}

Adams, M. S., P. Guilizoni, and S. Adams. 1978. "Relationship of dissolved inorganic carbon to macrophyte photosynthesis in some Italian lakes." Limnology and Oceanography 23(5): 912-919.

Alimi, T., and O. A. Akinyemiju. 1991. "Effects of waterhyacinth on water transportation in Nigeria." Journal of Aquatic Plant Management 29: 109-112.

Allen, Y. C., B. R. Couvillion, and J. A. Barras. 2012. "Using multitemporal remote sensing imagery and inundation measures to improve land change estimates in coastal wetlands." Estuaries and Coasts 35(1): 190-200.

Allen, Y. C., and G. M. Suir. 2014. Using high-resolution, regional-scale data to characterize floating aquatic nuisance vegetation in coastal Louisiana navigation channels. ERDC/TN APCRP-EA-27. Vicksburg, MS: U.S. Army Engineer Research and Development Center.

Anderson, M. R., and J. Kalff. 1986. "Nutrient limitation of Myriophyllum spicatum grown in situ." Freshwater Biology 16(6): 735-743.

Atchafalaya Basin Program. 2014. "FY 2014 annual plan.” Baton Rouge, LA: Louisiana Department of Natural Resources.

Atchafalaya Basin Keeper. 2014. The Atchafalaya Basin: America's river of trees. http://www.basinkeeper.org/.

Barko, J. W. 1982. "Influence of potassium source (sediment vs. open water) and sediment composition on the growth and nutrition of a submersed aquatic macrophyte [Hydrilla verticillata (L.f.) Royle].” Aquatic Botany 12: 157-172.

Barko, J. W. 1983. "The growth of Myriophyllum spicatum L. in relation to selected characteristics of sediment and solution.” Aquatic Botany 15(1): 91-103.

Barko, J. W., D. G. Hardin, and M. S. Matthews. 1982. "Growth and morphology of submersed freshwater macrophytes in relation to light and temperature." Canadian Journal of Botany 60(6): 877-887.

Barko, J. W., M. S. Adams, and N. L. Clesceri. 1986. "Environmental factors and their consideration in the management of submersed aquatic vegetation: A review." Journal of Aquatic Plant Management 24: 1-10.

Barko, J. W., and R. M. Smart. 1981a. "Comparative influences of light and temperature on the growth and metabolism of selected submersed freshwater macrophytes." Ecological Monographs 51(2): 219-236.

Barko, J. W., and R. M. Smart. 1981b. "Sediment-based nutrition of submersed macrophytes.” Aquatic Botany 10: 339-352.

Barko, J. W., and R. M. Smart. 1983. "Effects of organic matter additions to sediment on the growth of aquatic plants." Journal of Ecology 71(1): 161-175. 
Barko, J. W., and R. M. Smart. 1986. "Sediment-related mechanisms of growth limitation in submersed macrophytes." Ecology 67(5): 1328-1340.

Barras, J., S. Beville, D. Britsch, S. Hartley, S. Hawes, J. Johnston, P. Kemp, Q. Kinler, A. Martucci, J. Porthouse, D. Reed, K. Roy, S. Sapkota, and J. Suhayda. 2003. Historical and projected coastal Louisiana land changes 1978-2050. OFR 03334. Reston, VA: U.S. Geological Survey.

Barras, J. A. 2006. Land area change in coastal Louisiana after the 2005 hurricanes-A series of three maps. OFR 2006-1274. Reston, VA: U.S. Geological Survey.

Barras, J. A. 2007. Satellite images and aerial photographs of the effects of Hurricanes Katrina and Rita on coastal Louisiana. Data Series 281. Reston, VA: U.S. Geological Survey.

Barras, J. A., J. C. Brock, R. A. Morton, and L. J. Travers. 2010. Remotely sensed imagery revealing the effects of Hurricanes Gustav and Ike on coastal Louisiana. Data Series 566. Reston, VA: U.S. Geological Survey.

Barras, J. A., P. E. Bourgeois, and L. R. Handley. 1994. Land loss in coastal Louisiana 1956-90. OFR 94-01. Lafayette, LA: U.S. Geological Survey National Wetlands Research Center.

Boyd, C. E., and E. Scarsbrook. 1975. "Influence of nutrient additions and initial density of plants on production of waterhyancinth Eichhornia crassipes." Aquatic Botany 1: 253-261.

Braud, D. H., and W. Feng. 1998. Semi-automated construction of the Louisiana coastline digital land/water boundary using Landsat Thematic Mapper satellite imagery. OSTAPD Technical Report Series 97-002. Baton Rouge, LA: Department of Geography and Anthropology, Louisiana State University, Louisiana Applied Oil Spill Research and Development Program.

Brix, H., and H. H. Schierup. 1989. "The use of aquatic macrophytes in water-pollution control." Ambio 18(2): 100-107.

Carignan, R., and J. Kalff. 1979. "Quantification of the sediment phosphorus available to aquatic macrophytes." Journal of the Fisheries Research Board of Canada 36(8): 1002-1005.

Carignan, R., and J. Kalff. 1980. "Phosphorus sources for aquatic weeds: Water or sediment?” Science 207(4434): 987-989.

Chabreck, R. H., and G. Linscombe. 1997. Vegetative type map of the Louisiana coastal marshes. Baton Rouge, LA: Department of Wildlife and Fisheries.

Chambers, P. A. 1987. "Nearshore occurrence of submersed aquatic macrophytes in relation to wave action." Canadian Journal of Fisheries and Aquatic Sciences 44(9): 1666-1669.

Clavero, M., and E. García-Berthou. 2005. "Invasive species are a leading cause of animal extinctions." Trends in Ecology and Evolution 20(3): 110. 
Coetzee, J. A., M. J. Byrne, and M. P. Hill. 2007. "Impact of nutrients and herbivory by Eccritotarsus catarinensis on the biological control of water hyacinth, Eichhornia crassipes.” Aquatic Botany 86(2): 179-186.

Cowardin, L. M., V. Carter, F. C. Golet, and E. T. LaRoe. 1979. Classification of wetlands and deepwater habitats of the United States. Washington, D.C.: U.S. Department of the Interior, Fish and Wildlife Service Office of Biological Services.

Dale, H. M. 1984. "Hydrostatic pressure and aquatic plant growth: A laboratory study." Hydrobiologia 111(3): 193-200.

Debusk, T. A., J. H. Ryther, M. D. Hanisak, and L. D. Williams. 1981. "Effects of seasonality and plant density on the productivity of some freshwater macrophytes." Aquatic Botany 10: 133-142.

DigitalGlobe. 2010. The benefits of the eight spectral bands of worldview-2. WP-8SPEC Rev 01/13. Longmont, CO: DigitalGlobe.

Doyle, R. D., and R. M. Smart. 2001. "Effects of drawdowns and dessication on tubers of hydrilla, an exotic aquatic weed." Weed Science 49(1): 135-140.

Duarte, C. M., J. Kalff, and R. H. Peters. 1986. "Patterns in biomass and cover of aquatic macrophytes in lakes." Canadian Journal of Fisheries and Aquatic Sciences 43(10): 1900-1908.

Evans, J. M. 2008. "Ecosystem implications of invasive aquatic plants and aquatic plant control in Florida springs." In Summary and Synthesis of the Available Literature on the Effects of Nutrients on Spring Organisms and Systems 231270. Gainesville, FL: University of Florida Water Institute.

Foret, J. A., J. R. Barry, and E. A. Theriot. 1980. Biological control agents on waterhyacinth at nineteen locations in Louisiana. Miscellaneous Paper A-80-4. Vicksburg, MS: U.S. Army Engineer Waterways Experiment Station, Environmental Laboratory, Aquatic Plant Control Research Program.

Freeman, T. E. 1977. "Biological control of aquatic weeds with plant pathogens." Aquatic Botany 3: 175-184.

Haller, W. T., J. L. Miller, and L. A. Garrard. 1977. Seasonal production and germination of hydrilla vegetative propagules. Journal Series No. 8080. Gainesville, FL: Florida Agricultural Experiment Station.

Helfrich, L. A., R. J. Neves, G. Libey, and T. Newcomb. 2009. Control methods for aquatic plants in ponds and lakes. Publication 420-251. Petersburg, VA: Virginia Polytechnic Institute and State University and Virginia State University.

Jakubauskas, M. E., S.W. Campbell, F. deNoyelles, Jr., S. D. Campbell, and D. Penny. 2002. "Mapping and monitoring invasive aquatic plant obstructions in navigable waterways using satellite multispectral imagery.” In Proceedings, ISPRS Commission I Mid-Term Symposium in Conjunction with Pecora 15/Land Satellite Information IV Conference Integreated Remote Sensing at the Global, Regional and Local Scale 10-15 November, Denver, CO. 
Jampeetong, A., and H. Brix. 2009. "Effects of NaCl salinity on growth, morphology, photosynthesis and proline accumulation of Salvinia natans." Aquatic Botany 91(3): 181-186.

Jensen, J. R., S. Narumalani, O. Weatherbee, and H. E. Mackey, Jr. 1992. "Measurement of seasonal and yearly aquatic macrophyte changes in a reservoir using multidate SPOT panchromatic data." Bethesda, MD: American Society for

Photogrammetry and Remote Sensing 1: 167-176.

Kissoon, L. T., D. L. Jacob, M. A. Hanson, B. R. Herwig, S. E. Bowe, and M. L. Otte. 2013. "Macrophytes in shallow lakes: Relationships with water, sediment and watershed characteristics." Aquatic Botany 109: 39-48.

Kral, F., R. Corstanje, J. R. White, and F. Veronesi. 2012. "A geostatistical analysis of soil properties in the Davis Pond Mississippi freshwater diversion." Soil Science Society of America Journal 76(3): 1107-1118.

Lacoul, P., and B. Freedman. 2006a. "Environmental influences on aquatic plants in freshwater ecosystems." Environmental Reviews 14(2): 89-136.

Lacoul, P., and B. Freedman. 2006b. "Relationships between aquatic plants and environmental factors along a steep Himalayan altitudinal gradient." Aquatic Botany 84(1): 3-16.

Lodge, D. M. 1991. “Herbivory of freshwater macrophytes.” Aquatic Botany 41(1-3): 195224.

Louisiana Coastal Wetlands Conservation and Restoration Task Force (LCWCRTF). 1993. Louisiana coastal wetlands restoration plan main report and environmental impact statement. Coastal Wetlands Planning, Protection, and Restoration Act.

Louisiana Coastal Wetlands Planning, Protection and Restoration Act Program. 2005. The Terrebonne Basin. http://www.lacoast.gov/geography/te/index.asp.

Louisiana Department of Environmental Quality (LDEQ). 2014. Water quality management plan: Volume 4 - Basin and subsegment boundaries. Baton Rouge, LA: Office of Environmental Services Water Permits Division.

Louisiana Department of Environmental Quality (LDEQ). 2011. Quality assurance project plan for the ambient water quality monitoring network. Baton Rouge, LA: Louisiana Department of Environmental Quality.

Louisiana Department of Wildlife and Fisheries (LDWF). 2005. State management plan for aquatic invasive species in Louisiana - Final management plan. Baton Rouge, LA: Louisiana Aquatic Invasive Species Task Force, Louisiana Department of Wildlife and Fisheries.

Louisiana Department of Wildlife and Fisheries (LDWF). 2009. Part VI-A: Henderson Lake - Lake history and management issues. Baton Rouge, LA: Louisiana Department of Wildlife and Fisheries Office of Fisheries, Inland Fisheries Division. 
Louisiana Department of Wildlife and Fisheries (LDWF). 2013a. Aquatic Vegetation Management Plan - Henderson Lake. Baton Rouge, LA: Office of Fisheries, Inland Fisheries Section, Louisiana Department of Wildlife and Fisheries.

Louisiana Department of Wildlife and Fisheries (LDWF). 2013b. Aquatic Vegetation Management Plan - Barataria Estuary. Baton Rouge, LA: Louisiana Department of Wildlife and Fisheries, Office of Fisheries, Inland Fisheries Section.

Louisiana Department of Wildlife and Fisheries (LDWF). 2013c. Aquatic Vegetation Management Plan - Atchafalaya Basin. Baton Rouge, LA: Louisiana Department of Wildlife and Fisheries, Office of Fisheries, Inland Fisheries Section.

Louisiana Department of Wildlife and Fisheries (LDWF). 2013d. 2013 Lake Fields, Lake Long, Company Canal Vegetation Control Plan. Baton Rouge, LA: Louisiana Department of Wildlife and Fisheries, Office of Fisheries, Inland Fisheries Section.

Louisiana Department of Wildlife and Fisheries (LDWF). 2013e. 2013 Bayou Black / Terrebonne Marsh Vegetation Control Plan. Baton Rouge, LA: Louisiana Department of Wildlife and Fisheries, Office of Fisheries, Inland Fisheries Section.

Louisiana Department of Wildlife and Fisheries (LDWF). 2014. Unwanted vegetation. http://www.wlf.louisiana.gov/fishing/unwanted-vegetation. (retrieved 22 August 2014).

Louisiana Department of Wildlife and Fisheries (LDWF). 2015. Unwanted vegetation. http://www.wlf.louisiana.gov/wma/2765. (retrieved 13 February 2016).

Lovell, S. J., and S. F. Stone. 2005. The economic impacts of aquatic invasive species - A review of the literature. Working Paper 05-02. Washington, D.C.: U.S. Environmental Protection Agency, National Center for Environmental Economics.

Mack, R. N., D. Simberloff, W. M. Lonsdale, H. Evans, M. Clout, and F. Bazzaz. 2000. "Biotic invasions: Causes, epidemiology, global consequences, and control." Issues in Ecology (5):1-22.

Madsen, J. D., and C. S. Owens. 2000. Factors contributing to the spread of hydrilla in lakes and reservoirs. ERDC TN-APCRP-EA-01. Vicksburg, MS: U.S. Army Engineer Research and Development Center.

Masterson, J. 2007. Indian River Lagoon species inventory - Non-native and invasive species. Fort Pierce, FL: Smithsonian Marine Station. http://www.sms.si.edu/irlspec/Nonnatives.htm. (retrieved 13 February 2016).

McCreary, N. J. 1991. "Competition as a mechanism of submerged macrophyte community structure.” Aquatic Botany 41(1-3): 177-193.

McFarland, D. G., and J. W. Barko. 1999. "High-temperature effects on growth and propagule formation in hydrilla biotypes." Journal of Aquatic Plant Management 37: 17-25. 
Mobley, B. 2013. “U.S. Army Corps of Engineers: Invasive species efforts.” In Proceedings, 16th Annual Transportation and Infrastructure Summit, Irving, Texas.

Morton, R. A., J. C. Bernier, J. A. Barras, and N. F. Ferina. 2005. Rapid subsidence and historical wetland loss in the Mississippi Delta Plain: Likely causes and future implications. OFR 2005-1216. Baton Rouge, LA/Petersburg, FL: U.S. Geological Survey.

Nelson, L. S., and J. F. Shearer. 2009. Integrated weed management strategies for control of hydrilla. ERDC/TN APCRP-CC-09. Vicksburg, MS: U.S. Army Engineer Research and Development Center.

Nico. L. G., P. L. Fuller, P. J. Schofield, M. E. Neilson, A. J. Benson, and J. Li. 2006. Ctenopharyngodon idella. Nonindigenous aquatic species database. Gainesville, FL.: U.S. Geological Survey. http://nas.er.usgs.gov/queries/FactSheet.asp?speciesID=514.

Novacek, M. J., and E. E. Cleland. 2001. "The current biodiversity extinction event: Scenarios for mitigation and recovery." Proceedings of the National Academy of Sciences of the United States of America 98(10): 5466-5470.

Office of Technology Assessment. 1993. Harmful non-indigenous species in the United States. OTA-F-565. Washington, D.C.: U.S. Government Printing Office. http://govinfo.library.unt.edu/ota/Ota_1/DATA/1993/9325.pdf.

O’Neil, T. 1949. The muskrat in Louisiana coastal marshes. New Orleans, LA: Louisiana Department of Wild Life and Fisheries.

Page, L. M., and B. M Burr. 1991. A field guide to freshwater fishes: North America North of Mexico (Peterson field guides \#42). Boston, MA: Houghton Mifflin Harcourt.

Pimentel, D., L. Lach, R. Zuniga, and D. Morrison. 2000. "Environmental and economic costs of nonindiginous species in the United States." BioScience 50(1): 53-65.

Pimentel, D., R. Zuniga, and D. Morrison. 2005. "Update on the environmental and economic costs associated with alien-invasive species in the United States." Ecological economics 52(3): 273-288.

Poirrier, M. A., K. Burt-Utley, J. F. Utley, and E. A. Spalding. 2010. "Submersed aquatic vegetation of the Jean Lafitte National Historical Park and Preserve." Southeastern Naturalist 9(3): 477-486.

Reddy, K. R., M. Agami, and J. C. Tucker. 1990. "Influence of phosphorus on growth and nutrient storage of water hyacinth (Eichhornia crassipes (Mart.) Solms) plants." Aquatic Botany 37(4): 355-365.

Riis, T., and B. J. F. Biggs. 2003. "Hydrologic and hydraulic control of macrophyte establishment and performance in streams." Limnology and Oceanography 48(4): 1488-1497. 
Robles, W., J. D. Madsen, A. Mathur, and L. M. Bruce. 2006. “Ground-truthed hyperspectral data for remote sensing of waterhyacinth." In Proceedings, Southern Weed Science Society $59^{\text {th }}$ Annual Meeting: Vision for the future 23-25 January, San Antonio, TX, 59: 194.

Robles, W., J. D. Madsen, and R. M. Wersal. 2010. "Potential for remote sensing to detect and predict herbicide injury on waterhyacinth (Eichhornia crassipes).” Invasive Plant Science and Management 3(4): 440-450.

Rockwell, Jr., H. W. 2003. Summary of a survey of the literature on the economic impact of aquatic weeds. Marietta, GA: Aquatic Ecosystem Restoration Foundation.

Room, P. M. and P. A. Thomas. 1986. "Nitrogen, phosphorus and potassium in Salvinia molesta mitchell in the field: Effects of weather, insect damage, fertilizers and age." Aquatic Botany 24(3): 213-232.

Sanders, D. R., and J. L. Decell. 1977. A concept for the development of long-term management plans for aquatic plant control. Miscellaneous Paper A-77-1. Vicksburg, MS: U.S. Army Engineer Waterways Experiment Station.

Sasser, C. E., J. M. Visser, E. Mouton, J. Linscombe, and S. B. Hartley. 2008. Vegetation types in coastal Louisiana in 2007. OFR 2008-1224. Reston, VA: U.S. Geological Survey.

Sasser, C. E., J. M. Visser, E. Mouton, J. Linscombe, and S. B. Hartley. 2014. Vegetation types in coastal Louisiana in 2013. Scientific Investigations Map 3290. Reston, VA: U.S. Geological Survey.

Schmitz, D. C., J. D. Schardt, A. J. Leslie, F. A. Dray, Jr., J. A. Osborne and B. V. Nelson. 1993. "The ecological impact and management history of three alien aquatic plant species in Florida." In Proceedings, Biological pollution: The control and impact of invasive exotic species, 25-26 October 1991 173-194. Indianapolis, IN: Indiana Academy of Science.

Sheldon, R. B., and C. W. Boylen. 1977. "Maximum depth inhabited by aquatic vascular plants." The American Midland Naturalist 97(1): 248-254.

Silva, T. S. F., M. P. F. Costa, J. M. Melack, and E. M. L. M. Novo. 2008. "Remote sensing of aquatic vegetation: Theory and applications." Environmental Monitoring and Assessment 140(1-3): 131-145.

Skubinna, J. P., T. G. Coon, and T. R. Batterson. 1995. "Increased abundance and depth of submerged macrophytes in response to decreased turbidity in Saginaw bay, Lake Huron." Journal of Great Lakes Research 21(4):476-488.

Smart, R. M. 1990. Effects of water chemistry on submersed aquatic plants: A synthesis. Miscellaneous Paper A-90-4. Vicksburg, MS: U.S. Army Engineer Waterways Experiment Station.

Smart, R. M., and J. W. Barko. 1988. Effects of water chemistry on aquatic plants: Interrelationships among biomass production, plant nutrition, and water chemistry. Technical Report A-88-5. Vicksburg, MS: U.S. Army Engineer Waterways Experiment Station. 
Smart, R. M., G. O. Dick, J. R. Snow, D. R. Honnell, D. H. Smith, and J. K. Smith. 2009. Ecological effects of exotic and native aquatic vegetation. ERDC/EL TR-09-10. Vicksburg, MS: U.S. Army Engineer Research and Development Center.

Steyer, G. D., C. E. Sasser, J. M. Visser, E. M. Swensen, J. A. Nyman, and R. C. Raynie. 2003. "A proposed coast-wide reference monitoring system for evaluating wetland restoration trajectories in Louisiana." Environmental Monitoring and Assessment 81: 107-117.

Suir, G. M., C. L. Saltus, and J. A. Barras. 2011. Development of methodology to classify historical aerial photography to analyze land area and shoreline change in coastal Louisiana - Point Au Fer Island - from 1935 to 2010. ERDC/EL TR-11-17. Vicksburg, MS: U.S. Army Engineer Research and Development Center.

Thouvenot, L., C. Puech, L. Martineza, J. Haury, and G. Thiébauta. 2013. "Strategies of the invasive macrophyte Ludwigia grandiflora in its introduced range: Competition, facilitation or coexistence with native and exotic species?" Aquatic Botany 107: 8-16.

Tipping, P. W., M. R. Martin, T. D. Center, and T. M. Davern. 2008. "Suppression of Salvinia molesta mitchell in Texas and Louisiana by Cyrtobagous salviniae calder and sands." Aquatic Botany 88(3): 196-202.

Tucker, C. S., and T. A. Debusk. 1981. "Seasonal growth of Eichhornia Crassipes (Mart.) solms: Relationships to protein, fiber, and available carbohydrate content." Aquatic Botany 11: 137-141.

Tulane University. 2010. Louisiana's invasive species website. New Orleans, LA: Tulane /Xavier Center for Bioenvironmental Research. http://is.cbr.tulane.edu/images_ProjectBackground/ProjectBackground.pdf.

Twilley, R. R., and J. W. Barko. 1990. "The growth of submersed macrophytes under experimental salinity and light conditions." Estuaries 13(3): 311-321.

U.S. Army Corps of Engineers (USACE). 1998. Cultural resources investigations of the east and west Bayou sale tie-in Levee, St. Mary Parish, Louisiana, Final Report. CEMVN/PD-98/o8. New Orleans, LA: U.S. Army Corps of Engineers New Orleans District.

U.S. Army Corps of Engineers (USACE). 2009. Inland waterway navigation - value to the Nation. Alexandria, VA: U.S. Army Corps of Engineers Institute for Water Resources, Civil Works Program.

U.S. Army Corps of Engineers (USACE). 2012. "West Wax Lake outlet wetlands diversion PPL22 project nominee fact sheet." In Proceedings, Coastal Wetlands Planning, Protection and Restoration Act - Technical committee meeting, 19 April, New Orleans, Louisiana. New Orleans, LA: U.S. Army Corps of Engineers New Orleans District.

U.S. Department of Agriculture (USDA). 2002. Final project plan and environmental assessment for GIWW bankline restoration project (TE-43) Terrebonne Parish, Louisiana. Alexandria, LA: U.S. Department of Agriculture, Natural Resources Conservation Service. 
U.S. Environmental Protection Agency (USEPA). 2008. Effects of climate change for aquatic invasive species and implications for management and research. EPA/600/R-08/o14. Washington, D.C.: National Center for Environmental Assessment, Office of Research and Development.

U.S. Geological Survey (USGS). 2016. Nonindigenous aquatic species. http://nas.er.usgs.gov.

Valinoti, C. E., C. K. Ho, and A. R. Armitage. 2011. "Native and exotic submerged aquatic vegetation provide different nutritional and refuge values for macroinvertebrates." Journal of Experimental Marine Biology and Ecology 409(1-2): 42-47.

Van, T. K., K. K. Steward, A. O. Jones, and R. D. Conant, Jr. 1985. U.S. Department of Agriculture/Corps of Engineers Cooperative Aquatic Plant Control Research -Annual report for FY 1983, Chemical control technology. Miscellaneous Paper A85-3. Vicksburg, MS: U.S. Army Engineer Waterways Experiment Station.

Van der Heide, T., R. M. M. Roijackers, E. H. Van Nes, and E. T. H. M. Peeters. 2006. "Simple equation for describing the temperature dependent growth of freefloating macrophytes." Aquatic Botany 84(2): 171-175.

Vant, W. N., R. J.Davies-Colley, J. S. Clayton, and B. T. Coffey. 1986. "Macrophyte depth limits in North Island (New Zealand) lakes of differing clarity." Hydrobiologia 137(1): 55-60.

Vis, C., C. Hudon, and R. Carignan. 2003. "An evaluation of approaches used to determine the distribution and biomass of emergent and submerged aquatic macrophytes over large spatial scales." Aquatic Botany 77(3): 187-201.

Visser, J. M., C. E. Sasser, R. H. Chabreck, and R. G. Linscombe. 1998. "Marsh vegetation types of the Mississippi River Deltaic Plain.” Estuaries 21(4): 818-828.

Walls, M. M., S. Darley, and J. Siikamäki. 2009. The state of the great outdoorsAmerica's parks, public lands, and recreation resources. Washington, D.C.: Resources for the Future.

Wilde, S. B., R. S. Haynie, J. A. Herrin, M. W. Hook, J. Kupfer, and M. D. Netherland. 2013. Environmental factors influencing blooms of a neurotoxic stigonematalan cyanobacterium responsible for avian vacuolar myelinopathy. ERDC/TN ANSRP-13-1. Vicksburg, MS: U.S. Army Engineer Research and Development Center, Aquatic Nuisance Species Program.

Wilson, J. R., N. Holst, and M. Rees. 2005. "Determinants and patterns of population growth in water hyacinth." Aquatic Botany 81(1): 51-67.

Xie, Y., M. Wen, D. Yu, and Y. Li. 2004. "Growth and resource allocation of water hyacinth as affected by gradually increasing nutrient concentrations." Aquatic Botany 79(3): 257-266. 


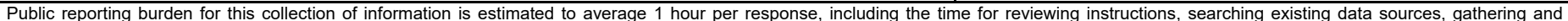

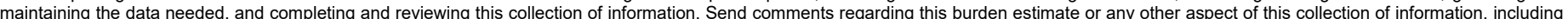

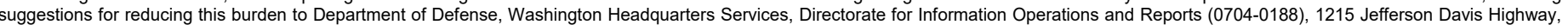

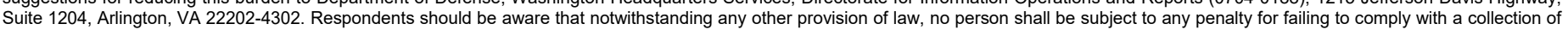
information if it does not display a currently valid OMB control number. PLEASE DO NOT RETURN YOUR FORM TO THE ABOVE ADDRESS.

\begin{tabular}{l|l|l} 
1. REPORT DATE (DD-MM-YYYY) & 2. REPORT TYPE & 3. DATES COVERED (FrOm - To)
\end{tabular} February 2018 Final report

\section{TITLE AND SUBTITLE}

Use of Remote Sensing to Detect and Predict Aquatic Nuisance Vegetation Growth in Coastal Louisiana:

Summary of Findings

5a. CONTRACT NUMBER

\section{AUTHOR(S)}

Glenn M. Suir, Kevin J. Suir, and Sijan Sapkota

\section{5b. GRANT NUMBER}

5c. PROGRAM ELEMENT NUMBER

\section{5d. PROJECT NUMBER}

450620

5e. TASK NUMBER

5f. WORK UNIT NUMBER

\section{PERFORMING ORGANIZATION NAME(S) AND ADDRESS(ES)}

8. PERFORMING ORGANIZATION REPORT NUMBER

U.S. Army Engineer Research and Development Center, Environmental Laboratory 3909 Halls Ferry Road, Vicksburg, MS 39180-6199

ERDC/EL TR-18-3

9. SPONSORING / MONITORING AGENCY NAME(S) AND ADDRESS(ES)

10. SPONSOR/MONITOR'S ACRONYM(S)

Headquarters, U.S. Army Corps of Engineers

Washington, DC 20314-1000

APCRP

11. SPONSOR/MONITOR'S REPORT NUMBER(S)

\section{DISTRIBUTION / AVAILABILITY STATEMENT}

Approved for public release; distribution unlimited.

\section{SUPPLEMENTARY NOTES}

\section{ABSTRACT}

On an annual basis, federal and state agencies are responsible for mapping and removing large expanses of aquatic nuisance vegetation from navigable waterways. This study set out to achieve four primary objectives: (1) utilize recent advancements in remote sensing techniques to classify the extent and distribution of aquatic vegetation in coastal ecosystems using satellite imagery, (2) assess primary aquatic vegetation growth and management efforts in coastal Louisiana, (3) statistically identify the ecological drivers that promote growth and infestation of aquatic nuisance vegetation, and (4) develop numerical models and a spatial tool to predict the probability of occurrence and growth of aquatic vegetation given ecological drivers. Moderate spatial resolution multispectral satellite imagery were used in conjunction with environmental variables from available data streams to generate regression models that predict aquatic vegetation occurrence in the eastern coastal region of south Louisiana. Geospatial tools were developed to execute the model logic using recent environmental conditions, thereby predicting aquatic vegetation occurrence and producing classified maps for end users. These products provide more efficient and enhanced capabilities for management of aquatic nuisance vegetation.

\begin{tabular}{lll}
\hline 15. SUBJECT TERMS & Environmental management & Remote sensing \\
& Aquatic plants & Introduced organisms \\
& Coasts--Louisiana & Intracoastal waterways
\end{tabular}

\begin{tabular}{l|l|l|}
\hline \multicolumn{3}{|l|}{ 16. SECURITY CLASSIFICATION OF: } \\
\hline \begin{tabular}{l|l} 
a. REPORT \\
UNCLASSIFIED
\end{tabular} & $\begin{array}{l}\text { b. ABSTRACT } \\
\text { UNCLASSIFIED }\end{array}$ & $\begin{array}{l}\text { c. THIS PAGE } \\
\text { UNCLASSIFIED }\end{array}$ \\
\hline
\end{tabular}

\begin{tabular}{l|l} 
17. LIMITATION & OF ABSTRACT \\
UNCLASSIFIED
\end{tabular}

\section{NUMBER OF PAGES}

99 19a. NAME OF RESPONSIBLE PERSON 19b. TELEPHONE NUMBER (include area code) 